


For

H.Al. Pittembouse

from her father
Oet -1825

otrkeler

LIBRARY

IMIYERSITY OF

calinowia

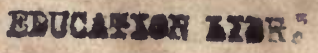


T. R. bole

from
Yargaret K. Cbeyney

Tuly 17. 2927 


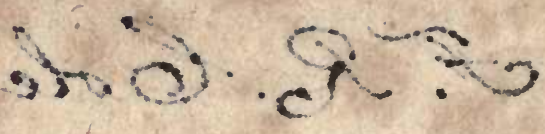

$$
\begin{aligned}
& 4 \% \div \cdot
\end{aligned}
$$

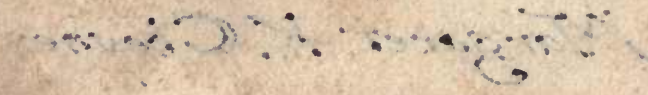

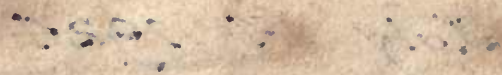

$$
\begin{aligned}
& \text { - }
\end{aligned}
$$


wasy) (a)

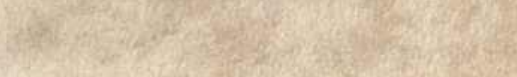

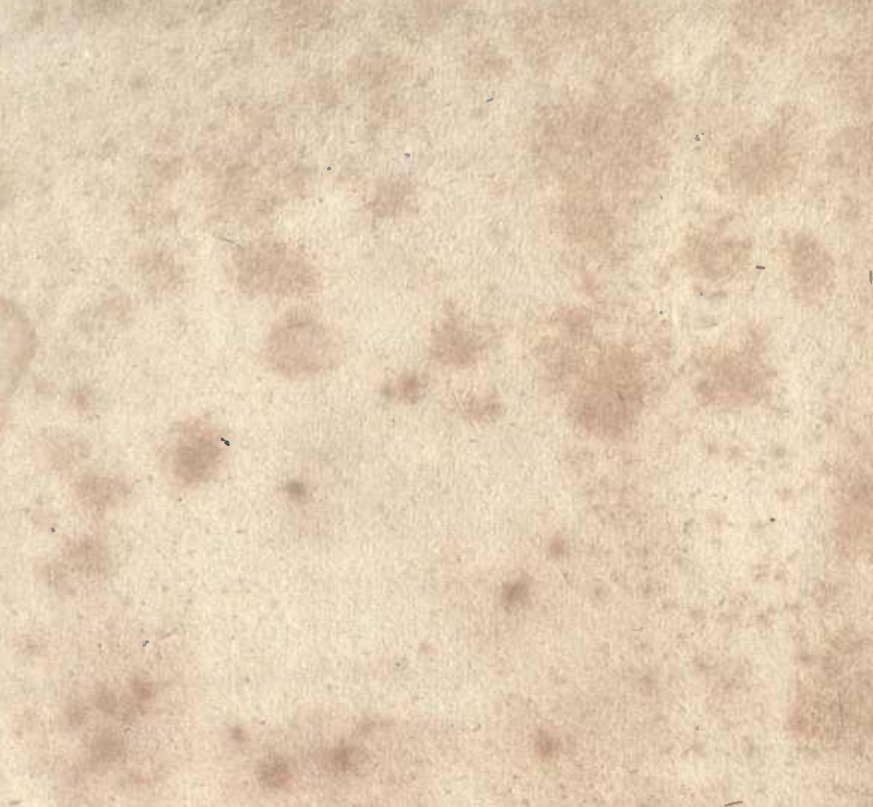

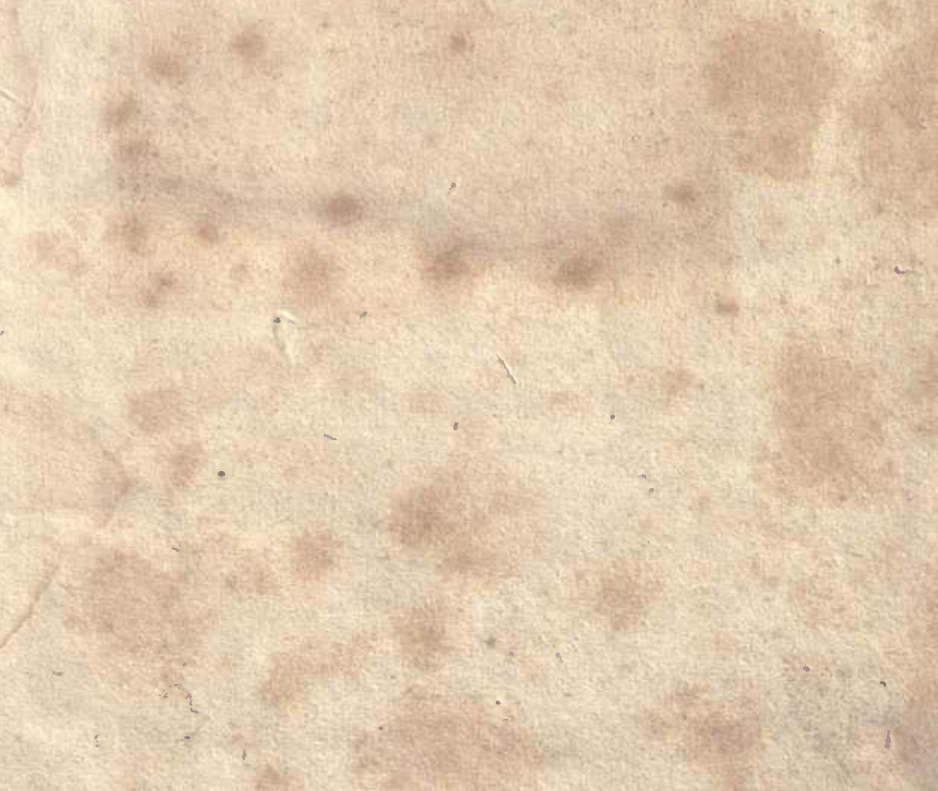




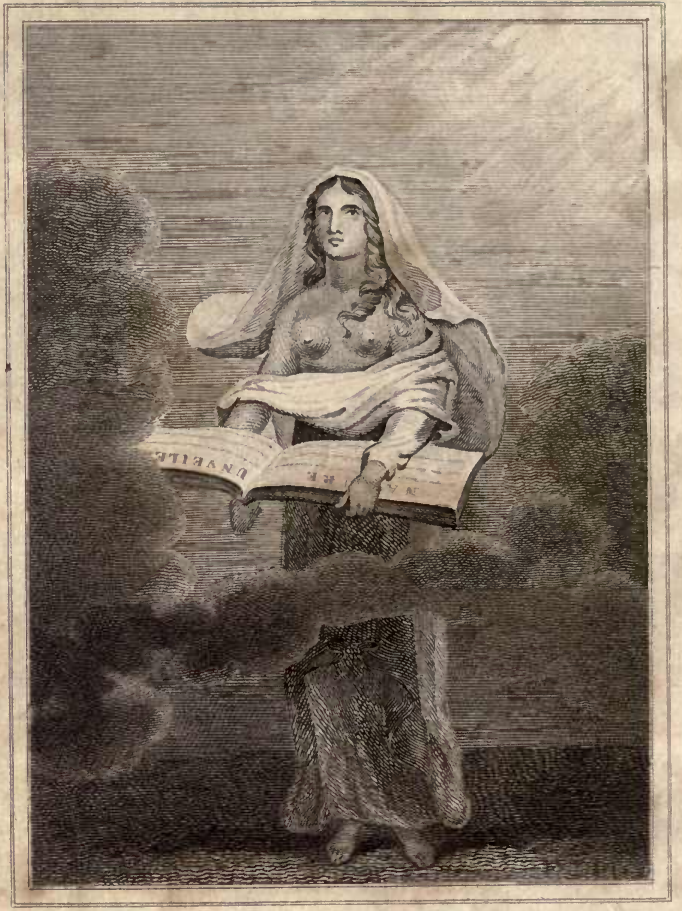

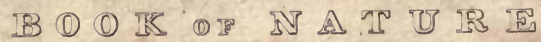



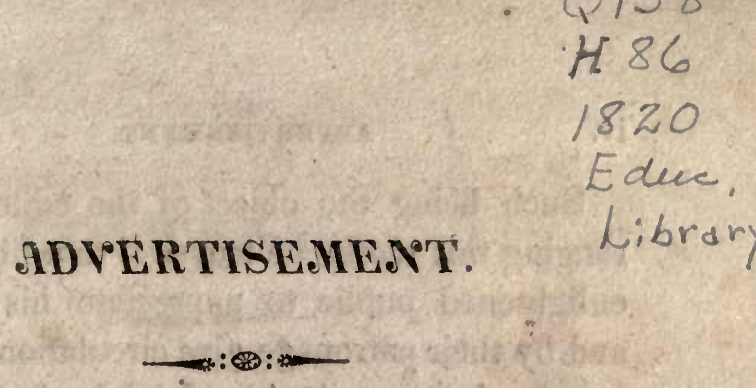

IT has long been the opinion of the editor of this volume, that the noblest employment of the mind of man is the contemplating the works of his Creator;-these living testimonies of the being and attributes of God have also ever appeared to him infinitely superior to the best arguments that the understanding of man has been able to advance.

To lead, especially, the youthful mind, to this happy turn of observation, has been his object in the arrangement of these pages; and he trusts that the familiar and comprehensive delineations of Nature, which he has endeavoured to give, will be found not only calculated for the improvement and extension of knowledge, but shew to the reader, that in every object in nature there are ample traces of the wisdom, power, and bounty of the Creator, and convince him, that even the vilest weed and the meanest insect offer incontestible evidences of their Maker. 
iv.

ADVERTISEMENT.

Such being the object of the editor in alranging this work, he leaves it to a liberal and enlightened public to appreciate his labours, and by their patronage give circulation to what he conceives may be beneficial in forming the mind to piety and just views of things.

CHLETSEA, October, 1820. 


\section{CONTENTS.}

Air, weight of,

- elasticity and resistance of, _ _ _ $\quad$ _ 164

- how cleansed, - $\quad-\quad \quad \quad-170$

Alternate succession of day and night, benefits

resulting therefrom,

Animals, their construction and properties, - $\quad 38$

diversity of bulk, taste and habit of, $\quad 40$

prodigious numbers of, _ - _ $\quad i b$.

instincts of, - - - $\quad 4$ ?

provision for keeping their numbers

within due limits,

of the graminivorous kind, $\quad \quad \quad 49$

of the weasel kind, - $\quad-\quad \quad \quad 50$

varieties of, - $\quad-\quad-\quad 56$

divisions into classes, orders, \&c. $\quad i b$.

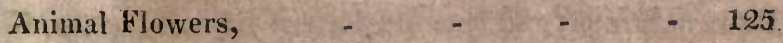

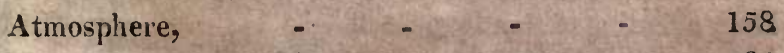

extent of, - - - - 164

its use, - - - 165

great thoroughfare to the feathery

creation,

phenomena of, - - - $\quad 172$

Atmospheric phenomena, meteors, \&c. uses of, $\quad 178$

Beavers, their wonderful foresight, \&c. $\quad-\quad 52$

Birds, their structure, appetites, \&c. _ _ 63

amazing strength of their wings, $\quad-\quad 65$

\section{A 2}


Vi.

CONTENTS.

Birds, admirable structure of their nests,

- peculiarities as to food, make, \&c,

- migration of,

$-71,265$

Bismuth, various situations of their nests, -

Camels;

Celestial appearances, : $\quad$ - $\quad-\quad 176$

Chick in the egg, description of, $\quad \ldots \quad-\quad 242$

Clay, its importance and usefulness, - _ 11

Coal, Chalk, Cinnabar, \&c.

Cod fish, incalculable number of,

$-156$

Comets, their number, motion, \&ce.

Connecting links in nature, 206

Copper and Tin,

Corn, construction and vegetation of,

Crustaceous tribe, instinctive sagacity of,

$-151$

Design of this work,

Dew, nature of, and benefits derived from,

Dog, affectionate tenderness of,

Shepherd's and Newfoundland,

Earth, form or shape of,

- structure of the, :-

spherity of the,

- surface of, its inequalities, \&c. - - $\quad 15$

_ verdant colour of the, two-fold motion of the, - - $\quad 185$

Earth worm,

Blectric fluid and its effects, 
CONTENTS.

rii.

Electricity, a most powerful agent in nature, . 180

Emu, its great swiftness, _ _ _ _ _ $\quad$ - 64

Fall of the leaf, observations on, $\quad-\quad-\quad 270$

Fishes, _ - $\quad$ - _ - $\quad-140$

- structure of, $\quad-\quad \ldots \quad$ - $\quad 142$

- immense number of, - - $\quad-\quad 145$

construction of, - - - - 147

instincts of, $\quad-\quad-\quad \quad-\quad 150$

sagacity of, in depositing their spawn, $\quad 151$

migration of, $\quad-\quad-\quad-\quad-\quad-152$

uses of, - $\quad-\quad-\quad \ldots \quad 153$

how they contribute to the comforts of man, 155

Fixed stars, their beauty and number, _ _ 209

why so called, - $\quad$ - $\quad 212$

their distance from the earth, $\quad 214$

their uses, $\quad$ - $\quad$ - $\quad 215$

Flowers, their exquisite structure, - _ _ $\quad 23$

- their variety and fragrance, _ _ _ $\quad 29$

purposes for which they were designed, 35

Fogs, Mists, Clouds, and Rain, salutary effects of, 181

Fruit, reflections on, - - $\quad$ - $\quad 260$

Frost and Snow, uses of, in the economy of nature, 182

Groats, their remarkable agility, \&c.

50

Harvest moon described,

$-\quad 191$

Herbs, use and importance of, _ _ _ $\quad 32$

Iferrings, Cod fish, Mackerel \&c. prolific powers of, 146 their immeuse numbers, - _ _ $\quad \mathbf{1 5 5}$ observations on the natural history of, 261

Insects, most numerous of nature's productions, $\quad 81$ beauty and symmetry of some, _ _ $\quad 82$ 
viii. CONTENTS.

Insects, peculiarities in this order of beings, - $\quad 84$ - their strength and agility, - _ $\quad-\quad 87$ - their wonderful transformations, _ $\quad$ - $\quad i b$. - their surprising instinct, _ _ _ $\quad$ - $\quad 89$

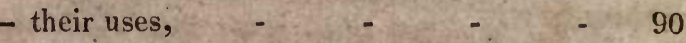

Instincts of the Monkey, the Cat, and the Hare, 52 the Lion, Bear, Porcupine, Horse \&c. 53

Iron, its usefulness and importance,

Jewels and Gems,

Kraken, its immense size,

I.ama of South America,

I.and Crab, its instinctive qualities, - $\quad$ - 134

Lead,

Limpet, how protected,

I.oadstone, its importance,

Lobster, justly styled wondrous,

— young, its instinctive habits,

Man, intellectual pre-eminence of, - _ - 3

Marble, Alabaster, Flint, \&c. - _ - - 10

Metals, their nature and importance, _ - 8.

Meteors, fiery, the use of, - - - 180

Meteors, watery, _ _ _ _ $\quad$ - $\quad 176$

Mineral kingdom, treasures of the, - $\quad-\quad 7$

Mineral Salts, $\quad$ - $\quad$ - $\quad$ - $\quad$ - $\quad 9$

Mineral and medicinal Waters, _ _ $\quad 20$

Milky way described, _ _ _ _ _ $\quad 211$

Moon, her phases, \&c. - _ _ _ _ _ _ $\quad$ _ 189

- eclipses of, $\quad$ - $\quad$ - $\quad$ - $\quad 190$

_- her salutary influences enumerated, _ $\quad 193$ 
Mother-of-pearl, mode of fishing for,

Motion, the soul of the universe,

Mountains and Vallies,

their use,

Muscle, Cockle, Periwinkle, Nautilus, \&c.

Natural objects, classification of,

Natural appearances in January, February, 224 March, April, May,
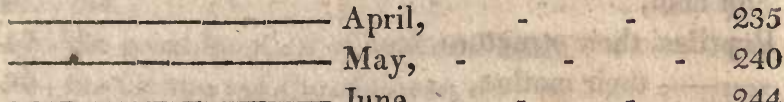
July,
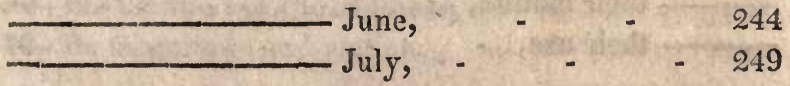
- Augrest, September, October, November, December,

Northern and southern lights, how formed,

Ocean, its magnificence,

- murmur of the, its use, _ - $\quad$ - $11 \%$

- usefulness of the luminous appearances of, $i b$.

- the uses of, - $\quad$ - $\quad-\quad$ - 115

- the great vehicle of commerce, _ $\quad 116$ benefits derived from this wonderful fluid, 118 Oran Outang, or wild Man of the Woods, - $\quad 50$ Ostrich, Emu, and Cassowary, remarkable size of, 63 - its swiftness, - $\quad$ - $\quad \ldots \quad$ - 64

Pilchards, vast shoals of, - $\quad-\quad \ldots \quad-\quad+\quad 155$

Planets, their magnitudes and motions, - _ $\quad 199$ Plaius, wide and extended, their uses, _ _ $\quad 21$ 
Plants, sexual system of, sleep of,

Quadrupeds, their conformation,

Quicksilver, its uses, \&c.

Rainbow, beauty of,

Religion, a sense of, the peculiar characteristic of man,

Reptiles, their structure, \&c.

- their motion, their use, -

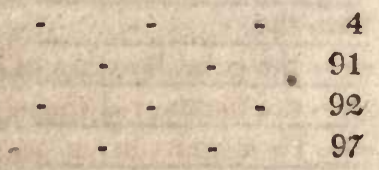

Saline substances and sulphureous bodies, - $\quad 9$

Sea, its vast extent and bounds,

- a source of fertility to the land, 103

- a purifier and restorer of nature, - 104

- currents of the, 105

- contains the greatest quantity of salt in the torrid zone, - - - - - - ib.

- saltness of, how beneficial, $\quad-\quad 109$

- colour of, deception relative thereto, - 114

- vegetable productions found at the bottom of, 119

- vegetables, the use of, _ _ _ _ 123

Sea-horse of the northern ocean, - - $\quad 50$

Sea-tortoise, its instinctive sagacity, - - 132

Seasons, changes of the, and vicissitudes of day

and night, how produced,

beneficial effects in the changes of the, 186

Serpents, some peculiarities relative to, - 93

- their poison, \&c. _ _ _ _ _ 94

- wonderful sagacity of, $\quad . \quad \ldots$ 
Shell-fish, their uses,

Shrubs, Silver, Copper, Tin, \&cc. 157

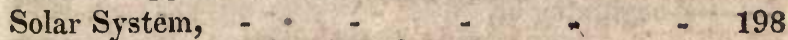
Soldier crab, peculiarities of, Spring, influence of, on man, - reflections on, Springs and rivers, Stones and fossils, Sun, the, (30) 31

8

- the great fountain of light and heat, - $\quad 194$

- - the fountain of cheerfulness, - - $\quad 196$

- its magnitude and motion, _ _ _ 198

Tellina, Ścallop, Razor shell-fish, \&c. peculiarities relative thereto, - $\quad-\quad$ - $\quad . \quad 136$

Thunder storms, their nature and influence, $\quad 252$ Tides, where greatest, - $\quad$ - $\quad$ - $\quad$ - 105

\begin{tabular}{llll}
- & \\
\hline
\end{tabular}

Vegetables, variety of, _ $\quad \ldots \quad \ldots \quad 23$

- their use and importance, - _ $\quad 24$ structure of, - - - i $i b$. sub-marine, striking peculiarities in, 122

Vegetable kingdom, properties and peculiarities of, 27 Volatiles, their use, - $\quad$ - $\quad$ - 75

Waterspouts, of two kinds, - $\quad-\quad$ - 109 description of one in the atlantic

ocean,

Whales, their immense size, $\quad-\quad-\quad 140$

Whirlpools, fidelity of to each other, 
xii. CONTENTS.

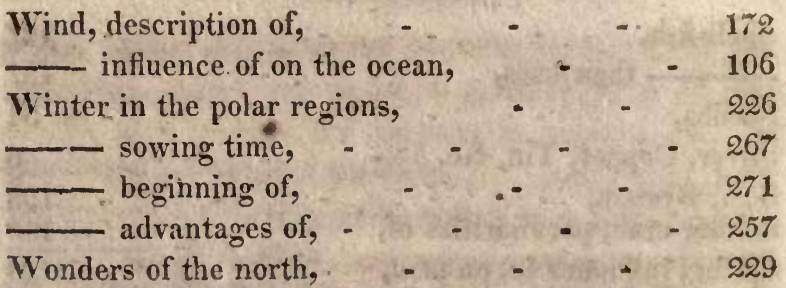


THE

\section{B(0)IR (1) NE}

\section{CHA PTER I.}

\section{INTRODTCTION:}

EVERY page of the volume of Nature is fraught with instruction. Not only do the canopy of the heavens, and the luminous orbs which bedeck the glowing hemisphere on a clear frosty evening, declare the glory of the Supreme, but the whole of created existences, however insignificant, simple, or minute they may appear, plainly evince to the contemplative mind the wisdom and power of the Creator; and shew that

All Nature is a glass reflecting God, As by the Seal reflected is the Sun, Too glorious to be gaz'd on in his sphere.

Natural objects, for the purpose of classification, have been in general arranged under the three grand divisions of animal, vegetable, and mineral, each of which will admit of many lesser subdivisions, 
about which we mean not here to treat. One ob. servation, however, upon a general view of the whole, as it cannot fail in time to present itself to every person who engages in this study, may here be introduced: it is, that however easy it may seem, at the first glance, to discriminate the three classes of objects from each other, yet every class of natural objects will be found to approach so nearly in the extreme of other classes, that it is a matter of difficulty to say with precision where the one ends, and the other begins. The whole are so closely connected, like the links of a chain, that there is no possibility of finding a disjunction in any part. Among animated beings, bats are the connecting link between beasts and birds: the numerous class of amphibia conjoin beasts and fishes; and lizards unite them with reptiles. The humming-bird approaches the nature of insects, and the flying-fish that of birds The polypus, the sea anemony, and the sea pen, though of animal origin, have more the habits of vegetables than of animals; while the fly-trap, the sensitive plant, and some other vegetable productions, by their spontaneous movements, or extreme sensibility, seem to participate more of animal origin. Corals and corallines, from the different forms they assume, may be more easily mistaken for mineral or vegetable than animal productions, to which class they are now referred, by the unanimous decision of naturalists. The trufle, though a vegetable, assumes rather the appearance of a mineral; and there is reason to believe that the 
anomalous substance called peat is actually a live. vegetable rather than an earthy or mineral substance, as it has been often supposed.

Nor is it with regard to corporeal forms only, and peculiarities of organization, that this disjointed connection subsists between the different objects which inhabit the globe: the same concatenation is observed to take place respecting mind, beginning with man, who forms the highest link of the chain, and descending from him by an almost imperceptible dimunition of mental powers, through an innumerable serics of existences, till it ends at last in mere animation alone, with a seeming privation of all mental perception whatever. It is indeed true, that though, in regard to intellect, some of the higher order of animals appear, in certain points of view, to approximate to the lowest of the human species, yet there can be no doubt that man is much farther exalted above them all, than any one of these excels the next below it; so that if there be any break in the chain at all, it is here that the rupture takes place. For though many of the higher orders of animals possess a kind of memory, and the faculty of reasoning in a certain degree; though "the ox knoweth his owner, and the ass his master's crib," yet, unless it be in recollecting their dependence on others for food, and a few circumstances of a similar nature, tending chiefly to the preservation of existence, the intellectual powers of even the highest order of animals are extremely circumscribed Man alone can reason from consequences to remote causes, 
and can from the creature trace an idea of the Creator. A sense of religion, then, is the charac. teristic peculiarity which decisively marks a separation between man and all other animals.

In the view we are about to take of Nature, then, it shall be our chief aim, while we expatiate on the wonderful variety it presents in each department, to endeavour to establish and strengthen this pre-eminent characteristic of our species, and counteract that tendency to infidelity which has of late, by the labours of the wicked and designing, been rendered too prevalent.

Indeed the contemplation of the works of Nature invariably leads to a consideration of the attributes of the Creator. The subject is so replete with dignified feelings, that we cannot help being surprised that atheism should ever have had a teacher or a convert. These infatuated men attempt to make every thing subservient to their reasonings, and they are unwilling to acknowledge that a superior mind can have created the wonders around them. Their favourite arguments against the intervention of Providence lie in a reference to physical and moral evils; such as pestilenee, tempests, volcanoes, and death. They have no pleasure in contemplating the beneficent part of the works of Nature; show them a flower, and they will point out the worm which consumes its bosom. It is by dwelling on scenes of waste that they seek to make us converts to their doctrine of annihilation; it is by making us bend under the pressure of the evils of life, that they 
expect to bring us to renounce the hope of eternity. To minds thus perverted, all that excites sorrow among mankind aftords a ground of triumph; even when living in the country, they shut their eyes to the plentiful harvest that waves around them, to the beautiful sky over their heads, and to the benefieent effects of the orb of day. Let us not lend an ear to those gloomy reasoners, who, while they are admitted to the enjoyment of so many blessings, refuse to trace them to their Divine Author Their theories are contradicted by the concurrent voice of every people; the most uncivilized nations are impressed with a belief of the existence of a Creator, and are accustomed to contemplate him in his works Hardly had our world risen out of chaos, hardly had our ancestor's been admitted to the enjoyment of light and life, when their thoughts were directed with gratitude to the throne of their Maker. Their mode of worship was in the beginning as simple as the nature that surrounded them; but the first application of their progress in art and science was to give dignity and splendour to their adoration. Temples were constructer with magnificence, and assembled tribes repeated there the hallowed verses taught to them by their fathers.

That man does not receive instruction from the creatures of God is not their fault. but his own. Their language is not dull and languid, hut loud and incessant; while he, alas! remains deaf to the reiterated cries of mature; and althongh " day unto day uttereth speech, and night unto night sheweth 
knowledge," he continues to post on in his career, without once reflecting on the importance of $\mathbf{N a}$ ture's universal call to

Stand still, and consider the wonderous works of God.

The task, therefore, be ours, in this work, to direct the attention of our fellow-travellers in the - journey of life to this universal call of Nature, and by pointing out a few striking passages in the stupendous volume of the Creator's works, endeavour, while we instruct, to excite their adoration, love, and gratitude to нгм who gave them being, and has so abundantly provided for all their wants.

But where, in the midst of the multiplicity of nature's works shall we begin? From what spot of this prospect shall we set out? Struck with the vastness of our task, we stand, as it were, in the Temple of the Universe, insensible to every thing but our own insignificance; we know not scarcely how to commence our labours, so prolific of instruction, and so attractive is every page of this vast volume; for when we look around us, every object, whether in the form of things animate or inanimate,-existing in the heavens or on the earth, in the waters or in the air, conspire with one accord to arrest our attention, and to point out the almighty power of the Supreme, his consummate wisdom, and the infinitude of his goodness to the children of men. As the traveller, however, in setting out on a voyage of discovery takes his departure from his native land, and should, at least, before visiting regions 
more remote, first make himself a little acquainted with those nigh home, we shall, previous to extending our researches to more distant bounds, first indulge ourselves with a cursory glance at the lowest compartment of the vast edifice, by taking a view of the internal structure of our globe, and see what commodities there present themselves for our use and accommodation.

\section{CHAP. II.}

THE INTERNAL STRUCTURE OF THE EARTH.

Thus in thy world material, Mightx Mind, Not only that which solaces and shines, The rough, the gloomy, challenges our praise!

The treasures of the mineral kingdom, being more concealed, are not so alluring to the senses and are of course, to most men, less interesting than animals or vegetables; but they present themselves to the reflecting mind under innumerable points of view that are interesting, chiefly as affording the materials on which nature, by her slow but certain operations, is continually producing changes that tend to augment the multiplication of plants, for the preservation and the accommodation of animals; while man, in the mean while, is endowed with faculties which enable him to avail himself of the qualities they possess for his own purposes. 
When we penetrate the dark and subterraneous magazine of Nature, we find veins fiaught with the richest Metals; from hence comes that which gives value to the monarch's crown, and weight to his sceptre; which, formed into coins, gives energy and life to traffic, rewards the toils of labour, and puts it in the power of the affluent to warm the bosom of adversity, and make the widow and the orphan sing for joy, or, beaten out into an inconceivable thinness, is made to cover with a transcendant lustre some of the coarest of nature's productions, and render them ornamental in the palace of the great.

Here also is laid up the pale brightness of the Silver, which, formed into a variety of doniestic utensils, sets off with peculiar lustre the choicest dainties of the rich man's table; and here is found the ponderous Lead, from which the cool and clean cistern is formed, as well as those convenient and safe aqueducts, by which the useful element of water is conveyed into the very hearts of our dwellings. Here too are stores of Copper and 'Tin, by which sundry ulensils, formed of the former metal, are rendered more safe and fit for use: and here do we find in profuse abundance Mines, whose contents, although they may not be reckoned of equal value, have been found to be more heneficial in their services to man, than any of those already mentioned. Iron furnishes the mechanic, the artist, and the labourer with their most useful implements and tools; by Iron the farmer is enahler to tear up the most stubjorn soil; Iron secures our dwellings from the 
midnight thief, and confines, by its massy bars, the disturber of our peace to his gloomy cell; by means of Iron, the vessel tossed with tempest is firmly attached to a place of safety, or prevented from being broken up by the raging elements, when overtaken by a storm in the midst of the watery waste.

In these dark vaults are also found that subtle, insinuating metal, Quicksilver, which so much resembles a fluid; the uses of which in philosophy and medicine, are so well known, as well as its importance in various arts and sciences.

From hence, also, are extracted a multitude of Mineral Salts and Saline Substances, together with a variety of Sulphureous bodies. The astringent Alum, the green Borax, the volatile Nitre, the blue Vitrol of Hungary and Cyprus, the green of Germany and Italy, the shining Bismuth, the glittering Antimony, the brown-coloured Cinnabar, the white Chalk, have all an origin in these dark apartments; as also that truly invaluable black inflammatory substance Coal, which ministers to our comfort in the room, presents its services in the kitchen, assists the chemist and philosopher in their experiments, renders the work of the artist more easy, transforms the coarest materials into transparency itself, by which means the light of day is admitted into our dwellings, while the cold inclemency of the weather, is exclurled-the astronomer is enabled to extend his researches to worlds before invisible to mortal eye - the naturalist to observe the minutix of creation-and the feeble eyes or old age furnished with 
new and invigorating powers.-From hence also is derived that wonderful mineral, whose magnetic quality guides the mariner, with unerring precision, beyond the pillars of Hercules, and enables him to find his solitary way across the pathless deep.

Here also in these dark recesses are conveniently laid up, a variety of strata of Stones, and beds of Fossils; and hence derive their origin a number of valuable Jewels and transparent Gems, as well as the firm and compact Marble, the Alabaster, the Porphyry, and the hard pellucid Flint.

Here are to be found those quarries of Stones, fiom which are constructed secure and comfortable dwellings for man and beast-by which the arms of the pier are strengthened to repel the surges of the sea-the rampart is raised above the basis nature had formed-our property secured from the depredations of intruders - the arched bridge thrown across the broad and rapid stream, and the stupendous aqueduct carried over the deep-sunk glen.

Here too are deposited a variety of curious Fossils and extraneous substances, which bafle the wisdom of the wise, and puzzle the reasoning of the naturalist to account for: and here are those vast layers or strata of earth, in all their variety, whose nature and uses are more apparent-where the vegetable kingdom derives its support and nutriment, the trees of the forest spread their wide extended roots, and the tender herb and flower of the field takes hold of the dust ; where the pliable worm forces itself quietly along, the mole finds its darksome way, the foxes 
have holes, and the coneys burrow themselves. Here is that tough tenacious species of earth, which administers its services to man in such a variety of shapes, and acts as a substitute for other commodities in situations where nature has denied them. Are some in want of stones for building? Clay, by undergoing a process, becomes firm and hard, to withstand the most rigid blasts of winter. Are there no Slate quarries in the neighbourhood? Clay, in the shape of Tiles, forms an excellent substitute. Are we in want of Lead for pipes to convey our water from a distance? Clay comes seasonably to our aid. In short, by this mean looking, dirty, and despised substance, we are abundantly supplied with a great variety of utensils and ressels, neat in their structure, cleanly in the use, and though cheap in the purchase, extremely valuable in point of utility. Here are also, commodiously lodged, a variety of other useful earths, which it would encroach too much on our limits to attempt to enumerate. These, with an innumerable variety of other useful and valuable materials, of which those we have mentioned may be considered as only a specimen, are safely locked up by Providence in this great storehouse of Nature, and the key given to Industry to take out and apply as necessity may require, or circumstances direct; and in the disposition of which we may be at a loss what most to admire, the bounty of the Creator, in thus so largely making provision for our numerous wants, or his wisdom in placing them at sucli convenient distances below the 
earth's surface, as neither to obstruct by their bulk the operations going on upon it, or to be beyond the reach of moderate labour, when the necessities of man call aloud for their use.

How inconvenient would it have been, and what small space left for cultivation, had these useful layers of Stone and Lime, Coal and Clay, been promiscuously scattered about in our fields and vineyards, or plied up in uncouth, naked, and deformed masses, without the slightest depth of soil for a covering; and how inaccessible to human labour and ingenuity, or to what an expence of loss of time must man have been put in coming at them, had they been sunk miles instead of feet into the bowels of the earth? Reflecting upon these things, we have good reason to exclaim, In goodness, as well as " in wisdom hast Thou made them all!"

\section{CHAP. III.}

\section{THE FORM OF THE EARTH.}

“ O Nature! all-sufficient, over all!

Enrich me with the knowledge of thy works!"

On returning from our subterraneous excursion, our attention is naturally directed to the shape or form of that stupendous fabrick, which contains so many convenient apartments, and is enriched by so many valuable materials; and were we to trust to appearances as they present themselves to our limited 
powers of vision, we might be led to conclude (as was the opinion of some of the ancients,) that the carth is a wide extended flat, bounded by the horizon.

This belief, however, is now completely exploded, and the figure of the earth demonstrated to be globular, by the voyage of a number of circumnavigators, from the days of the famous Magellan down to those of our illustrious countryman, Captain Cook.

By these voyagers it has been fully ascertained, that a vessel leaving Europe in a certain direction, may return to the point from whence she set out, without altering her course farther than is necessary to avoid intervening obstacles, or give her, what the sailors call sea room.

The spherity of the earth is also apparent from the circumstance, that two ships at sea, sailing in contrary directions till they lose sight of each other, first do so bv the disappearance of the hulls and lower rigging, and afterwards of the higher sails and topmasts. The roundness, from North to South, is evident from the sinking of northern stars to the horizon, till they actually disappear to those who travel far southward; and from East to West by the difference of sun-rise in proportion as we go eastward or westward.

The form of the earth being therefore proved by arguments the most incontrovertible, to be that of a globe or sphere, permit us here to pause and acknowledge the wisdom and goodness of the Creator, as manifested in that particular form. This wisdom 
and goodness is highly apparent, when we consider that this is the most capacious, compact, and durable of all figures, the most convenient for a body in motion, for the equal distribution of light and heat, for the proper disposal of land and water, as well as for the beneficial influence of the winds.

The earth, which is the habitation of so many creatures, must be sufficiently capacious not only to contain them, but what is necessary for their preservation ; and being, as it were, the basis of this sublunary creation, it must be so firmly and compactly girt together, as to be beyond the reach of accident to destroy any of its parts, till the fiat shall have gone forth, that Time shall be no more.

Had it been of an Angular form, the points of the angles behoved to have been considerably weakened by their distance from the centre of gravity, and consequently would have been in continual danger of being loosened, or flying off, by the rapidity of the earth's diurnal motion round its axis; or, had it been possible for them to have remained, what resistance must these angles have occasioned in the performance of that motion! What a continual state of perturbation and tempest in the air must they have caused! How incommodious to the diffusion of light and heat, and for the wise and useful distribution of the waters!

\section{The Surface of the Earth.}

In casting our cyes abroad over the face of the ehrth, we observe it covcred with two great bodies 
of Land and Water; but as it is to the appendages and productions of the former we mean first to direct our thoughts, we will leave the consideration of Nature's mighty Reservoir, and the wonders of the Ocean, to an after occasion, and will proceed to consider the magnificent scene which the dry land presents.

The first thing that here strikes the imagination is that wonderful diversity every where observable and those numerous inequalities so conspicuous on its surface. On one part, we behold the gently rising hillock, scarcely perceptible amidst the surrounding level; in another, the tremendous precipice, yawning horribly over the mountain's brow! Here a deep-sunk glen, imbosomed among rocks, recedes from the eye, and screens the little rivulet that glides along its bottom; there, the lofty summits of the Andes and the Alps, with cloud capt tops wrapt in garments of perpetual snow, bid defiance to vegetation or smile above the blast in sunshine, while the reverberating sound of distant thunder proclaims the raging of the storm below.

In one place we behold the pleasantly sheltered meadow, decked in all its luxuriance of herbage, and in a another a wide naked waste, or sea-like fen, losing itself in the distant prospect. Here, broad and rapid rivers separate nations at variance; there the purling stream, partly fordable, and partly surmounted by the convenient bridge, unites and connects those who enjoy the mild blessings of peace. Here a vast tract of uncultivated heath stretche 
across the districts of the mountains, while lakes of considerable magnitude lave their basis, and cover by their limpid waves the interjacent vallies.

We have just been considering the earth as a globular body. But how, it may be asked, are we to reconcile this with those unequal appearances observable on its surface? To this we answer, that the elevation of the highest mountain bears no more . proportion to the diameter of this wonderful structure, than the inequalities on the rind of an orange does to its bulk; and although these may render it, comparatively speaking, a little uneven, they do nothing to subtract from the beauty of its appearance, or the general roundness of its figure.

Deformities, indeed, they cannot be called; for if the human mind delights in variety, these inequa. lities present us with a variety the most pleasing and picturesque; and if the contemplative phitusopher is captivated by the multiplicity of nature's productions, these furnish food for the most keen researcher into the wonders of creation. But a gratification of taste for the sublime and beautiful were not the only objects the Creator had in view in this diversity of the earth's surface.

\section{Mountains and Vallies.}

These have other great and important uses. Is Health the greatest of all earthly blessings?-to one class of valetudinarians the mountain breeze is beneficial, while to another the genial warmth of the 
well sheltered valley produces the most salutary effects. Does the east wind rage with fury, or cold, with its freezing particles, visit us from the norththe deep-sunk bosom of the valley, or the lee-side of the mountain, defend us from the fury of the tem. pest, and shelter us from the raging storm.

By this happy diversity of towering mountain and sinking dale, we have a variety of soil in a small compass, and are furnished with the productions of different climates almost at our doors. These serve also for the harbour and lodgment of a variety of animals that would have been ill accomodated in the open plain. They are also convenient not only for the generating of metals and minerals, but for digging them out with infinitely less trouble and expense than if they had been situate at considerable distances below a level surface; and mountains are the birth place of many valuable Mines and precious Stones.

In the burning regions of the torrid zone, ridges of mountains, running from East to West, arrest with their towering heads the vapours in their flight, and, condensed into rain, force back the fugitives in cooling and refreshing showers.

In places where earthquakes prevail, mountains are converted into funnels, for the purpose of vomiting forth these volcanic eruptions of liquid fire, which, but for such vents, might have shaken kingdoms from their foundations, and swallowed up provinces in one mighty gulph.

c 2 
But the most general use to which Providence seems to 'have applied mountains and vallies, and consequently, without doubt, the most important one for which they were designed, is the elevation of Springs, and convenient distribution of Waters, agreeably to the language of the Royal Psalmist: "They go up by the mountains, they go down by the vallies, unto the place which thou hast appointed for them." And this use alone would have afiorded us abundant motives of gratitude and thankfulness, although there had been no other, that from mountains and vallies we are supplied with these inestimable blessings.

\section{Springs and Rivers.}

Water is not only one of those necessary elements of which our very means of existence are composed, but it administers to our wants and conveniences on a variety of occasions, and in many different shapes.

With water our choicest bread is mixed, and it makes part of the composition of our favourite be. verage. By water the beasts of the field, and the fowls of the air, quench their thirst ; and by means of it the lofty cedar of Lebanon derives its nutritriment, as well as the tender herb that creepeth against the wall. By this necessary and useful fluid we are assisted in many a tedious and laborious operation:-Formed into canals it helps the deepladen barge forward in its progress; confined into dams it sets the ponderous mill-wheel in motion; or 
evaporated into steam, it puts in play the massy arms of the huge engine.

But how does it come to pass that water is rendered thus serviceable? It is partly owing to the wise manner in which the great Creator distributes it from his treasures, by causing Springs to take their rise in elevated situations, and partly from the general law impressed upon fluids to regain their level, that water is impelled forward in its course, and made to surmount so many obstacles in its progress to the sea, while its suitable consistency fits it for being easily turned aside, and diverted into such other channels as the necessities of man may require.

If, as might have been expected, Springs had been confined in general to the lower situations of the earth, extensive tracts must have been left unwatered, while plains in their immediate neighbourhood would have been deprived of their fertility by inundation, or rendered pestilential by stagnant waters pent up without the means of escape. Had water been deprived of that admirable property of rising to its level, how liable would it have been to be obstructed in its progress by every insignificant hillock, or trifling rise of the ground; and, with respect to its consistency, besides being rendered incapable of being converted to so many useful purposes, had it been thinner, how would it have answered the purpose of supporting so many burdens, or keeping within its bounds; had it been thicker, how would it have been adapted for quenching thirst, or ascend. ing the minute tubes of the vegetable tribe? 
But by this wise and beneficial arrangement, $\mathbf{R}$ vers being elevated at their head, in situations at a distance and remote from the sea, are necessitated to pass over a large tract of country, before they lose themselves in the main, and following the course of those numerous sunken beds made for them in the vallies, they are at once confined within their proper limits, and made to wind in many a lengthened turn, to the more copious diffusion of their benefits, than would have otherwise been the case; while their pliable nature renders them easily turned aside as they glide along, to water those fields removed at a small distance from their banks, or for other purposes to which the ingenuity of man may make them subservient.

\section{Mineral and Medicinal Waters,}

Are also amply provided by nature, and dispense their salutary virtues in a variety of situations. These are not so numeruus as the other, but are sufficiently so for the purposes to which they are adapted; for all men, and every living creature, need food, but we have reason to be thankful that all need not the aid of medicine. Many there are, however, who stand in need of their beneficial influences, and many an invalid have they been the means of restoring to renovated powers, and the blessings of health. Like the pool of Bethesta, they may be said to be of a healing nature; but blessed be the adorable Physician who has opened up these 
fountains, that they have been found to be for the healing of multitudes who resort thither, and not for him alone who is fortunate enough to be first plunged into the troubled stream.

\section{Wide and extended Plains}

Also cover a considerable portion of the face of our globe, and these are not without thcir uses. Did nothing but huge mountainous districts, intercepted by deep vallies, present themselves, what room would be left for tillage? What ineredible labour and fatigue in travelling! What insurmountable barriers to the purposes of trade and commerce! But these facilitate the operations of agriculture, and cause the stubborn glebe to be broken up with ease. Carriages with immense burdens glide along on the level of a rail-way; the traveller on horseback, enveloped in darkness, pursues his journey without danger of stumbling; the loaded waggon is wheeled anwards without interruption; and the swift post flies with astonishing celerity on the wings of business.

The last thing we shall touch upon in the general appearance of the surface of the dry land is the

\section{Verdant Colour of the Earth;}

For whatever diversity of hue there may be in natural objects when viewed separately, there can be no doubt but this is the most general and prevailing 
colour; and as nature does nothing in vain, the circumstance certainly ought not to be overlooked. In this the wisdom and goodness of our Creator will appear by attending to the following considerations: Had the robe of nature assumed a more light or brilliant cast, and the generality of objects appeared of a white, yellow, orange, or red complexion, it would have been too much for the strength of our nerves, and instead of being refreshed and delighted, we would have been blinded and overpowered with the dazzling splendour.

Had she put on a more sombre aspect, and been clothed with a violet, purple, or bluce mantle, the prospect must have been sad, dismal, and gloomy, and instead of imparting to the animal spirits the exhilarating draught to keep them in full play, would have suffered them to subside into dejection and despondency. To prevent these two extremes, nature is clothed with a verdant mantle, being that proper combination of light and shade, that neither dazzles nor darkens the prospect, which rather refreshes than fatigues the eye, strengthens and invigorates instead of weakening the powers of vision, and creates in the soul that increasing delight and lengthened rapture, which the poet had in view when he wrote the following lines:

"Gay green!

Thou smiling Nature's universal robe;

United light and shade! where the sight dwells

With growing streng $h$, and ever new delight !", 


\section{CHAP. IV.}

\section{VEGETABLES.}

"s Your contemplation further yet pursue;

The wondrous world of Vegetables view!

See varied Trces their various fruits produce,

Some for delightful taste, and some for use.

See Sprouting Plants enrich the plain and wood,

For physic some, and some design'd for food.

See Fragrant Flowers, with different colours dy'd, On smiling meads unfold their gaudy pride!

From the verdant colour of creation the transition is natural to a consideration of the objects by which it is occasioned. These are the numerous vegetable tribes which cover and adorn the surface of our globe in all that variety of Trees, Shrubs, and Herbs which we behold.

Here Trees, like stately turrets, raise their lofty heads; there, the more pliant and humble thick set Shrubs unite their foliage; while the herbaceous tribe in mingled profusion cling more closely to the earth, and cover the fields with their verdure. Man cannot contemplate the regetable creation without recalling the idea of beauty, sweetness, and a thousand charms that captivate the senses. The perfume of the rose, the brilliancy of the lily, the sweetness of the violet, and the stately magnificence of the forest, successively catch his attention and delight him. 


\section{The Structure of Vegetables,}

In all their varied forms, is truly wonderful. How excellently adapted are the roots for taking hold of their parent earth, as well as for drawing nourishment for the support of the plant, and imbib. ing moisture from the neighbouring soil! How commodiously are the various tubes and fibres which compose the trunk or stalk arranged, for the motion of the sap upwards to all the extremities of the leaves and branches! How nicely are the leaves formed for the important services they are made to yield in the economy of vegetation! See how they serve to concoct and prepare the sap; how they prevent by their shade the moisture at the root from being too speedily evaporated; how they embrace and defend the flower in the bud, and carefully conceal the fruit before it arrives at maturity; and by catching the undulations of the gentle breeze, how they convey that motion to the trunk and branches, which (for ought we know, may be as essentially necessary to the vegetable life as exercise is to animal health. What an excellent clothing does the bark afford, not only for protecting the stem and branches from external injury, but from the hurfful extremes of heat and cold? What evident marks of wisdom and design do the Flowers evince in their beautiful and delicate construction! how nicely are they formed for the protection and nourishment of the first and tender rudiments of the fruit ! and when it has attained more firmness and solidity, how 
readily do they relinquish their charge, and drop off in decay when no longer necessary! How wonderfully does the fruit, in some classes, envelope and protect the seed till it has arrived at maturity; and, lastly, what a passing strange piece of organized mechanism is the seed itself, and, being necessary for the reproduction of its species, what a remarkable provision is made for its preservation and succession! What but the wisdom of a Deity could have devised that those seeds which are most exposed to the ravages of the inhabitants of the forest, should not only be doubly, but some of them trebly enclosed! that those most in request as articles of food, should be so hardy and abundantly prolific; and that seeds in general, which are the sport of so many casualties, and exposed to injury from such a variety of accidents, are possessed of a principle of lasting vitality, which makes it indeed no easy matter to deprive them of their fructifying power. Plants are also multiplied and propagated by a variety of ways, which strengthen the provision for their succession.

Nor is the finger of Providence less visible in the means of diffusing or spreading abroad vegetables, than in the provision made for keeping up their succession. The earth may be said to be full of the goodness of the Lord ; but how comes it to pass, that in parts untrod by man, and on the tops of ruinous buildings, so many varied specimens of the vegetable creation are to be found? Is it not from the manner in which Nature's great husbandman 
scatters his seeds about? While the seeds of some plants are made sufficiently heavy to fall down and take up their abode nigh the place of their nativity; and others, after having been swallowed by quadrupeds, are deposited in the neighbouring soil; some are carried by the fowls of the air to places more remote, or, being furnished with a soft plumage, are borne on the winds of heaven to the situations allotted for them. To prevent some from pitching too near, they are wrapt up in elastic cases, which bursting when fully ripe, the prisoners fly abroad in all directions: to prevent others from straying too far, they are furnished with a kind of grappling-hooks that arrest them in their flight, and attach them to the spot most congenial to their growth.

In the construction of plants we observe a considerable difference in the consistence of the three classes. Compared with the shrubby race, how hard, firm, and tenacious is the trunk of the majestic Oak; and, compared with the herbaceous tribe, how woody, tough, and elastic is the hawthorn twig; but for this, how could the mighty monarch of the wood have been able to withstand the fury of the tempest; and, while the more humble and lowly shrubs stand not in need of such firmness of texture, their pliability and elastic toughness, together with the prickly coat of mail by which they are enveloped, render them less susceptible of injury in their exposed situation.

Softness, united with a still greater degree of flexibility, are the distinguishing characteristics of the 
berbaceous order; and how wisely has this been ordered for the various purposes for which they were created; with the firmness of trees, to what a prickly stubble must Nature's soft and downy carpet have given way? with the tenacity of shrubs, how would it have answered as food for our cattle?

There are, besides, a number of other properties and peculiarities in the vegetable kingdom, in which the wonderful working of Divinity shines pre-eminent. How strange, for instance, that if a seed is sown in a reversed position, the young root turns of itself downwards, while the stem refuses to sink deeper in the soil, and bends itself round to shoot up through the surface of the earth. How surprising, that when the roots of a tree or plant meet with a stone or other interruption in their progress underground, they change their direction and avoid it. How amazing, that the numerous shoots which branch out from the root in quest of moisture, pursue as it were by instinct the tract that leads to it; will turn from a barren to a more fertile soil ; and, that plants shut up in a darksome room, bend or creep to any aperture through which the rays of light may be admitted.

In these respects the vegetable tribes may be said to possess something analogous to animal life; but here the resemblance does not drop-how surprising the phenomenon of what is called the sleep of plants, and the sexual system of Linnæus, founded on the discovery that there exists in the vegetable, as well as in the animal kingdom, a distinction of sexes ! 
What amazing variety of size, of shape, and hue, do we discover among this multitudinous order of things! What different properties do some possess from others! and what a near approach do a few make to that superior order immediately above them, in the scale of existence! The Sensitive plant, when slightly touched, evinces something like the timidity of our harmless animals; the Hedysarum Gyrans, or moving plant of the East, exhibits an incessant and spontaneous movement of its leaves during the day, in warm and clear weather; but in the night season, and in the absence of light and heat, its motions cease, and it remains, as it were, in a state of quiescence; and the American Venus' Flytrap, like an animal of prey, seems to lie in wait to catch the unwary insect. These are wonderful properties of the vegetable creation, but these are necessary in the infinitude of the works of creation, as links to connect it with the order of animals, and preserve unbroken the most minute gradations in Nature's universal chain!

Flowers are undoubtedly among the most exquisite pieces of nature's workmanship. What beautiful tints do they display! what lively colours do they unfold! what variegated beauties do they discover! and what delightful perfumes do they emit! In view of these well might the poet exclaim:

"Who can paint

Like Nature? Can imagination boast

Amid its gay creation, hues like hers?

Or can it mix them with that matchless skill, 
And lose them in each other, as appears In every bud that blows?"'

But we have no less to admire in the general contrivance and delicate structure of their several parts, and beautiful harmony of the whole, than in the laying on of the colours by which they are embellished.

The diversity of shape, and torm, and complexion, in those of different kinds, is not more remarkable than that no two are to be found cxaclly alike, even of the same species, and growing on the same stalk or knot.

Nor should the aromatic fragrance which those beautiful sons and daughters of nature send forth, more excite our gratitude, than that well ordered succession, by which the pleasures we receive from these transitory visitants, are lengthened out and protracted all the year round.

Before winter with his cloudy firont has taken his departure, the early Snow.drop boldly steps forth in his pure white robe, the Crocus next, with an air of timidity peeps out, and, as if afraid to venture, keeps close to the earth; then comes the Violet with her varied beauties, accompanied by the sparkling Polyanthus, and splendid Auricula; afterwards groves of Tulips display their rich and gaudy attire, followed by the Anemone in her spreading robe.Now the Ranuncules expands the richness of his foliage, the Sun-Flower shoots forth his golden rays, and the beautiful Carnation with a numerous train bring up the rear, and close the procession. 
The Use of Vegetables.

Trees. - Those stupendous specimens of creating art spread not their wide extended roots, nor lift their lofty heads in vain. Beneath their cooling shades, our flocks and herd's find a comfortable asylum from the scorching rays of the summer sun; the wild stragglers of the forest have a place of refuge among their woods and thickets; whilst the feathery songsters of the grove build their little dwellings in security, and sing among their branches; "as for the stork, the fir trees are her house."

But in what a variety of respects, besides affording the inhabitants of warm climates an agreeable shelter from the mid.day heat, do they yield their services, or are made subservient to the use of man. Some, as the bread fruit tree of the Pacific Ocean, - the cabbage tree of East Florida, the tea tree of China, the sugarmaple tree of America, the coffee tree and sugar cane in the West Indies, and the nu-

- merous luxurious fruit bearing trees scattered over the face of the globe, contribute to our wants in form of food. The fountain tree on one of the Canary Islands, is said by voyagers to furnish the inhabitants with a supply of water; while the paper-mulberry tree of the Southern ocean, and the cotton shrub of America, provide us with materials for clothing. The candle-herry myrtle presents the inhabitants of Nankeen with a substitute for animal tallow. The salt tree of Chili yields a daily supply of fine salt. The cimnamon, nutmeg, clove, and pimento, furnish 
us with a supply of spices. The Jesuit's bark, manna, senna, and others, produce a variety of simple but useful medicines. Some trees yield a precious balsam for the healing of nations; some a quantity of turpentine and rosin, and others give out their quota of valuable oils and gums.

Nor are trees serviceable only in a natural state: by the assistance of art, some are converted into houses to protect man from the inclemency of the weather, or are moulded into a variety of forms for the purposes of building, and domestic comfort; others raise the huge fabric of the floating castle or bulky merchantman, by which the articles of indus. * try and commerce are transported, and a communication kept up with the remotest regions.

Our limits do not permit us to enlarge upon these specimens, or point out the various uses to which a number of other woods in general use may be applied; but the reader's own thoughts may suggest these, as they are sufficiently obvious: and mean time we will proceed to the order of

Shrubs. - As much that has been already said respecting the utility of trees, may be applied in common to this order, we will confine ourselves to the three particulars in which they may be said to differ most from the former; the first is their stature, the second their greater pliability, and the third the prickly armour by which many of them are covered.

Some shrubs, as the gooseberry, the rasp, and the currant bushes, so common in our gardens, gratify the palate, and temper the blood during the summer 
months with agreeable and cooling fruit; others, as the rose, delight and please the eye by the beauty of their flowers; or regale the olfactory nerves with the fragrance of their perfumes, as the sweet scented briar: but how could these several ends have been accomplished, if, by a more exalted exposure, the fruit-bearing bushes had placed their treasures beyond our reach-every rose, with its back turned to us, had been " born to blush unseen," and each aromatic shrub, removed far above the sense of smel. ling, had literally been left

"To waste its sweetness in the desart air."

With regard to that considerable share of pliant elasticity possessed by some of them, how easily does this admit the branches to be turned aside, and to resume their former position, in gathering of the fruit or flowers, and how serviceable does this property enable us to make some of them in the form of hoops, baskets, or wicker work of any description; while the sharp-pointed prickles by which they are armed, serve not only as weapons of defence for themselves, but furnish us with cheap and secure fences against the inroads of straggling cattle, and the unwelcome intrusion of the unprincipled vagrant.

Herbs - in an especial manner may be said to constitute the food of man and beast, as well as to yield their assistance in an infinity of ways; and behold, in what profusion they spring forth; in what numerous bands they appear! Yonder, a field of golden-eared wheat presents to the view a most 
prolific crop of what forms the chief part of the staff of life. Here a few acres of long.bearded barley ripen to provide us with our favourite beverage. On the right hand stand the tall growing and slen. der oats and flowering potatoes, to revive and keep alive the hopes of the poor; while on the left the heavy laden bean, and low-creeping pea, in lengthened files vegetate to furnish provender for our horses; or the globular turnip increases its swelling bulk to lay up for our herds a supply of food when the softer herbage of the field is locked up by the congealing powers of winter.

But what a spontaneous crop of luxuriant herbage do our meadows present in the appointed season, and in what a profusion of wholesome pasture do the numerous flocks of sheep and cattle roam! Whether they frequent the solitary holm, beside the still waters, or range the pathless steep, still they are followed by the goodness of the Lord: myriads of grassy tufts spring up on every side, and they are satisfied out of the treasures of Providence.

But the herbaceous productions of the field are not universally calculated for the purposes of food. In some places numerous groups of tall, thin, flexible plants make their appearance, whose filmy coats being properly manufactured, are converted into the most costly and delicate raiment; while others of a coarser texture furnish the mariner with wings to his vessel, cordage to tighten his masts, or the ponderous cable to stay his bark in the midst of the fluctuating element. 
But here their services do not end; for when worn out in one shape, they assume a new form, and not only furnish the material from which is formed the wrapper of the manufacturer, and the package of the merchant, but that invaluable article upon which we write-upon which we are able to hold converse with friends at a distance-and by means of which, man transmits his thoughts to man, and gener ations unborn are enabled to hold converse with past ages!

By means of these pliant productions we are also supplied with a variety of seeds and oils, of much request in common life; and wherever disease is known, there, we have reason to believe, medicinal herbs spring up as antidotes; some communicating their healing virtues by the root, some by the leaves, and others by the flowers or seeds. A number of these, and many others of the greatest utility in medicine, come forth in various parts of the globe without the aid of art, and are found growing wild among the herbs of the field - but these are not the effects of chance. They were originally planted by the hands of Omnipotence, at the suggestion of Divine benevolence, prompted by Omniscience. It was the Lord who created medicines out of the earth; He foresaw the distresses of his creatures, and in pity to their calamities, not only commissioned the balm to spring up in Gilead for the healing of the eastern tribes, but has spread abroad that boundless variety of medicinal plants, which are to be found in every climate, suited to the diseases of 
those particular spots, where Providence, all-wise, hath fixed the lot of their inhabitants.

What a beautiful variety of nutritious esculents, and exquisitely formed flowers do our gardens present! Here the Parsley with her frizzled locks, the Celery with her outstretched arms, the Asparagus with his towering stem, the Artichoke with his turgir top, the Cauliflower with her milky dome, the Cabbage with her swelling form, a variety of greens with their curled leaves, and long files of peas and beans, await in silence their master's call to do homage at his table; and here too is deposited, among a number of valuable and useful roots, that excellent farinaceous substitute for bread, the wholesome potatoe.

Flowers.-But for what purpose do these charming flowers come forth? Is it merely to please our eyes with their brilliant colours, and regale the sense of smelling with their odoriferous perfumes, that they unfold their fascinating beauties and emit their pleasing fragrance? Or is it to attract those numerous insects which swarm among them, and riot amid their liquid sweets?

That flowers were designed for both these purposes is apparent from the sensations we experience when we have leisure to visit those delightful spots, and the assiduous eagerness which the busy bee evinces in roaming from flower to flower, to extract their balmy juices. But there is another, and that a most important use to which the flowery race may 
be made subservient:-In reason's ear they become preachers.

The upright philosopher of the land of $\mathrm{Uz}_{\mathrm{z}}$, and that devout admirer of the works of Nature, Israel's king David, both took occasion to compare the uncertain tenure of human life, to the frail and perishable state of a flower. The prophet Isaiah repre. sents the transient glory of the crown of pride as being like to one of these fading beauties; and our Sàviour has demonstrated that an important lesson may be learned against a too anxious care, and pride in dress, by a right consideration of these gay visitants: "Consider the lilies how they grow ; they toil not, they spin not, and yet I say unto you, that Solomon in all his glory was not arrayed like one of these."

It must, therefore, add much to the value of these short lived monitors, in the estimation of the wise, and make their peaceful abodes be sought after with the greater avidity by those who take pleasure in the works of God, that they are thus capable of affording matter for serious reflection and moral improvement.

Mr. Addison seems to have been sensible of this, when he breaks out into the following declamation, in praise of the pleasures of such a retirement:"You must know, Sir," says he, in one of his papers in the spectator, "that I look upon the pleasure which we take in a garden, as one of the most innocent delights of human life. A garden was the habitation of our first parents before the fall. It is 
naturally apt to fill the mind with calmness and tranquility, and to lay all its turbulent passions at rest. It gives us a great insight into the contrivance and wisdom of Providence, and suggests innumera. ble subjects for meditation. We cannot but think the very complacency and satisfaction which a man takes in these works of Nature, to be a laudable, if not a virtuous habit of mind."

But let not the poor complain, or those who have no garden to retire to, no beautifully adorned enclosure, where, secluded from society, they may give themselves up to reflection. Still the fields are open to them, and what, in the words of an eminent naturalist, is the earth, but " an immense garden, laid out and planted by the hand of the Deity?-the lofty mountains and waving forests are its terraces and groves; fertile f:elds and flowery meadows form its beautiful parterres."

We cannot, we are persuaded, conclude this head of our subject better than with the following quotation from the author of The Seasons:

"s Soft roll your incense herbs, and fruits, and flowers,

In mingled clouds to $\mathrm{H}_{1 \mathrm{M}}$, whose sun exalts,

Whose breath perfumes you, and whose pencil paints." 


\title{
CHAP. II.
}

\section{ANIMALS.}

\begin{abstract}
6s Fountain of elegance, unseen thyself, What limit owns thy beauty, when thy works Seem to possess, to faculties like mine, Perfection infinite! the merest speck Of animated matter, to the eye That studiously surveys the wise design, Is a full volume of abundant art.
\end{abstract}

In ascending from the Vegetable to the Animal kingdom, we cannot help our attention being forcibly engaged by the singular construction, and amazing properties of those little wonders found at the bottom of ditches, and adhering to the underside of the broad leaves of Aquatic Plants, known by the name of Freshwater Polypuses. See that little thing in form of a funnel or bell, adhering by the lower extremity to some extraneous substance at the bottom of the water! Observe how it shoots out its slender arms from the margin of its wide mouth, and casts them around, occasioning a vortex in the fluid! Sce how those insects, after being drawn into that vortex, are caught hold of by its arms, and conveyed to the mouth with a celerity that is astonishing; but for these signs of life and animation would you not have taken what you first saw to be a flower?. Now observe how it shoots out from its sides something in form of buds; return in a few days, and, what do you behold?-these buds converted into perfect Polypuses, but still ad- 
hering to the parent. See how, by a sudden jirk; they separate, and immediately fix on other situations; cut one of these in two, the upper part shoots out a tail, and the under produces a head; cut one in three, and the upper and under do the same, while the midalle division produces both a head and a tail; cut one down lengthways to the middle, and you have a monster with two heads; divide these, again and again, as often as you please, and you have a Hydra with many heads, in short cut the Polypus into ten, or ten hundred parts, the effect will be the same, and you will have as many Polypuses.

If the Sensitive Plant, the Hedysarum Gyrans, and Venus' Fly-Trap, may be considered as so many links at which the vegetable creation ends, these living plants, if we may use the expression, and animal flowers, which are found adhering to the rocks on the sea shore, may, as well as the Oyster, and other shell-nish (which form the connection betwixt the animal and the mineral kingdom,) be reckoned among those at which the mysterious and multitudinous order of beings begins, which is continued in such an infinitude of shapes and sizes, shades and differences, and possessed with such a number of dissimilar appetites and instincts, from the lowest gradation amongst the number of these imperfectly formed animals, till it arrives at that most complete piece of Nature's workmanship-that cape-stone of the inferior creation, or link which unites it with superior intelligences-Man. 
The number of animated creatures is prodigious indeed! The whole creation teens as it were with existence! The dry-land sends forth its multitudes; the air hath its swarms; the sea its numerous shoals: and the very depositories of corruption produce their myriads! Indeed in the class of Insects alone there are a greater number of species than there are kinds of Plants on the surface of the earth. In a little rain water, after standing some days, Mr. Lewenhoeck discovered innumerable animalcules, many thou. sands of times less than a grain of sand, and in proportion to a mite as a bee is to a horse! Having examined the melt of a cod, he concluded that it - contained more living animalcules than there were people living in the world; and by a method he made use of in order to ascertain the comparative size with the thickness or breadth of a hair of his head, it was found that 216,000 of these minute ercatures are but epual to a globe whose diameter is the breath of a hair. How amazing the wonders of Omnipotence!

Yet notwithstanding these immense numbers, this amazing diversity of form and bulk, of taste and habit, all are conveniently and comfortably lodged; all are fed to their hearts' content, at the same common table, and in such a manner as not a fragment can be lost. How wonderful is it to observe how well adapted are the various appetites of his creatures, to fulfil the will of the Great Creator, that not a fragment may be lost. Some animals of the carniverous kind have an unquenchable thirst for: 
blood warm from the animal; others are satisfied with the flesh newly killed: a third are not pleased with it till it is in a state of putridity : of those of another description, some live upon fruits and roots; others can partake of bark and leaves; a third put up with the soft herbage of the meadow; and a fourth are content with the very refuse of our fields and gardens: while each pursues that particular path chalked out for him by Nature, without repining or envying the lot of his neighbour.

The unwieldly Whale in the Greenland seas, the numerous herds of Elephants which graze the extensive regions betwixt the river Senegal and the Cape of Good Hope ; and the gigantic Ostrich of the sandy borders of Egypt and Palestine, roam as much at large as the winged inseet that flits from flower to flower, or the invisible Animalcule which swims in the liquid drop. 'The polar Bear of the Arctic Circle, wrapt in his shaggy covering, the Ermine of Siberia in his furry mantle, and the Water-Fowl with her thick-set oily feather's, no doubt feel as comfortable as the Barbary Cow, almost naked, the rhinoceros, sheltered from the tropical heats by his coat of mail, or the monstrous Hippopotamus (the Behemoth of Job, when he retires to cool himself at the bottom of the African rivers. Those abhorred insects which feed upon ordure; or still more loathsome, that riot in putrefaction, we have reason to believe feed as deliciously as the Racoon on his West-Indian sweets, or pampered Lap-dog from the hand of its mistress. And if the 
foxes have holes, and the birds of the air have nests, we have no reason to suppose but the former feel as happy when they have formed their habitations at a convenient distance from the hen-roost, and the latter, when from their lofty situations they can behold the fowler at a distance, as the fiocks and herds which graze our fields, or the domestic fowls which partake of our care and bounty. By this wise and happy arrangement, the harmony of the universe is preserved, and the prodigious multitude of Earth's numerous tenants enabled to exist without disorder or confusion.

But if we attend to the internal structure of these wonderfully complicated and intricately woven machines, called Animals, we will still find more reason to admire and adore that Great Supreme, whose omnipotent fiat brought them all into existence. No wonder that Galen, at the sight of a human skeleton, should relinquish his former atheistical thoughts; and, that the Psalmist, on the contemplation of his material structure, should exclaim, "I am fearfully and wonderfully made;" but the greater surprise is, that so many skeletons of animals and animated. wonders can be beheld with so much indifference by that creature to whom God has given reflection for the wisest of purposes; for to what purpose can the thoughts of man be better applied than to the contemplation of the Deity through the medium of his works!

"What variety of springs, what forces, and what mechanical motion (says Buflon,) are enclosed in 
this small part of matter which composes the body of an animal! What properties, what harmony, and what correspondence between the various parts! How many combinations, arrangements, causes, effects and principles, conspire to complete one end; and another writer observes: "In the single ounce of matter which composes the body of a Sparrow, we see all the instruments necessary for eating, for digestion, for respiration, for seeing, for hearing, for smelling, for walking, for flying, for the performance of every animal function, and of every motion. All the parts of the complicated machine are perfectly appropriated, completely adapted to their respective uses; and all disposed with the most exact organization." All this is very true, but would not the wonder have been still more augmented, had the specimens been taken from among those little curiosities of the Western hemisphere, called Hunmingbirds; with the addition that its beak is pointed like a needle, its claws not thicker than a common pin; that its nest is about half an inch deep, its egg about the size of a small pea ; and that nevertheless this diminutive bird is adorned with a plumage of the richest hues, and covered with a down that makes it resemble a velvet flower? Upon its head is a black tuft of incomparable beauty; the breast is of a rose colour, its belly white as milk, the b ck, wings, and tail are grey, with a border resembling silver, and as if streaked with gold of the brightest hue! But indeed the structure of the smallest insect, or minutest animal in the creation of God carries 
along with it the most indisputable evidence of its Original; namely, that it is beyond the possibility of art to imitate, or the utmost stretch of human ingenuity to comprehend.

Motion is one distinguishing characteristic of the animal from the vegetable kingdom of Nature; and this peculiarity will be found to be absolutely neces-

- sary; for if the food or nutriment of animals is not brought to them as to plants, by means of roots or other conductors, they must needs go in seateh of it; and how wisely are they furnished with instruments for the purpose, some in the form of limbs, some of wings, some of fins, and some of the reptile tribe are enabled to move by the disposition of the museles and fibres of their bodies; but what would this power of motion and means of performing it have signified, had these creatures been left to grope in the dark, without ability to distinguish the good from the bad:

"To shun their poison, and to choose their food."

Might they not as well have remained to perish on the spot which gave them birth, as to have strayed only to get their frames shattered by every intervening obstacle: or the vital spark extinguished by mistaking the beautiful plant for the wholesome herb. To remedy such evils, however, Nature, or rather the God of Nature, has not only provided them with senses, but has taken the utmost precantion to guard from external injury these wonderful pieces of exquisite skill, as well as that seat of all sensc- 
tion, from whence the ramifications of the nerves take their rise.

To mention only one or two of the most obvious, for instance; what a curious and wonderful piece of mechanism is the human Eye, so admirably contrived with its various coats, muscles, vessels, humours, nerves, and retina, for the purposes of vision! How excellent its situation for the use it was designed! and how safely guarded by tise projecting eye brows and watchful eye lashes, everon the alert, from external injury! The Lut, too, is a most wonderful structure, contrived by its ridges and hollows to gather and concentrate sounds till they strike on the transparent membrane that forms the surface of the drum, although deeply lodged that it may also be preserved from outward accident. These are strange pieces of mechanism indeed! and is it not natural to conclude, "He that planted, the ear shall he not hear? he that formed the eye shall he not see?"

If the brain, which is the seat of sensation and the fountain of the animal spirits, is environed round with such a hard, thick, and tough substance as the skull, the heart and lungs are wisely placed in the centre of the body, and encompassed by a double fence of bones or ribs, muscles, and skin.

Without breathing, to put the wheel in motion at the cistern, no animal could exist, and how admirably situated and guarded also, as we have observed, are the organs of respiration, and that mysterious movement, "that faints not, neither is weary," but 
by night and by day, asleep or awake, in motion or at rest, beats in unremitting pulsations, with greater regularity than a watch, in the breast of some animals for sixty, in some seventy, and in others upwards of one hundred years. We might also notice the admirable structure and wise disposition of the other parts in the animal economy, but this would be inconsistent with our present limits and design; we must, however, observe on the whole, that each will be found most conveniently situated for its respective uses, and formed in the wisest manner for its various purposes; that while nothing is wanting to render the structure complete, there is nothing superfluous or made in vain. The feelers of the Butterfly are no less essential to her well-being than the proboscis of the Elephant; and the leg of the Fly can no more say to its wing, than the eye of the human body to its hand, "I have no need of thee."

But if the right consideration of the structure of animals as well as the wise provision made for their lodgment and subsistence, is convincing to the most sceptical, that all are the doings of a Being infinite in power, and fearful in working; and inspire the religious philosopher with such sentiments as David expressed when contemplating the formation of the human frame; must we not also adopt such language as he made use of on another occasion, and say, when reflecting on the manner in which these ereatures are reproduced, and the wonders of that procreative power by which a continued succession is kept up; Thine eyes saw them when they were 
made in secret, and curiously wrought in the lower pluces of the earth. Whether they come into the world in the shape of animals completely formed, or through the medium of eggs, still the business of generation must remain a mystery, and be reckoned amongst the number of the dark things of the Creator.

The provision for keeping the number of living creatures within due limits, is no less remarkable than that for bringing them into being. The most - formidable monsters are thinly scattered, or confined to particular spots. The destructive Tiger, for instance, is not very common, and the greatest rendezvous of this blood-thirsty animal is said to be a sort of insulated situation, the Sunderbunds or Woody-Islands, at the mouth of the Ganges in India. Long lived animals are observed to have few young at a time; while those of the greatest utility or such as are used for animal food, abound in every climate, and the short in duration are uncommonly prolific!

The instinct displayed by many of the irrational creation for the preservation of their young, is also truly astonishing, and in some instances has been referred to as examples of the strongest proofs of affection. "How often," says our Saviour, "would I have gathered thy children together, as a hen gathereth her chickens under her wings, and ye would not!"- but there are some of this order who stand not long in need of parental protection and instruction; for the newly-calved Hippopotamus on the death of his dam, will, at the sight of danger, betake himself to a place of safety in his natural element, 
the bottom of the river. This might bring us to speak more fully of those particular instincts by which animals are distinguished; but as we shall have occasion to notice a few of these in considering some peculiarities in the different orders as we go along, we will here drop the general survey, and proceed to that of

\section{Quadrupeds.}

Of this order it may be remarked in general, that they derive their name from the number of their legs; and this naturally occasions in those that make use of them for the purpose of walking, the prone posture by which they are distinguished; but this posture, far from incommoding them, is, by the wise conformation of the other parts, rendered the most commodious possible for their habits and manner of living. Quadrupeds are, for the most part, furnished with tails, and these are highly useful in the absence of arms, for sweeping off vermin and troublesome animals. Having no hands to lift their food to their mouths, the necks of this order are in general proportioned to the length of their fore legs; their legs are made to bend in such a direction as with the greatest ease to facilitate their motion forwards; they have, for the most part, a covering of hair or wool; and, that the weight of the head might not becorse too heavy in the act of feeding, each of these animals is furnished with a strong tendinous insensible ligament, braced from the head 
to the middle of the back, which both enables them to support their burden with ease, and to recover their head at pleasure.

In the particular construction of the various species of Quadrupeds, with their several dispositions and appetites, there are several things very remarkable; but we will only mention a few of them, in which the wisdom and goodness of the Creator, in adapting them so wonderfully to their different situations, habits, and manners of living, are very conspicuous.

Animals of the graminivorous kinds, such as the Horse, the $\mathbf{O x}$, and the Sheep, are furnished with masticating organs, adapted to the soft herbage they eat ; being of harmless dispositions, they are only armed with defensive weapons, and for mutual safety associate together in herds

Those whose natures are fierce and savage, and whose cruel dispositions, like those of the Tiger and Hyena, cannot be satisfied but at the expense of blood, come forth solitary and alone; but they are armed with fearful claws and horrid tusks, and monstrous jaws, wonderfully fitted for the seizure and destruction of their victims.

The Camel. doomed to traverse the parched and burning deserts of Arabia, where continued drought and sterility reign, has not only a foot admirably fitted for his element, and endowed with a remarkable abstinence, but carries along with him a natural reservoir which he fills with water at every well. 
The Lama of South America (the only original beast of burden it produces,) is remarkably sure footed, and climbs and descends with the greatest safety the craggy rocks it has to encounter among the rugged steeps and narrow paths of the Andes, though encumbered with its load.

Goats range the craggy steep, and delight to crop the uncultivated heath from the mountain's brow; and behold how admirably their hollow hoofs are formed for taking hold of the rock, and with what surprising agility they bound from cliff to cliff!

Animals of the Weasel kind, that live chiefly in holes, and feed upon vermin, are not only furnished with furs to preserve them from the damp, but have long, slender, flexible bodies, well adapted for their various windings. The Sea-horse of the Northern Ocean, whose element is sometimes in the water, and sometimes on the ice, is not only web-footed, to assist in swimming, but has two monstrous tusks, bending down from the upper jaw, which, together with his claws, enable him to scramble up the icy beach at pleasure. In short, the Mole is moulded in the best possible manner for his subterraneous habitation-the Squirrel for his aerial flights-the Kangaroo for his tremendous leaps--and the Bat, which unites the Quadruped with the Volatile race, is shaped in the most convenient manner for his predatory excursions.

But if this remarkable accommodation of the parts and appetites of quadrupeds to their habits and pursuits, is apt to excite our surprise, what must 
we think of those still more surprising and remarkable instincts by which many of them are distin. guished. In their internal formation some of this order are so strikingly analogous to the human body, that it is said, some skill in physiology is necessary to be able to notice the difference; and in the external appearance of the Orang-outang, or Wild-man of the Woods, there is certainly no little resemblance. So much, indeed, does the exterual appearance of this creature resemble the human, that "the Negroes imagine them to be a forcign nation, come to inhabit their country, and that they do not speak for fear of being compelled to work." They are also the only animals that imitate man in the use of weapons otherwise than what are natural; frequently attacking their enemies with sticks and stones. That they possess an eminent share of - natural sagacity in the absence of reason, is evident from the manner in which they make sheds for shelter, and go to sleep in trees for security, as well as from their descending from the mountains, when they no longer find fruits, to the sea shore in search of shell-fish. In the passage of one of these animals from Angola to England, it made many friends on board, and seemed to despise the monkies of a lower species, by avoiding that part of the ship where they were confined. Buffon describes one of these animals which he saw, as sitting down at table, unfolding his napkin, wiping his lips, making use of a fork or spoon, pouring out his drink into a glass, touching glasses with the person who drank 
with him, giving his hand to shew the company to the door who came to see him, and walk about as gravely as if he formed one of the society. "All these," he observes, "I have seen, without any other instigation than the signs or command of his master, and often of his own accord." He also mentions, that his deportment was grave, his movements regular, and his disposition gentle, very different from other apes. Francis Pryard relates, that in the province of Sierra Leone there is a species so strong limbed, and so industrious, that when properly trained and fed, they work like servants.

But to proceed ; what wonderful prudence, foresight, and industry, does the republic of Beavers display, as in a state of social compact, with an overseer at their head, each exerting his powers and contributing his exertions in raising the mole, and forming with care the fortified settlement! What sagacity does the Elephant discover, as he discharges the water from his mighty trunk, in order to cool himself in the midst of the burning plains of Caffraria!

Who knows not the affectionate tenderness of the Dog, the mischievous cunning of the Monkey, the inflexible perseverance of the Cat, in watching her prey, and the subtle artifices of the Hare, in eluding her pursuers?

The Lion, at whose tremendous roar creation flies, as if knowing the terror which his fearless form inspires, has recourse to cunning, and watches his prey in ambush, in the neighbourhood of those 
springs and waters to which they must necessarily come to quench their thirst. The Bear, in autumn, betakes himself to his winter quarters, nor ventures abroad till spring has again renewed the face of the earth. The Chamois Goat, when elosely pursued in his mountainous retreat, will suddenly rebound on the huntsman, and precipitate him over the rock. The Hedge-hog in winter wraps himself up in his mossy seat. The Porcupine when almost overtaken in the pursuit, on a sudden rolls himself up, and presents to his antagonist, instead of a delicious morsel, a ball of prickles: and the Armadillo, actuated by the same unerring impulse, joins his extremities beneath his shelly covering, and rolls over the precipice unhurt, to the confusion of his ene-. my. But this is not all; Horses in a state of na- ture are not only said to keep a centinel on the lookout, but, when attacked, join heads together and fight with their heels. Oxen in a similar state join tails together, and fight with their horns. Swine get together in impenetrable herds to resist an attack, and what is observable in all, they place the young in the middle, and keep them safe in the day of battle!

These are some of the wonders of instinct; -and can we behold them without admiration!

\section{The Uses of Quadrupeds}

Are so various, that we must content ourselves with only naming a few of them. Of what great 
utility for the purposes of agriculture, travelling, industry, and commerce, is that docile and tractable animal the Horse! In what a variety of ways do those of the $\mathbf{O x}$ and Sheep kind administer to our wants! and, happily for the world, these creatures - are most extensively diffused, from the polar circle to the equator.

Goats, in many of the mountainous parts of Europe, constitute the wealth of the inhabitants : they lie upon their skins, convert their milk into cheese and butter, and feed upon their flesh. The Reindeer, to the inhabitants of the icy regions, supply the place of the horse, the cow, the sheep, and the goat. The Camel is to the Arabian what the Reindeer is to the Laplander. The flesh of the Flk is polatable and nutritious, and of his skin the Indians make snow-shoes and canoes. The Flephant, in warm countries, is useful as a beast of burden, and draws as much as six horses.

What an unwearied pattern of unremitting exerlion and fidelity is that invaluable animal the shepherd's Dog! What humane and excellent life preservers, the Newfoundland species! and what sagacious guides and safe conductors are that useful breed, trained in the Alpine solitudes, to carry provisions to the bewildered traveller, and lead his steps to the hospitable convent!

To what a number of depredators would our substance be exposed, were it not for that convenient and agile, but often ill-fated domestic animal, the Cat; which, in consequence of an ill-founded pre- 
judice excited against her for those very habits and propensities which render her valuable, and were implanted in her nature for the Best of purposes, often becomes the victim of unfecling boys, and of- ten, too often, alas! is made the sport of more unfeeling barbarians, who deserve not the name of men. The Ichneumon is to the Egyptians, in several respects, what the Cat is to us; but far from thinking of hanging her up in a barrel, and amusing themselves with her sufferings, that more grateful people have worshipped the Ichneumon as an emanation of the Deity! Cannot our more soberminded countrymen adopt a conduet between the two extremes, and at least treat the purring race with kindness? Animals of the Weasel kind furnish us with a number of rich and valuable furs; the Civet, the Genet, and the Musk, with a supply of perfumes; the tusks of the Elephant and the Seahorse with ivory; the beautiful skin of the Tiger decorates the seats of justice of the mandarins of the East; the flesh of the White Bear is eaten by the Greenlander, that of the Leopard is much relished by the African; and the Lion, even the Lion, the living tomb of so many creatures, is frequently eaten by the Negroes at the last !

We have reason to be thankful that in our happy country we are abundantly supplied with food of a more harmless nature, and much easier to be obtained than those formidable monsters of the desert, and that when taking a solitary ramble through our peaceful fields, we have no occasion to adopt 
the following sentiments of the poet, so feelingly. expresser :

"What if the Lion in his rage I meet?

Oft in the dust 1 view his printed feet;

By hunger rous'd, he scours the groaning plain,

Gaunt Wolves and sullen Tigers in his train;

Before them Death with shrieks directs their way,

Fills the wild yell, and leads them to their prey."

\section{CHAP. VI.}

\section{ON THE VARIETIES OF ANIMALS.}

"To all has Nature given a bound precise

Of being and perfection; and promulg'd

To every varying rank, her varying laws;

- Urging to this, from that restraining firm."

In the science of natural history, philosophers have found it expedient to arrange objects first under a few grand divisions, and then to divide, and afterwards subdivide these in the following manner. The most general divisions are called Classes; each class is again divided into several lesser parts, which are called Orders; each order contains a certain number of Genera ; each genus consists of several Species; and each species contains certain Varieties, which is the smallest subdivision that they have taken notice of. It is this lowest link of their chain of classification which will form the subject of the present chapter. 
It is unnecessary for us to enter deeper into this system of classification than merely to point out the distinguishing circumstance that they have laid hold on to mark the boundaries between what they call a species and a variety; and this will be the easiest done by choosing a familiar example for illustration. The horse and the ass are both of the same genus of quadrupeds; and they resemble each other so much, that they might well be mistaken for beings of the same species; but although it be found that it is possible to make them procreate, yet it is also known that the mule, which is produced from this intermixture, is not capable of continuing its kind, which circumstance induces naturalists to rank them as a different species. When animals procreate together, and produce an offspring that is capable of continuing their kind, however different they may be in their appearance and other particulars, they are accounted as only varieties of the same species; nor is there any criterion that we know of, for distinguishing a variety of any particular kind of animal from a distinct species of the same genus, but that of producing a fertile or an unfertile progeny. In this particular, we believe, all naturalists are agreed.

That there are many varieties of most species of animals is well known; and as many of these varieties, especially among domesticated animals, readily intercopulate with each other, and produce a mixed race, participating of the qualities of both parents, it necessarily must happen, that in cases 
where they are suffered to mix together, the descendants of an animal of one of these varieties is very different from that of the parent race. This fact having been remarked, has given rise to an opinion, that there has been originally but one pair of animals of each species, and that all the varieties we now discover of the same species, have been produced by accidental circumstances only, such as a variation of climate, of food, or of some other extraneous peculiarity; and that, of course, one variety may be transmuted into another without any intermixture of blood, purely by a change of circumstances only. This doctrine being once admitted, the inferences which necessarily result from it, have proved highly detrimental to the practice of individuals in their attempts to improve the breed of domestic animals; as it tends, in as far as that doctrine is believed, to turn the attention of men from fixed and certain principles, which admit of no variation, to others that are vague and erroneous, which tend only to puzzle and confound the mind, and leave it in perpetual darkness and uncertainty.

The boldest asserter of the doctrine, that all the varieties of every species of animal are derived from one common stock, is the celebrated Bufton, who, instead of searching for proofs to support his hypothesis, contents himself with mere assertions, uttered with as much confidence as if the matter had been before proved beyond a possibility of doubt; and he takes as the subject for his illustration the dog kind, though the varieties of this species are more 
distinctly marked than those of perhaps any other animal with which we are intimately acquainted. He says, that the shepherd's dog (a variety of the canine species, by the bye, which cannot be so distinctly recognized as many other kinds, ) is the original stock from which the greyhound, the spaniel, the pointer, the harrier, the bull-dog, the lap-dog, the mastiff, the terrier, and every other variety, are all directly produced; and he even goes so far as to specify the means that are necessary to be adopted for producing these changes. It is painful to dwell upon the accidental failings of a man of genius; for which reason we decline following him in his excursive career, and exposing the absurdities into which he has fallen in pursuing it. We have only to regret, that a man of such distinguished talents. should have so far overlooked facts that were easily within his reach, as to have so positively dogmatised upon this subject in direct contradiction to them; for the multitude, who think not at all, follow the authority of one who is, on many accounts, so respectable, without the smallest degree of hesitation. In consequence of this great authority, the hypothesis above stated has been tacitly, at least, assented to by the literary world in general, for some time past, though it will not require great exertions to "bring such evidence, as we hope will prove satisfactory to every reader, to shew that the fact is directly the reverse of what this learned philosopher has stated it to be. 
If it were true, that a change of climate affected an animal to such a degree as this hypothesis supposes, it would be impossible that any person existing should not have had opportunities of observing very striking instances of that kind. But, instead of this, the most direct proofs of the contrary must have fallen within the observation of every man in the kingdom, in respect to the very animal that he has selected for illustration. The dog is a favoured domestic; he attaches himself to his master, and follows him wherever he goes. He is thus carried through all the climates of the globe, under the immediate controul and inspection of man; and no instance hath ever been known in which an individual dog has ever thus experienced any material

- change in his external form, far less in his internal qualities. If a smooth-haired Spanish pointer, for instance, be carried to the torrid or the frozen zone, from Kamtschatka through the whole extent of Asia and Europe into America, he is the same smooth-haired dog every where; and his master recognizes him for the same creature at the first glance : but if the pile of its hair and external appearance be not altered, far less is the animal changed in its other qualities : it still scents the game in the way peculiar to that kind of dog; it does not, like the greyhound, pursue it by the eye ; it does not, like the hound, burst forth in sonorous howling when it feels the scent strong: this variety of the dog kind steals upon its prey with extreme caution and circumspection. These qualities it pos- 
sessed at its birth, and these qualities it retains till its dying hour, in spite of any change of climate or kind of food it may be made to experience. The same thing may be said of every other kind of dog. The English bull dog, displayed the same unconquerable obstinacy on the arena of ancient Rome, as he does at this day in the island which gave him birth: and the Newfoundland dog of the present day is equally gentle, equally attached to his mas. ter, and alike firm in his defence in every part of Europe as in America. In short, the universal experience of mankind incontrovertibly proves, that the same individual dog continues the same in regard to all its essential characteristics in every region of this globe, and under every different system of management. He may be rendered fatter or leaner, diseased or sound, and these variations of management will produce a temporary change in his appearance; but no evidence was ever known of a dog of one kind being converted into one of another sort. The terrier continues to ferret out the lesser animals with silent assiduity ; the lap.dog to bark at every thing that moves; the pointer retains his quick sense of smelling; the greyhound searches. for his prey by the eye in every region alike; so that there is no reason to doubt that every kind of dog, considered individually, retains the same faculties unchanged throughout the whole course of its life, to whatever changes of food or climate it may be subjected. 
But if the individual itself remain unchanged under every possible variation, how are we to conceive that a change in this respect can affect the progeny? Can any one believe that if a greyhound bitch, while with young, were allowed to bring forth her litter in one place (in Britain suppose, the place of her nativity,) she would produce true greyhounds, but if she were carried to Norway, the litter would turn out to be mastiffs; in Turkey longhaired pointers; and in other countries hounds, terriers, and all the other varieties of dogs? At the bare mention of such a position the mind revolts from it, as from a self-evident absurdity : but if the litter were not brought forth in these states in different climates, the puppies must be changed instantaneously after they come into the world; for, as we have seen, they are not changed by it at any other period of their life, it must be now that the change is effected, (like tadpoles into frogs,) or never. But who has ever heard of such a metamorphoses? We all know that no such thing takes place. Yet this, and more, must have happened were there the smallest foundation for this hypothesis. These changes must have happened not once only, but often; not casually, but invariably; of course it would have been utterly impossible to propagate a greyhound in one country, or a beagle in the other; in short, every country would have had its own particular variety of dogs, and none other. But this we know is contradicted by the clearest facts, and the universal experience of man- 
kind; and it must appear to be not a little surprising to those who reflect upon it, that an hypothesis which is, under cvery point of view, so absurd, should ever have obtained currency for one moment among men who had their eyes open, and were not deprived of the power of reasoning.

\section{CHAP. VII.}

\section{BIRDS.}

"6ut who the various nations can declare, That plough with busy wing the peopled air? These cleave the crumbling bark for insect food;

Those dip the crooked beak in kindred blood; Some haunt the rushy moor, the lonely woods; Some bathe their silver plumage in the floods."

- The Ostrich, the Emu, and the Cassowary, are not only remarkable, by reason of their superiority of size, but seem to claim our first attention among the feathery tribes, on account of their constituting some of those apparent links, by which the winged tribe is united to the order of Quadrupeds. For although. these animals resemble birds in the outline, and in several parts of their conformation, they certainly cannot be classed among the more perfect orders of the species, in as much as they do not make use of their wings for the purpose of flying; and as to in. ternal formation, the Ostrich is said to have as great a resemblance to the four-footed as to the volatile order. 
The structure of these creatures, as well as their appetites, is however well adapted for the situations in which they are severally placed, and they appear to know well how to supply the defect of some of their members by the use which they make of others.

Of all animals that move or their legs, the $\mathbf{O s}$. .. - trich is by far the swiftest; and although the Arabians train their fleetest horses for the chase, it is not likely they would be successful in the pursuit of this animal, were it not for his circling manner of running. Nor is this surprising, when we consicier: that this lofty mass of light materials is not only carried forward by his long springing legs, but is impelled along by his wings, which he keeps in constant motion, and apparently serve the purpose of oars.

The Emu, or Ostrich of the new continent, is also a remarkably swift runner, but its manner of assisting its legs is somewhat different from the former; besides making use of something behind, like a heel, to push it forward, this animal uses a kind of action peculiar to itself, first lifting up one wing and keeping it elevated for some time in form of a sail, then letting it drop and elevating the other; by this means it moves along with such rapidity, that even the Greyhound can seldom overtake it. The favourite climate of the Cassowary seems to begin where that of the Ostrich terminates, in the old world; and although its wings are so very small, that being covered with the hair on the back they are scarcely perceptible, it kicks up behind with the 
one leg, and then making a bound forward with the other, proceeds with such amazing speed, that the siviftest racer would be unable to maintain the pursuit!

In the structure of Birds of the more perfect order, a few things demand our most serious attention:

The whole body is "shaped in the most convenient manner for making their way through the air ; being, as Mr. Ray observes, constructed very near Sir Isaac Ne̊wton's form of least resistance. According to Bar, in his continuation of Buffon, "It is neither extremely massive nor equally substantial in all its parts ; but, being designed to rise in the air, is capable of expanding a large surface without solidity. The body is sharp before, to pierce and make its way through that element; it then gradually increases in bulk, till it has acquired its just dimensions, and falls off in an expansive tail."

- The motion of this order being two-fold, walking and flying, they are provided with legs at once wonderfully contrived to walk with, and raise them like a spring for their flight; wings to buoy them up and waft them along; and a tail to keep them steady in the air, assist them in their evolutions, and to direct their course.

Although their feathery covering is admirably constructed for lightness and buoyancy, their wings are furnished with a strength that is amazing; so that the flap of a Swan's wing has been known to break a man's leg; and a similar blow from an Eagle has produced instant death; and by these they 
are enabled to impel themselves forward with a rapidity that exceeds the fleetest quadruped. To fit them the better for their flight, the feathers are dis. posed in the most perfect order, lying one way; and that they may glide more smoothly along, they are furnished with a gland situated on the rump, from which they occasionally press out oil with the bill, and anoint the feathers. In water-fowl this oil is so plentiful, that by it their plumage is rendered completely water-proof.

The beak, or bill of birds, is a curious piece of art, formed of a hard horny substance, constructed in the most commodious manner for piercing the air. Their ears stand not out from their head to retard their flight, while their eyes are placed in such situations as to take in nearly a hemisphere on either side.

Birds have no teeth to chew their food; but those of the granivorous kind are provided with two stomachs; in one of which the victuals are softened and macerated before they enter the other to be completely digested: Being often employed in traversing the upper regions, where they behoved to be much incommoded did they bring forth their young in the manner of quadrupeds, their manner of generating is wisely made to differ, and their offspring are produced by means of eggs. In the speedy growth of young birds, by which they acquire a degree of strength and size to be able so soon to provide for themselves, we have also an instance of the tender care of Providence. 
What power unseen inspires these little creatures with " the passion of the groves," at the most fit season for forming their alliances-when the 'genial temper of the weather covers the trees with leaves, the field's with grass, and produces such swarms of insects for the support of their future progeny! And how comes it to pass, that no sooner is the connubial league formed than those little warblers (a pattern to new-married couples in humble life, who have nothing "but their own industry to depend on,) immediately set about building their nests, and making preparations for their tender offspring!

In the building of their nests, what art and ingenuity are displayed! Whether they are constructed from the collected portions of clay and mortar, or from the more light materials of moss and straw, these little creatures contrive to mould them into the most convenient forms, and to give them a durability proportionate to their wants.

\section{"It wins my admiration,}

To view the structure of that little work, A bird's nest; mark it well within, without, No tool had he that wrought, no knife to cut, No nail to fix, no bodkin to insert, No glue to join! his little beak was all! And yet how neatly finish'd."

Nor is the wonder less, that birds of the same kind, however widely separated, should all follow. the same order of architecture in the construction 
of their habitations; that each should make choice of the situation most suitable to its kind.

"Some to the rude protection of the thorn

Commit their feeble offspring; the cleft tree

Offers its kind concealment to a few ;

Their food its insects, and its moss their nest.

But most in woodland solitudes delight."

And that all should agree in laying as many eggs as to be sufficient to keep up their species, yet no more than they can conveniently hatch and bring up.

In the incubation with what patience do these creatures set on their eggs when necessary, till the young are ready to be hatched, and then how officious in assisting the little prisoners to escape! With what inimitable care do they afterwards watch over and provide for the brood until it is capable of doing for itself; and with what scrupulous exactness, during this period, do they distribute to each his allotted portion of food.

"What is this Mighty Breath, ye sages say, That in a powerful language, felt, not heard, Instructs the fowls of heaven? - What but GoD, Inspiring Gov! who, boundless Spirit all, And unremitting energy pervades, Adjusts, sustains, and agitates the whole."

These observations are applicable to the feathery tribe in general; but if we turn to the peculiarities of a few of the different species, we shall observe that the wisdom and the goodness of the Deity are 
no less conspicuous. The Ostrich, formed to traverse the burning sands of Africa, is long legged, light, and amazingly agile. Denied the natural reservoir of the Camel, it is endowed with such an abstinence from water, that the Arabs assert that it never drinks! and as it may roam many hundreds of miles in quest of vegetation, it seems to have an appetite for almost every kind of food. So that there is no desert, however barren, but what possesses sufficiency to supply these creatures with provisions, for they eat almost any thing. Glass, stones, iron, \&c. have been found in their stomachs; and it is affirmed, that in one was found a piece of stone that weighed upwards of a pound.

The Condor of America, is said to be the largest bird endowed with flight; and being of the rapacious kind, is armed with a beak so strong as to pierce the hide of an ox.

The Eagle, the most noble of rapacious volatiles, has a taste too nice for carrion; and in order that he may secure his living prey, and bear it in safety to his nest in the inaccessible cliff, Nature has endowed him with the faculty of vision in an eninent degree, prodigious claws, amazing strength, and a profusion of feathers down to his very toes.

The Vulture delights in carrion and putridity; and this excellent anatomist may at once be distinguished from the Eagle by the nakedness of his neck and head, as well as that acute sense of smelling, by which, according to Herodotus, he can smell a dead carcase at the distance of fifteen thousand paces. 
How admirably formed are the eyes of the birds of night for seeing better when the sun is below than above the horizon. Those of the poultry kind are not furnished with hooked bills and formidable talons, or wings calculated for long flights; and while the solitary Eagle or Hawk pay us a transient visit, unaccompanied and alone, these surround our dwellings in numerous flocks. Those of the Grouse kind, who feed on moor-berries and the tops of heath plants, have their habitations assigned them in the most barren and uncultivated tracts where their favourite food abounds. The hooked bill of the Parrot is well contrived to assist him in climbing. Ducks, Geese, and many others, have long broad bills to enable them to grope for their food in water and mud; on the contrary, a thick, short, and sharp edged bill, is as necessary to those who have occasion to husk and flay the grain they swallow. The Wood-pecker's bill is sufficiently strong to dig holes; that of the Swallow is slender and sharp pointed, and he is also furnished with a very wide mouth, to enable him to catch the winged insect in its flight; and the ease with which Sea pies raise their favourite food from the rocks, by means of their long, narrow, and compressed bills, is astonishing. Even Limpets, which adhere so firmly to the rocks, as not to be easily separated by a knife, these birds find no diffi. culty to raise with the instrument Nature has provided them with for the purpose.

The long legs and necks of birds of the Crane kind, together with their sharp pointed bills, are 
wonderfully adapted for the purpose of wading and picking up their food from the bottom of the shallows; and the webbed feet, oily feathers, and broad bills of those of the Swan kind, are equally so, to enable them to swim along, and lay hold of their prey in the watery element.

The Pelican of the wilderness is a most dexterous fisher, and nature has provided him with a prodigious pouch, of a singular construction, under his bill, which, although scarcely perceptible when empty, enables him when full to bear ashore as many fish at a time as would suffice sixty men for dinner The Albatross, the most formidable of the Gull kind, preys not only on fish, but water fowl of an inferior size; and his bill terminates in a crooked point, by which he is enabled to lay hold of them on the wing. The Penguin seldom leaves the water; and while others of the feathery race only skim its surfice, pursues his prey to the greatest depth, and he approaches the finny tribe in his formation as well as in his disposition and habits. Indeed, these animals may be justly reckoned one of the connecting links between the volatile and finny tribes, as not only their fin-like wings and broad webbed feet, but their body being covered more warmly all over with feathers than any other bird whatever, and the particular construction of their lungs, all tend to shew that water is their principal element.

How wonderful the migration of birds! or that surprising instinct by which " the stork in the heavens knoweth her appointed times," "and the crane 
and the swallow observe the time of their coming." When Storks take their departure for Europe, it is said they all assemble on a particular day, decamp during the night, and leave not a single one of their company behind. Now what power unseen commands them to this general assembly, directs them in their course, orders them to halt as occasion requires, and then to renew their flight till they arrive at the exact point of their destination?

"Who bids the Stork, Columbus-like, explore Heavens not his own, and worlds unknown before? Who calls the council, states the certain day? Who forms the phalanx, and who points the way?"

"6 Where do the Cranes, or winding Swallows go, Fearful of gathering winds and falling snow?

If into rocks or hollow creeks they creep,

In temporary death confined to sleep;

Or, conscious of the coming evil, fly

To milder regions and a southern sky ?"?

Birds in the torrid zone, where their nests, otherwise situated, would be exposed to the assaults of the snake when he twines up the trunk, or the depredations of the ape, suspend them at the point of a bough, or the extreme branches of the trees; and some, as the Taylor-bird, not content with that precaution, attach their nests to the side of a leaf. The expertness of this little bird, at the profession from whence it derives its name, is admirable. When it has picked up a dead leaf, it sews it to the side of a living one, its slender bill being its needle, and its 
thread some fine fibres; the lining is composed of feathers, gossamer, and down The Eagle constructs her habitation among inaccessible rocks, where it is shielded by projecting craigs; and the Flamingo builds her nest in the middle of an extensive morass, beyond the reach of danger.

" From man retir'd, amid the lonely marsh, Flamingoes build and tend their curious nest."

What sagacity does the Vulture display as he sits silent and unseen in the American forest, watching the operations of the monstrous Crocodile, while she deposits her eggs in the sand on the banks of the river! The little Butcher-bird, that attacks creatures four times bigger than himself, seizes its victims by the throat, and strangles them in an instant; and, as if conscious of its inability otherwise to separate the food it has so secured, contrives to spit it on a neighbouring thorn, and then pulls it pieces with its bill The solitary Owl takes up its station in the corner of a barn at the approach of night, and with inflexible perseverance watches its prey. The Magpie is noted for its singular cunning Bussards are said to keep a sentinel on the look-out to apprize them of danger. The Partridge acts with the greatest subtlety, in order to decoy away a dog or other animal when he approaches her nest ; and the affection of the Hen for her tender brood is such, that for their protection she will attack the hog or the mastiff, and even not hesitate to fly at the fox. 
What animal eyinces more courage than the Cock, as he struts in sovereignty on his favourite dunghill? The facility with which Parrots are taug $t$ to speak, and retain and repeat a number of words is truly surprising Cormorants in China are trained for the purposes of fishing; and Hawks, in other countries for fowling; and the Carrier Pigeon performs his lengthened embassy with unerring precision, and with astonishing celerity Thevenot says, they commonly travel from Aleppo to Alexandria in Syria in six hours, which is a distance of eighty-eight miles The letters are generally fastened under their wings. In order to ascertain with some degree of accuracy the speed of these curious birds, a gentleman, some years ago, sent a carrier pigeon from London to a friend at Bury St Edmunds, desiring it to be thrown up at a particular time two days after its arrival; this was attended to, and the pigeon returned to the Bull Inn, Bishopsgate-street, two hours and a half afterwards, having in that time travelled seventy two miles - Even the stupid Ostrich, as it may be called in other respects, is not so destitute of natural affection and instinctive cunning as some are apt to imagine; for if she more frequently leaves her eggs than other birds, it is only in those hot climates where there is no necessity for constant incubation; and if she thrusts her head in the sand, when every chance of escape is at an end, it is no less certain that she contrives to prolong the chace and distance her pursuer, by occasionally lowering 
Qne of her wings, aud disappointing him with a mouthful of feathers.

\section{The Uses of Volatiles.}

'The uses of the poultry kind, especially of such as are domesticated, are too obvious to be enumerated; it may, however, be remarked, that the common Hen, if well supplied with food and water, is said to lay sometimes two hundred eggs in a year; and the fecundity of the Pigeon in its domestic state is so great, that from a single pair, near fifteen thousand may be produced in four years.

The flesh of the Grouse kind is esteemed for its delicacy; the Peacock, in some countries, is considered as a luxury; and although it is in a great measure for his singular plumage that man has been tempted to follow the Ostrich in his desert retreat, some of the African tribes are very fond of his flesh, and even the Romans appear to have considered it a dainty; for it is recorded of Heliogabalus, that he had the brains of six hundred of these animals, at a feast, served up in one dish! He should immediately after partaking of that dish, have buried his head in the sand, and been ashamed to resume the erect form of man, whose character he had disgraced.-There are, besides, many parts of this animal which are supposed to be very salutary for medicinal purposes, and their strength and swiftness seem to render them very fit for the purposes of travelling or carrying burdens; for Moore relates, that at Joar in Africa, he 
met a man travelling on an Ostrich; and $\mathrm{Mr}$. Adam: son informs us, that when he was at the factory of Podore there were two young Ostriches, the strongest of which was much fleeter than the best English race-horse he ever saw, although he at that time earried two negroes on his back.

If in the feathery tribe some appear to be formed to please us with the beauty of their plumage, as the Goldfinch, the Bullfinch, and the Humming bird; others, as the Thrush, the Blackbird, and the $\mathbf{C a}$ nary, delight us with the melody of their song. The Lark soars aloft and salutes the new-born day with his cheerful notes. The Nightingale soothes. the weary labourer as he returns from his daily toil, by his fascinating strains. The little Robin, in return for the protection our fences have afforded him, exerts himself to render the hedges vocal, in soft and - tender melody; and the Sparrow endeavours to amuse us with her chirpings.

The Swallow, also, as if sensible of the undisturbed possession she has been allowed to take of our premises, during the time of her necessities, catches upon the wing a multitude of flies, gnats, and beetles, and frees us from a number of troublesome vermin before she bids us farewell. Birds of the Rook and Pie kind, although a noisy and chattering tribe, may be of infinitely more use than we have the sense to discover, by the destruction of grubs, worms, and eggs of vermin; and the common carrion crow may be no less necessary in our climate, than the Egyptian Vulture and the Ossifiage of Syria. The Vuk 
ture, indeed, is common in many parts of Europe, and abounds in America, Asia, and Africa. In Egypt and other warm countries, he is of singular use. Numerous flocks of them are always hovering in the neighbourhood of Grand Cairo; and for the services the inhabitants experience, by these animals devouring the carrion and filth of that great city, which, in such a sultry climate, would otherwise soon putrify and corrupt the air, they are not permitted to be destroyed. The Ossifiage of the. woods of Syria and Egypt feeds on the dead carcases of fowls and reptiles. This brings us to say a few words on the use of rapacious fowls, which may be also applied to wild beasts in general.

Better perhaps it may appear to the imperfect reasoning of short-sighted mortals, that the business of mutual destruction had been avoided in the eco. nomy of nature, and instead of that circuit of prey and devastation which we observe, all animals had been formed to live on vegetable food, and suffered to die a natural death. But, independent of the difficulty that occurs as to how such a number of creatures could be fed from the same source, we do not consider the state of suffering to which many of them must necessarily have been exposed, if they had been left to perish by protracted famine, after the decay of their bodily powers rendered them unfit to go in quest of food. Compared with this, is it not a far more happy dispensation that animals are formed for the destruction of each other? and that (to follow the course of one circle by way of specimen, ) 
while the tree-louse lives on plants, the musca aphidivora lives upon the tree-louse; the hornet lives upon the musca aphidivora; the dragon-fly on the hornet; the spider on the dragon-fly; the small birds on the spider; and the hawk on the small birds.

Deprived of reason, the innocent lamb licks the hand raised for its destruction; and the sufferings which animals feel upon the speedy extinction of the vital spark, must be momentary indeed, in comparison of the pangs they must have undergone, if they had been left to expire by old age. Indeed, according to this plan, old age would be impossible; for what would the world soon become were its numerous tenants so cut off, and the putrid carcases to lie unburied?-the circumambient air, now the source of life and vitality, must then in a short time be rendered pestilential, and bearing upon its wings the noxious vapours, deal death and desolation with increasing malignity to every climate, until the beautiful theatre of life and activity became one great charnel-house, and the animating flame be for ever extinguished in the awful silence of eternal night.

Instead, therefore, of finding fault with the merciful dispensations of our all wise Creator, and repining that lions and tigers, bears and wolves, eagles and vultures, serpents and crocodiles, and voracious monsters of the deep of every description exist, let us rather rejoice that wherever the carcase is exposed on the field, there will the vultures be gathered together; and that, where the lion and 
serpent may dic in their sequestered retreats, innumerable vermin, attracted by the scent, will soon find them out, and leave not a vestige of putrifaction behind.

Before we conclude with the tribe of volatiles, we will just remark, that these are not the only uses far which this order of beings seem to have been created. From the feathery creation we may also learn lessons of wisdom on the most interesting and important subjects. What an example of conjugal constancy and fidelity do we discover in the turtledove! What a pattern of filial affection in the young stork! What a lesson for presumptuous pride have we in the answer of Solon to the monarch of Lydia!When seated on his magnificent throne, and surrounded by all the appendages of external pomp and pageantry, Crœsus asked the Greek philosopher, if he had ever seen so magnificent a spectacle: "After having seen the plumage of the Pheasant, he could not be astonished at the sight of any other finery," was the cool reply!-And what comfort may we derive, under the vexatious losses and crosses of life, from the argument drawn by our Divine Teacher against sinking under despondency or anxiety: "Behold the fowls of the air ; for they sow not, neither do they reap, nor gather into barns: yet our heavenly Father feedeth them. Are ye not better than they?"

" Behold, and look away your low despair;"

See the light tenants of the barren air: 
To them nor stores, nor granaries belong;

Nought but the woodland and the pleasing song;

Yet, your kind heavenly Father bends his eye

On the least wing that flits along the sky."

\section{CHAP. VIII.}

\section{INSECTS.}

"Where greatness is to Nature's works deny'd,

In art and beauty it is well supplied :

In a small space the more perfection's shown, And what is exquisite in little's done."

Insecrs have been reckoned by some among the more imperfectly formed of Nature's works; but in this most numerous class of animated beings, where shall we find a single instance in which this is made to appear? In all that prodigious variety that exist between the Scorpion and the Mite, we certainly behold in the structure of insects abundant evidence of the most exquisite skill; and if by means of the microscope we extend our researches downwards through that minute order of beings, till we arrive at those invisible animalcules which are computed to be twenty-seven millions of times smaller than the mite, the same evidence of wisdom and design present themselves in every gradation, and all ideas of imperfection cease. 
Of all productions in nature, insects are by far the most numerous, and though at first sight herbs of the field seem to be the parts of organized matter produced in the greatest abundance, yet upon minute inspection we find every plant supporting a multitude of creatures scarcely perceptible, that fill up the compass of youth, vigour, and age, in the space of a few days' existence. In Lapland, and some parts of America, insects are said to be so numerous that if a candle is lighted they swarm about it in such multitudes that it is instantly extinguished! As insects are endowed with the various powers of creeping, flying, and swimming, there is scarce any place, however remote and secure, in which they are not to be found.

It is the infinite number of these invisible animals that makes stagnating waters appear of so many different hues, as green, brown, reddish, \&c.

It is not at all surprising then, that such an accurate researcher into Nature's works as the excellent Mr. Boyle, should observe, "that his wonders dwelt not so much on Nature's clocks as her watches." In several kinds of these creatures, invisible before to mortal eyes, it is not only easy to discover, by means of a good magnifier, the external appearance of their mouths, their horns, their trunks, and other members, but the very motion of their heark and lungs! Now, as it has been remarked, as these little animals are discovered to be organized bodies, how fine and subtile must be the several parts that compose them! How difficult to conceive the ex- 
treme minuteness of the muscles necessary to the heart, the glands for the secretion of the fluids, the stomach and bowels for the digestion of the food, the fineness of the tubes, nerves, arteries, veins, and above all, of the blood, the lymph, and animal spirits, which must be infinitely more so than any of these! Here the utmost stretch of imagination is brought to the test, without being able to form any adequate conception; but these inconceivable wonders, instead of conveying any idea of imperfection, as to the skill of the artist, must, from what they make to appear, inspire the attentive observer with very different emotions, and force him to exclaim,

"Thyself, how wond'rous then!"

The beauty and symmetry of some of those minute objects so viewed, are surprising indeed. What a metamorphosis do they seem to undergo under the magic-working glass! Creatures that before seemed small and despicable, now " appear the pride of nature, wherein she has bestowed more nice and delicate art, and displayed more profusely the rich embroidery and elegant beauties and garniture of colours than in any of the larger species of animals." Even the dust that adheres to the butterfly's wing, and to which it owes the beautiful tints and variegated hues which adorn it, is said to be an innumerable collection of extremely small feathers, as perfect in the structure and symmetry of the arrangement, as they are beautiful in the colouring. 
But this is not all, the very circumstances adduced as marks of imperfection in the insect tribes, viz. their being enabled to live for some time after being deprived of those organs necessary to life in the higher ranks, and their amazing numbers, ought rather to be considered as arguments to the contrary.

The former is no doubt essentially necessary to the preservation of a species exposed to so many casualties, as those in particular who live on blood, and cannot, therefore, partake of a meal, without giving their enemies notice of their presence; and the latter, to prevent the extinction of a short-lived race, which come into existence at a time when there are so many open mouths ready to devour them.

Without these two characteristic distinctions of the insect tribes, although they may be deemed imperfections by the more imperfect powers of short sighted mortals, it is probable that long ere now some of those exquisite pieces of Nature's workmanship must have disappeared from the creation, and for want of those connecting links, the whole beautiful fabric of the universe must have fallen to decay ; for, trifling as some of those minute or imperceptible objects may appear, the language of philosophy is:

"Each crawling insect holds a rank

Important in the plan of HiM who fram'd

This scale of beings; holds a rank, which lost,

Would break the chain, and leave a gap

That Nature's self would rue."

Instead, therefore, of having the presumption to stigmatize, in the most remote degree, this particular 
order of the creatures of the Almighty, as affording evidences of imperfection, let us rather, from similar considerations, adopt the words of the more judicious Swammerdam; "After an attentive examination," says he, "of the nature and anatomy of the smallest as well as the largest animals, I cannot help allowing the least an equal, or perhaps a superior degree of dignity. If, while we dissect with care the largest intimals, we are filled with wonder at the elegant disposition of their parts, to what a height is our astonishment raised, when we discover all these parts arranged in the least in the same regular manner."-And sum up the dispute in the words of another naturalist: "Of this dispute it is only necessary to observe, that the wisdom of the Creator is so conspicuous in all his works, and such surprising art is discovered in the mechanism of the body of every creature, that it is very difficult, if not impossible, to say where it is most, and where it is least to be observed."

It is impossible, in the compass of this book, to do any thing like justice to a subject which can never be sufficiently investigater. We will, however, consistent with our general plan, notice a few facts and striking peculiarities in this mysterious and numerous order of beings, by which it is most distinguished from the others, and in which it will be sufficiently evident that insects are also the children of the same common parent, whose wisdom and good. ness are so conspicuous in his other works: 
In the head of an inseet no orginization of the brain is said to be discovered, but the want of this is abundantly made up by that medullary thread which communicates the vital principle to the other parts of their bodies, and endows them with that tenacity of life, which, as has been already observed, is so useful to the species. Neither are they apparently furnished with the usual organs of smelling and hearing, but whether the olfactory nerves communicate with the feelers, and the auricular organs are situated in the antennæ, as Mr. Barbutt supposes, or not, there cán be no doubt from the readiness of Wasps, Flies, \&ce. to betake themselves to their wings and fly to dainties at a distance; and the alertness of Bees in sallying out to the relief of a brother in distress, when he alarms them by his noise outside the hive, that insects are not deficient in the senses of hearing, wherever the organs may be situated. The manner of respiration is different in insects from other animals; they breathe through pores placed in the sides of their bodies, and this also fits them for that remarkable peculiarity of living in separate parts. In the composition of insects no bones are made use of, but this defect is supplied in some by a membraneous or muscular skin, and in others by a crustaceous or horny eovering Their eyes are fixed, and they have no eyebrows, but, to prevent them from injury, the latter want is supplied by the external tunic of their eyes being hard and transparent, and to remedy the former, some insects have four, some six, others eight, while the number of lenses in some of those who 
- have only two is amazing indeed. Flies, wasps, \&c. have the outward coat of their eye made of curious lattice-work. Pagett is said to have discovered no fewer than 17,325 lenses in the cornea of a butterfly!

The eyes of insects are admirably adapted for seeing minute objects nigh at hand, but from the smallness and convexity of their lenses, it is apparent that they can neither see far, nor take in the larger ob: jects, and to remedy any inconvenience that might arise from this, may have been the principal reason why Nature has furnished them with those projecting horns or feelers with which they seem to grope as they advance. Insects are also distinguished by the number of their legs and wings; of the latter most insects have four, while no other species of animals have more than two; and although the greater part have six legs, others, as Mites and Spiders, have eight, and some ten, fourteen, sixteen, and even a great many more. The palpi are those little instruments fixed to the mouth of some insects, which seem to be intended to serve the purpose of arms, for they employ them to bring food to their mouths, and to keep it steady when eating. Some insects are furnished with stings for defence, or to assist them in procuring their food, others with a tube for injecting their eggs into the most convenient situations for hatching. The females of some winged insects, for instance, insert their eggs under the surface of leaves, and the worms when hatched, give rise to those tubercles or galls with which the leaves of the ash, the fir, and other trees sometimes abound; 
the eggs of the Cynips, inserted into the leaves of the oak, produce the eaterpillars, which give rise to the galls used in the composition of ink. The greater part of winged insects have a proboscis or trunk, which although not so large, is as wonderfully contrived as that of the Elephant, and serves the purposes of a mouth, a nose, and a windpipe! The proboscis is a machine of a very complicated nature; and that of a butterfly, when not in quest of food, is rolled up in form of a watch spring.

The degree of strength and agility which many of the insect tribes possess is amazing. A flea will draw a chain one hundred times heavier than itself; and the velocity of a mite, in proportion to its size, is said to outstrip that of a race-horse! With regard to sex, there is one thing very remarkable in this order, viz. that the Bees, the Wasps, and Ants furnish an example of a species that belong to neither sex, and so are called neuters; these however, are not without their uses ; and the affection they evince for the helpless little creatures left to their care, might serve as a lesson to those who are intrusted with the tender charge of infants not their own.

The last thing we shall mention in this general survey of the insect tribes, is the wonderful transformations many of them undergo in the different stages of an egg, a grub or worm, a crysalis, till they arrive at their most perfect or fly state.

"Observe the insect race, ordain'd to keep The lazy sabbath of a half year's sleep.

Entomb'd beneath the filmy web they lie, And wait the influence of a kinder sky. 
When vernal sunbeams pierce the dark retreat The heáving tomb distends with vital heat;

The full-formed brood, impatient of their cell, Start from their trance, and burst their silken shell."

In each change not only their form and structure, but their very nature and appetite undergo a complete revolution.-Take for example, yonder Butterfly, which in gaudy attire, and with a sprightly air, roves and flutters in quest of its balmy juices from flower to flower: how wonderful the change from that dead and inanimate state in which its beauties lately lay concealed, or from the grovelling reptile which on the cabbage-leaf partook voraciously of its coarser fare, nor evinced any relish for other dainties.

If any, thing were wanting to prove the wise disposition of the parts and appetites of animals to their various situations and habits, here we have it in the instance of the Butterfly, whose structure and taste both undergo an alteration when its sphere of action and propensities become different.

In regard to some peculiarities of a few of the different species of insects, we will briefly observe, that in the mouth of the Gnat we have an admirable specimen of the instrument necessary for such a blood thirsty animal; the nails or crotchets of the Horse-fly, as well as its tenacity of life, evince that it is apt to be disturbed in its banquets ; whoever attentively considers the form of a Louse, need not be told that it is a blood-sucker. The legs of the Locust and of the Grasshopper at once shew their 
propensity to leaping. The Bee, in danger of being robbed of its precious stores, is armed with its well known weapon. The female Wasp is larger and stronger than the male, to enable her to survive the rigour of winter; and the strong hairy legs of the Ant are no less well contrived to assist her in the indefatigable labours of the hill, than the two claws with which they are armed are for the purpose of climbing.

How surprising the instinct by which those little creatures are taught uniformly to deposit their eggs on such animal or vegetahle substances, as furnish a proper and plentiful supply of food for the worms or caterpillars, as soon as they are hatched. That those who pass into the Chrysalis or inactive state, select the most proper situations and modes of concealment; and that others, whose only metamorphosis consists in the addition of wings, surround themselves while undergoing the change by an envelope of spume or froth, proceeding from their body; as the Cuckoo spit, or Froth worm.

"The Locusts have no king, yet they go forth all of them in bands;" while the solitary Spider, having no wings to go to pursuit of her prey, weaveth to herself a web, and watches with patience the entanglement of a fly.-Our space will not permit us to dwell on the geometrical precision and mathematical exactness, with which Bees form their combs; the wonderful ingenuity and contrivance of the Wasp's nest, or the order and regularity observed in the construction of the Ant-hill, as well as the prudence and foresight which the whole of these 
evinee in their labours and pursuits; these, and the singular but convenient attitude which the Water-fly assumes in swimming on his back, to enable him the better to lay hold of his food, the under side of plants which grow on the water, we can only mention, and must proceed to consider a few of the

\section{Uses of Insects.}

From the number of animals in the different elements and regions of existence, which prey upon insects, there can be no doubt but the principal ob. ject the Creator had in view in the formation of these, was for the subsistence of many of the larger orders of creatures; but the following specimens serve to shew that some of these also contribute in no small degree, in their respective spheres, to the service of man. By the labours and exertions of the Bee, we are provided with stores of honey and wax; the seemingly contemptible little Silk-worm presents us, in its passage from the Caterpillar in the sleeping state, with materials for constituting our most costly raiment.-From the Cantharies come the Spanish Flies, so useful in blisters; the Kermes is also valuable for medicinal purposes; and the Cochineal - furnishes us with a rich and beautiful dye. The wonders accomplished by the united exertions of the Bees, the Wasps, and the Ants, shew what can be done by brethren dwelling together in unity. The watchfulness of the Spider, after she has woven her web, demonstrates the necessity of not folding our 
hands for slumber just at the time we have eompleted our preparations for activity; and to the Ant, the sluggard is sent to learn a lesson of prudence and foresight.

“These emmets, how little they are in our eyes!

We tread them to dust, and a troop of them dies

Without our regard or concern :

Yet, as wise as we are; if we went to their school, There's many a sluggard, and many a fool,

A lesson of wisdom might learn."

\section{CHAP IX.}

\section{REPTILES.}

«Lo! the green Serpent, from his dark abode, Which even imagination fears to tread;

At noon forth issuing, gathers up his train In orbs immense."

\footnotetext{
“' Thro' subterraneous cells,

Where scorching sunbeams scarce can find a way,

Earth animated heaves.-The flowery leaf

-Wants not its soft inhabitants."
}

In the order of Reptiles, we have a new display of the wonders of creating art. These creatures are also endowed with the power of motion, but how differently do they move from any of the orders we have already considered. Deprived of the usual apparatus of legs or wings, the ponderous Serpent is. sues from his concealment, and moves majestically along by means of his scales and strong muscular 
-powers; and the slender Worm draws and pushes himself forward by his rings and eontortions. The wisdom in these contrivances must be immediately apparent, when we consider that some of the former have their habitations assigned them in the most impenetrable thickets, where an elevated stature would expose them to many inconveniences. Some take up their abode in the swampv banks of great rivers, or among the reeds in morasses, where the weight of their body, supported by legs, must have sunk them deeper in the mire; others wind their way among heaps of rubbish or crumbling ruins, where projecting appendages, of any description, would have been apt to retard their progress; and the naked and defenceless bodies of the latter are admirably adapted to those subterraneous passages which they form to themselves unseen in the bowels of the earth.

Snails, also, are a species of Reptiles; but, being encumbered in their movements with their shelly appendage, they are furnished with an instrument peculiar to themselves, in that long, broad surface, by which they pull themselves along; and by which, assisted by the glutinous substance they emit from their bodies, they are enabled to adhere, in any position, to the smoothest of surfaces.

The motion of Caterpillars in their vermicular state is curiously performed, by means of a number of little legs, the foremost of which are differently constructed from the hindmost, but all are formed in the most suitable manner for assisting in their progress on the leaves of plants. 
Being deprived of those instruments of motion possessed by other animals, to carry them speedily forward in pursuit of their prey, Serpents are necessitated to have recourse to the resources of artifice, and to lie in wait for it; and, to enable them to do this to the best possible advantage, Nature has not only endowed them with the power of intwining themselves in ambush around the trunks and among the branches of trees, by the slender make and flexibility of their bodies, but, by a very particular and singular construction of the back-bone in Serpents, they are enabled to coil themselves up in a very small compass. In the generality of animals, the joints in the back-bone do not exceed thirty or forty; but in the serpent kind they amount to one hundred and forty five from the head to the vent, and twentyfive more from that to the tail. If Serpents are not furnished with the claws of the Tiger to lay hold of their prey, the strong hooked bill and talons of the Eagle to pull it to pieces, and the tusks of the Boar to devour it, several of this species are furnished with a poisonous sting for instantaneously inflicting the mortal wound, others are soon enabled to extinguish the vital spark by means of the convulsive energy of their enormous twistings; while the general conformation of the jaws, the width of the mouth, and yielding texture of the bodies of Serpents are such, as to enable them to swallow prodigious mouthfuls, and animals more bulky than themselves. A Serpent in the island of Java was observed at one time to destroy and devour a Buffalo; after having bro- 
ken the bones by its voluminous twistings, it was seen to lick the body all over, which covered it with its mucus, and make it slip more glibly down its throat.

But the assistance which some of these creatures receive from their poison in the seizing of their prey, is not the or.'y benefit they derive from it; it is also their most sure and effectual defence; and from the dread and horror which such an instrument as the sting of a Serpent inspires, (although only found in the possession of a few,) it serves, as it were, for a safeguard to the whole species.

Mankind, indeed, cannot treed with too cautious steps the paths frequented by these creatures; for although none of the most venomous kinds will attack man, except on the defensive, yet, without the power of discriminating, when accidently trod upon, they will make the intruder feel the power of their rengeance. What a merciful provision, therefore, has Providence made, for the safety of the American, in the tail of the Rattle-snake, than which there is not one of the serpent tribe more to be dreaded: yet the rattle in his tail, on the smallest motion, must give notice of his approach, or warn the traveller of the impending danger that lies concealed in his haunts. It is a melancholy truth, that the direful effects of the Serpent's poison is not confined to the wounds they themselves inflict, but, as a celebrated naturalist observes, by men more mischievous even than Serpents, who prepare their venom to destroy each other; with this the savages poison their arrows, 
and prepare their revengeful poisons. The ancients were known to preserve it for the purposes of suicide, and among barbarians the venom of snakes is used as a philter to this day. How much more honourable for human nature when the ingenuity of man is exerted for the preservation of his species! and as Vipers are the only animals of a venomous kind, from whose bite the inhabitants of Great Britain have any thing to fear, the discovery of William Oliver, the Viper-catcher at Bath, that the application of Olive Oil was an effectual cure for the bite of one of these animals, may not be improperly mentioned here, to the honour of that person, who submitted to some dangerous experiments in corroboration of the truth of this discovery.

Nor is the care of Providence less observable in the provision made for the security and preservation of the more harmless kinds of reptiles, than for those of a dangerous and venomous description. The naked and tender body of the Earth-worm is no doubt pretty securely lodged in the subterraneous vaults it forms for itself in the earth, and the Serpent, in the absence of defensive weapons, enjoys no little sccurity in the dread its very form inspires; but still the former is exposed to many an injury in his lowly situation, and the latter may oft wait long for the approach of his victims; but the feeble worm, when cut in several parts by the gardener's spade, evinces a remarkable tenacity of the vital powers; and the voracious Liboya, which can swallorv at a meal an animal three times as thick as itself, at other 
times, when no food presents itself, exhibits an abstemiousness that is astonishing. Indeed, a single meal with many of the Snake kind seems to be the adventure of a season; and is an occurrence for which they have been for weeks, nay, sometimes for months, in patient expectation. Vipers are often kept in boxes for six or eight months, without any food whatever; and there are small Serpents sent over to Europe from Grand Cairo that live for se. veral years without eating.

The instinctive sagacity of an animal, said at first to be more subtile than any beast of the field, and whose wisdom was pointed out by the Saviour of men as being necessary to be united with the harmlessness of the dove, in the dispositions of his disciples, must naturally be expected to be very remarkable, and it certainly is so, whether manifested in the wonderful docility which some of these creatures assume in a state of captivity - the dancing serpent, for instance, carried about by jugglers and strollers in the East Indies, will raise their heads and part of their bodies at the sound of music, moving them in such a manner as to keep time with the instrument, while their tails continue in a coil at the bottom of the basket:-the conveniest places in which they lie in wait fo; the approach of their prey-the commodious attitude in which those of the venomous kind put themselves for darting at their victims; or the subtle artifices to which those of the more harmless kind have recourse in eluding an enemy. Serpents the most venomous will suddenly spring up 
on their tail, at the approach of a larger animal, erect their head, and inflict the deadly wound in a moment; while some of those who are less so, when closely pursued, or excited by rage or fear, will emit a most horrible foetor, in order, as it were, to force the enemy to retire from the pursuit.

The Black Snake of Virginia lays its eggs in dunghills or hotbeds, where, aided by the heat of the sun, they are hatched and brought to maturity. The blind worms betake themselves, at the approach of winter, to those secret recesses, where, in a state of torpidity, they are sometimes found in vast numbers twisted together; and the common earth-worm, when warned of danger from the mole, by the moving of the earth, darts upwards to the surface, and is out of his reach in an instant.

\section{Uses of Reptiles.}

In a former part we noticed the indispensable necessity of animals of prey, and the bad consequences that must have inevitably ensued had the whole of earth's various tenants been left to die a natural death, and their carcases been left to rot unburied

Amongst animals of this description we may undoubtedly reckon the race of Serpents; and whether we consider the fitness of their bodies for entering the dens, and caves, and holes of the earth, or their voracious appetites for such sort of food in common with reptiles of an inferior order, we must certainly allow that they are wonderfully adapted for the pur. 
pose. This, then, may be one reason, and a very sufficient one too, for the formation of Serpents, that besides helping to rid the earth of a vast number of the smaller obnoxious vermin, they find their way with the greatest ease into the most secret recesses of putrefaction, and destroy those noisome carcases in a short period, to which the other large animals of similar tastes could not, by the peculiar structure of their bodies, have had access. The use of the Leech is also too well known to need description.

\section{CHAP. X.}

\section{THE OCEAN.}

\section{"And thou, majestic main!}

\section{A secret world of wonders in thyself !}

Sound His stupendous praise, whose greater voice Or bids you roar, or bids your roaring fall."

WHAT a grand and magnificent spectacle does the Ocean present! Whether we view it when wrought up by fearful agitation into all the horrors of the tempest, when the blackness of darkness rides trium- phant on the storm, and its foaming billows mix with the clouds, or gaze upon it, with a calm delight, as it gently advances or recedes in soft and hollow murmurs upon the sandy beach, when not a breeze is observed to breathe on its undulating bosom, and every wind is hushed, it is impossible to conceive 
any thing better calculated to excite in us lofty and sublime conceptions of the Creator.

"May not the sea," in the words of a modern author, " be styled the temple of contemplation? Viewed in all its stages, it exalts and improves the mind. Its level expanse, when a caln prevails, conmunicates a similar tranquillity to the reflecting breast; and when its billows lift their devouring heads, they suggest ideas the most sublime, meditations the most solemn. The very nature of the prospect, boundless and unbroken, presents a sensible argument for eternity of duration and infinity of space, more forcible than the subtilest reasoning of metaphysics."

The ocean, rolling its surges from clime to clime, is, undoubtedly, the most august object under the whole heavens. A spectacle of magnificence and grandeur which fills the mind, and engrosses the utmost stretch of imagination.

What an immense and mighty assemblage of watery particles must be contained in the great deep, and what a prodigious extent of the earth's surface doth it cover! Some natural philosophers, indeed, have carried their ideas on this subject so far as to assert, that if the bed of the sea were empty, all the rivers of the world flowing into it, with a continuance of their present stores, would take at least eight hundred years to fill it again to its present height. If, then, in a single drop of water, as much only as will adhere to the point of a needle, a philosopher has computed no less than thirteen thousand globules, what an inconceivable number must there be in the 
unfathomable depths, and unmeasurable extent of the ocean! where the eye is lost in wandering over the liquid expanse, and which, if we look upon a map of the world, we shall find to cover a considerably larger portion of the surface of the globe than even the dry land itself. Wonderful as the sea is in itself, and beneficial as it is to the sons of men, all its wonders and all its benefits reflect glory to Him who formed it, and poured it abroad. When we place ourselves upon the shore, and from thence behold that immense body of water, stretching away on all sides, as far as the eye can reach; and when we consider how large a portion of the globe is covered in like manner, what a noble idea are we en. abled to form of that Being, who taketh up the sea in his hand, and in whose sight the ocean is no more than a drop; who covered the earth with the deep as with a garment, and assigned it bounds which it cannot pass! And it is truly astonishing by what simple, yet potent means, this great and important end is accomplished; for it is neither by adamantine rocks nor tremendous precipices, nor shelving banks of well cemented sand, that the unruly element is confined within due limits, although these all no doubt lend their aid in repelling the lashings of its surges, and occasional attempts to encroach on the land; but by a barrier, simple, yet more effectual than all these, the word of the great Jeho. vah's strength, who has impressed upon this element that law of gravitation, by which the waters of the mountains are made to go down into the val. 
lies; and has-said to the fluctuating and unstable mass, "Hitherto shalt thou come, and no farther: and here shall thy proud waves be stayed." 'There are, however, some shores on which the sea has made temporary depredations; where it has overflowed, and after remaining, perhaps, some ages, has again retired of its own accord, or been driven back by the industry of man; but we have an instanee of one of a very considerable and lasting nature, whieb happened in the reign of Henry I. in which the sea overflowed the estates of Liarl Godwin, in Kent, and formed that celebrated bank now called the Godwin Sands. In the reign of Augustus, the Isle of Wight also made a part of Britain, so that the English crossed over to it at low water with cartloads of tin; and in the bay of Bair, near Naples, there are remains of houses and streets still visible below the present level of the sea. These, however, may have been occasioned by some earthquake, or other internal convulsion of the earth, in which case such tracts would no doubt have sunk, alihough they had been situated more inland; or if these facts must really be considered as evidences of the encroachment of the sea upon the land, as the adrocates for that theory insist, we must bring in the testimony of the Norway fishermen to balance them, who affirm, that the sea upon that coast has become much shallower in many places than it had been; that rocks, formerly covered with water, were now several fect above the surface of the sea, and that loaded vessels used formerly to ride where pin- 
naces and barks could now with difficulty swim; as nothing is more certain from the absolute necessity. that a proper equilibrium in the disposition of the waters of the ocean be kept up, that if the sea is suffered to gain upon the land in one direction, it must recede from it in another, and vice versa.

Indeed, so far from there being the smallest danger that the world of waters may escape from its present situation, and return again to cover the earth, it might rather be expected, from its known properties and penetrating quality, that it would find its way downward, so as to leave its banks dry by receding from our shores, or, by mixing with the internal composition of the globe, saturate its stores with the exuberance of its moisture. Whether the former of these is chiefly prevented by that other law impressed upon fluids, by which they have a natural tendency to regain their level, and the latter, by that stiff, tenacious coat of clay, which corers such a considerable portion of the bottom of this universal canal, we will not take upon us to say: one thing is certain, that, as no increase is observed on the waters of the ocean, notwithstanding, as the wise man observes, all the rivers flow into it; so neither is there any sensible diminution of that extent of surface so essentially necessary in the business of evaporation, which is continually going on from this great natural reservoir. The water, of which the clouds are formed, and which descends in rain or snow, is evaporated from the sea; and it has been found, by calculation, that, in a summer day, there may be 
raised, in vapours from the Mediterranean alone, no less than five thousand two hundred and eighty millions of tuns of water. The air and sun are the mighty engines which work, without intermission, to raise the water from this inexhaustible eistern.The clouds, as acqueducts, convey the genial stores along the atmosphere, and distribute them in seasonable and regular proportions through all the regions of the globe.

A superficial observer may be apt to imagine, that if the watery element had been less copiously diffused, and more confined to a deeper bed, a greater part of the earth might have been converted into dry land, and, consequently, made habitable to a larger portion of the human species; but such do not consider, that the clonds, which drop down fatness, derive thrir fertilizing quality from the vapours exhaled from the ocean, and that to abridge the liquid expanse of its extent, would be only depriving those aërial water-bearers of part of their geniat stores, so indispensably necessary to render that portion of the dry land we already possess productive. How amazing that water, without which we can scarcely perform any husiness, or enjoy any comfort, should be thus brought to stream by our door's, and enter our houses, from the remotest regions-from the far off and unfrequented paths of the great deep; that this houndless mass of fluid salt, so intolerably nauseous to the taste, should be the original source of those sweet and pleasing showers that descend to water and refresh the earth. 
The all-wise Creator foresaw this, and, in mercy to the inhabitants of the dry parts of this earthly ball, diffused his watery treasures over such a considerable portion of its surface; carefully balancing the Atlantic with the Pacific, and the Northern with the Southern ocean ; and if the old Continent can boast of its Mediterranean, Caspian, Baltic, Black, White, and Red seas, the New World is deeply indebted by the gulf of Mexico, and North $\Lambda$ merica has ob. tained the appellation of the Country of lakes.

But the ocean, as well as being the source of fertility, by the exhalations drawn up from its surface by the sun, is also the great receptacle of filth, and mighty purifier and restorer of nature. Almost all the rivers, indeed, run into the sea ; but it is not merely to empty their liquid stores, and to keep up the circulation in the huge machine of the universe; they convey also, as they go along to this capacious re. cciver, the refuse of nations, and deposit in the bosom of the great abyss the accumulated filth of our towns ann cities. How, then, it may be asked, are the waters of this mighty basin preserved fiom being . contaminated? And, instead of continuing the salubrious element of vitality to so many living creatures, how comes it to pass that the sea is not converted into a source of corruption, a fountilin of putridity, disease, and death?

The two great efficient eauses, which produce these happy results, are, that incessant motion by which the ocean is kept in perpetual agitation, even in its most tranquil state, and the saltness of its wa- 
ters; and that these might operate with the greatest possible effect where most necessary, it is wisely so ordered that both prevail most as we approach those warm regions, where the intense heat would be followed by most pernicious consequences on a standing pool, or stagnant fresh-water lakes, and are less perceptible in climates more remote from the equator.

The principal currents of the ocean are those observed in the Atlantic ocean, near Guinea, extending from Cape Verd to the Bay of Fernandos. These currents are so rapid, that vessels run as far in two days with them, as require six or seven weeks to return.

Near Sumatra there are rapid currents, as also between Java and Magellan, the Cape of Good Hope, and the Island of Madagascar; especially between Natal and the Cape on the coast of Africa; there are violent currents in the sea adjacent to the Maldivian Islands.

One of the greatest tides we know of, is that at the mouth of the river Indus, where the water rises thirty feet in height; it is no wonder, therefore, that Alexander's soldiers, who had been accustomed to behold the scarcely perceptible risings of the Mediterranean, should have viewed this striking phenomenon with a mixture of curiosity and apprehension. The tides are also remarkably high on the coasts of Malay, in the Straits of Sunda, in the Red Sea, and atong the coasts of China and Japan.

The sea contains the greatest quantity of salt in the torrid zone, where, otherwise, from the excessive 
heat, it would be in danger of putrefaction; as we advance northward, this quantity diminishes, till, at the Pole, it nearly vanishes altogether.

It may also be remarked, that the Caspian and other inland seas, that have no effuent river's to put them in motion, and circulate their contents, are salt; while the lakes of Ontario and Erie, through which the river St. Lawrence passes, in North America, are fresh-water lakes.

We have alreacly had occasion to remark the bad effects that must have inevitably ensued, had the putrid carcases of land-animals been left to rot in the air unburied; but what must this mighty recep. tacle of carrion and putrefaction have long ere now become, but for the correcting and renovating power imparted to it by its saltness and motion.

And it ought here to be remarked, that, from whatever cause the saline nature of the ocean may proceed, its saltness is as inherent in its composition as the heat is in the sun; while, to preserve and keep up the perpetual agitation of its fluid particles, its motion is not dependant on any one single cause.

The most perceptible agitation in this world of water that strikes our senses, is that occasioned by tle influence of the wind, when the raging billows heave their tumultuous throes, and threaten destruction to the affrighted mariner; yet this motion, even in the most violent storms, is said to be confined only to its surface That occasioned by the currents, however. must descend to the bottom, and be particularly strong among those narrow and deep 
inequalities most apt to produce them. The bottom of the sea, like the surface of the earth, is overspread with mountains, intersected with inequalities. In all mountainous places currents will be violent; in all places where the bottom of the sea is level, they will be almost imperceptible.

Whirlpools appear to be no other than the eddies of the water formed by the action of two or more opposite currents. The Euripus, nigh the Grecian coast, and famous for the death of Aristotle, alternately absorbs and rejects the water seven times in twenty-four hours. The Charybdis, near the straits of Sicily, rejects and absorbs the water thrice in twenty-four hours; and the greatest known whirlpool in the world, that in the Norway sea, which is affirmed to be upwards of twenty leagues in circumference, is said to absorb, for six hours, whales, ships, and every thing that comes near it, and afterwards returns them in the same quantity of time as it drew them in.

But that which gives to the sea its unremitting and universal impulse, which suffers it not to rest for a single moment over all its wide extended bounds, but keeps it in perpetual agitation, and makes it, a it were, remain vigorous, and acquire health by exercise, from one extremity of the earth to the other, is that wonderful and truly surprising phenomenon of nature, the flux and reflux of the tides.

This wonderful phenomenon, so inconceivable to the ancients, is accounted for by the moderns, on the principle of gravitation, and has been demonstrated to be under the influence of the moon; but from 
whatever secondary cause it may proceed, there can be no doubt as to the fact, that the waters of the sea ebb and flow alternately twice in the course of something less than twenty-five hours, with the greatest regularity. This is surprising indeed; but it is no less so, that they should adhere so invariably to the limits of their operation; that even when the waves lift up their hearls in the most ungovernable fury, and toss about in their most frantic ravings, they still confine themselves to the space allotted for them by Providence, and pay the most implicit bmission to that unerring law which regulates their movements.

When the tide begins to flow, it signifies not that the proudest earthly potentate be in the way. $\mathrm{Ca}$ nute may erect his throne on the beach, and command the sea to approach no farther; but it will be only to proclaim his own impotence; for, regardless of the mandate, the waters will press on, and, if the monarch persists, will sweep him from the face of the earth. When the ebb has commenced, it is equally vain to think of retarding the reflux; the rolling surges must return to the bosom of the ocean, from whence they came.

The bed of the ocean, gradually deepening as it recedes from our shores, till it loses itself in the dark unfathomed caves of the deep, renders it not only more commodious for the purposes of navigation, and safe for the inhahitants who dwell on its borders, but it is of singular service in removing, to a distance from our shores, those numerous deposits of noxious matter which are daily poured into it, 
while undergoing the process of purification amongst the sandy particles at the bottom. There the most offensive impurities having subsided into the mud, may be said to be buried in the depths of the sea; but not to remain, for even there a species of worms await their farther decomposition, and the last stage of corruption is made to assume a new form.

The saltness of the sea, besides the important part it bears in the renovating power of the watery element by its saline quality, is also of use in lending its aid to preserve that motion, the beneficial efficacy of which has just been demonstrated; for the saltness of the sea renders its waters less apt to freeze, and in those countries where, in the absence of heat, it is not so necessary otherwise, tends not a little to retard the progress of congelation. This serves only to render the water of the ocean heavier, and consequently of a proper consistency for supporting those numerous burdens which float on its surface.

Among the wonders of the great deep, we may justly reckon those awful phenomena, termed $W a$ ter-spouts; yet these no doubt have their uses.They are of two kinds; one of which is no other than a thick compressed cloud, reduced to a small space by contrary winds, which, blowing at the same time from many corners, give it a cylindric form, and cause the water to fall by its own weight. The quantity of water is so great, and the fall so sudden and precipitate, that if, unfortunately, one of these spouts break on a vessel; it shatters it to pieces, and sinks it in an instant. It is asserted, and possibly 
with foundatien, that these spouts may be broken and destroyed by the commotion which the firing of cannon excite in the air.

The other kind of water-spout is called a typhon, and does not deseend from the clouds, but rises up from the sea with great violence. "These Waterspouts," Thevenot observes, "are also very dangerous, for if they fall on a vessel they entangle in the sails so much that sometimes they raise it up, and afterwards let it fall with such violence as to sink it; or, at least, if they do not lift the vessel up, they tear all the sails, or let the water they contain fall on it, which often sinks it to the bottom." But, whatever mischief may be occasioned by Water-spouts, or however terrifying their appearance, we have abundant reason to belicve, from their being the productions of so wise and good a God, that the partial evil they may at times occasion, is nothing in comparison with the good they promote. As the burning torrent, issuing from the top of Etna or Vesuvius, alarms the surrounding inhabitants, and sometimes carries irremediable devastation among their dwellings, yet is absolutely necessary to prevent greater evils, so the terrific Water spout may act as the most simple and efficacious medium of restoring that equilibrium among the elements, which, if longer prevented, might not only occasion convulsions sufficient to swallow up whole navies, but be attended with the most direful effects upon the dry land. But were it for no other purpose than to add to the grandeur of such a scene as is about to be described, and awa- 
ken feelings similar to those experienced by the author of the following subline sketch, taken in the midst of the Atlantic ocean, these wonderful productions of the varying power of nature may be said not to have been created in vain.

"One evening," observes this writer, (" it was a profound calm,) we were in the delicious seas which bathe the shores of Virginia; every sail was furled; I was engaged upon the deck, when I heard the bell that summoned the crew to prayers; I hastened to mingle my supplications with those of the companions of my voyage. The officers, with the passengers, were on the quarter; the chaplain, with a book in his hand, stood at a little distance before them; the seamen were scattered at random over the poop; we were all standing, our faces towards the prow of the ship, which was turned to the west. The globe of the sun, whose lustre even then our eyes could scarcely endure, ready to plunge beneath the waves, was discovered through the rigging in the midst of a boundless space. From the motion of the stern, it appeared as if the radiant orb every moment clianged its horizon. A few clouds wandered confusedly in the east, where the moon was slowly rising; the rest of the sky was serene; and towards the north a Water-spout, forming a glorious triangle with the luminaries of day and night, glistening with all the colours of the prism, rose out of the sea like a column of crystal, supporting the vaults of heaven.

"He who had not recognised in this spectacle the beauty of the Deity, had been greatly to be piticd. 
Religious tears involuntarily flowed from my eyes. The consciousness of our insignificance, excited by. the spectacle of infinity; our songs resounding to a distance over the silent waves, the night approaching with its dangers; our vessel itself a wonder among so many wonders; a religious crew, penetrated with admiration and with awe; a priest, august in supplicating the Almighty God, inclined over the abyss, with one hand staying the sun at the portal of the west, with the other raising the moon in the eastern hemisphere, and lending, through immensity, an attentive ear to the feeble voice of his creatures; this is a picture which baffles description, and which the whole art of man is scarcely sufficient to embrace."

No person who has walked along the sea-shore but must have observed that incessant noise, that continued murmur, which, even when the greatest calm prevails, salutes his car, and the beautiful white edging by which the floating mantle is fringed at its extremities. This soft and placid murmur, and these graceful white curls, are occasioned by the motion of the waves on the extended beach; and, trivial as they may appear, serve as perpetual monitors to warn the passenger where the line of boundary com. mences, which separates the land from the water; and as the rushing noise of the rapid river, and the tremendous roar of the dreadful cataract, serve to point out the path of danger to the bewildered traveller, particularly under the cloud of night, these, as well as the luminous appearance of the sea, and the noise of the breakers on the rocks, in regions 
more remote from the habitations of men, may also be of use to the mariner in the midnight gloon, by enabling him to steer clear of impending dangers. The luminous appearance of the surface of the ocean, during the obscurity of the night, has been remarked by navigators, and is a curious phenomenon, which has long exercised the sagacity of philosphers; but, without enquiring into the cause of this singular phosphoric property of the waters, by which they are illuminated, and rendered more visible among breakers, or where the greatest a gitation prevails, we must allow that it, as well as the noise which they make in a state of turbulence, has been wisely imparted to the waves of the deep; for, in the words of that elegant writer already quoted, "How many ressels would peris's amid the darkness, were it not for those miraculous beacons, kindled by Providence upon the rocks!"

We have already had occasion to notice that law of nature by which fluids, when put out of order, have an uniform tendency to regain their level; and it is to this law that we must ascribe the facility with which the track of a ship, in the midst of the sea, is closed up. But for this, what a rugged and misshapen mass must the surface of the ocean long ago have appeared! It is, however, wisely ordered otherwise; and while the plough of the husbandman leaves the deepened furrows open in the stubborn glebe, those occasioned by the humblest bark or lightest skiff in the watery element, as soon as she has passed, are quickly swallowed up.

L 2 
To a spectator on land, the sea appears to be higher than the spot on which he stands; this, however, is by no means the case, as is demonstrated by the same experiment by which the globular form of the earth is proved; namely, the sinking of the hull of a ship in the horizon, as she recedes from our view, before the sails and higher parts disappear. This illusion is occasioned by that refraction in the atmosphere, or property of vision, by which objects are made to rise in the landscape in proportion to their distance from us, by which means our horizon is increased and objects longer kept in view, which otherwise must have been extremely limited, and our prospects of short duration.

We labour also under a deception in regard to the colour of the sea; for although when viewed from a precipice its waters afford a muddy greenish hue, arising from the depth and position of the eye; when beheld from a shelving beach it assumes the colour of the sky; although it is dark and black in the deep abyss, white and foaming in a storm, cloud. ed with the most beautiful colours when the rays of the setting sun shine upon it, or puts on the appearance of a beautiful green, when beheld from a boat in a sun-shine day, over a sandy bottom; yet there can be no doubt but the sea-water is of itself transparent and colourless, and that the various appearances it puts on must be entirely owing to accidental causes : and, indeed, how could it be otherwise, but that the medium of vision to so many living creatures should have remained in such a transparent 
and untinged state, as to enable them to distinguish each other, and the numerous inanimate objects which are to be found in it, by their colour.

The bottom of the sea being supposed to resemble the surface of the dry land, these inequalities in its depth which occasion the mariner to be so much on the alert, may easily be accounted for. But if these are the causes of the deceitful shallows and dangerous rocks, it must not be forgotten, that to these also we owe the deep unfathomable gulfs over which the vessel glides in safety, and those numerous islands which adorn and diversify the surface of the ocean.

\title{
The Uses of the Ocean.
}

\begin{abstract}
- " Adoring own
The hand Almighty, who its channell'd bed Immeasurable sunk, and pour'd abroad,

Fenc'd with eternal mounds, the fluid sphere

With every wind to waft large commerce on, Join pole to pole, consociate sever'd worlds, And link in bonds of intercourse and love Earth's univer'sal family."
\end{abstract}

The Ocean, as we have already observed, is the great reservoir of nature, the mighty source of evaporation, which supplies the earth with fertility, by causing the clouds to drop down fatness. "It is," in the words of an elegant admirer of Nature's works, "the capacious cistern of the universe, which admits as into a receptacle, and distributes as a reservoir, whatever waters the whole globe. There is 
not ${ }^{\prime}$ a fountain that gushes in the unfrequented descrt, nor a rivulet that flows in the remotest continent, nor a cloud that swims in the highest regions of the firmament, but is fed by this all-replenishing source." 'Thus, in the great, as well as in the lesser world, a continual circulation is kept up. The waters of the clouds ascend from the sea in vapours; they descend to the earth in showers, and return again to the deep in rivers, after having watered and fertilized the earth. The ocean, instead of being a bar of separation, is the great bond of union among the nations; for look at a map, and behold with admiration how wisely the sea, which the ancients looked upon as an impassable gulf, is disposed and distributed for comecting the remotest realms, and facilitating the intereourse of one nation with another. "By means of this element we travel farther than birds of the strongest pinion fly, and discover tracts which the vulture's eye has never scen. We make a visit to nations that lie drowned in midnight slumbers when every industrious person on this part of the globe is bestirring himself in all the hurry of business. We cultivate an acquaintance with the sun-burnt Ncgro and shivering Icelander. We cross the flaming line, we penetrate almost to the pole, and wing our way even round the globe."

The ocean is the great vehicle of commerce, and, instead of limiting the industry of man, enlarges his sphere, and excites him to action. There go the ships which transport the produce of nations from clime to clime, and enable one people to supply their 
wants from the abundance of another. And here permit us to observe that the arts of ship-building and navigation have, indeed, been of incalculable benefit to mankind. How astonishing, that such an enormous and heavy mass as a large ship should be so constructed as to be made to swim in water, with all her crew, stores, and appendages! Yet such masses are not only made to swim, but are constructed in such a manner as to move at the lightest breeze, and be guided in their course by a very small helm. These considerations alone might excite our surprise, even if the vessel did no more than coast it along, without losing sight of land; but, by the sister art of navigation, she is carried into the immense depths of the ocean, and made to find her way through pathless tracts, and across a distance of sonie thousand miles extent; and this by night and by day, foul weather and fair; as well when the sky is overcast as when it is clear, without the smallest danger of mistaking her port, or missing her desired haven.

Through this element are imported, at a small expense, the productions and rarities of almost every country; and while the workmanship of our artisans, and the produce of our manufacturers are widely diffused among the nations, our tables are furnished from the remotest corners of the globe. We are clothed during summer with the fleeces of the south, and are kept warm in the cold season of winter by the furry mantles of the north. The riches of both Indies are wafted to our shores; and our heavy laden merchantmen find their way to the remotest regions. 
And in this place we cannot pass without noticing how different our modern voyages from those undertaken by the ancients, who, even in the mildest climates, and in seas the least tempestuous, ventured only from their harbours in the summer months! and for this we are indebted to the Loadstone. It is the faithful and unerring guide which now conducts the pilot with so much certainty in the unbounded ocean, and enables the merchant to transpoit his goods at such a trifling expence, that a ship of six hundred tons burden, and navigated by between thirty and forty men, can be made to transport as many goods at a time, as would require upwards of twelve hundred horses and a proportionate number of men to manage them! What a difference in point of saving, were it no more than the victuals and provender made use of by such a number of men and horses!

By the invention of navigation, and the discovery of the magnet, we are enabled to correspond with the most uncultivated barbarian in the isles of the sea, and hold converse, as it were, with those who divell in the uttermost parts of the earth. By means of these, savages the most distant may be humanized and instructed in the knowledge of the arts and sciences, and a way opened up for the more universal spread of the gospel.

In short, it is impossible to enumerate the benefits to be derived from the wonderous fluid. As the medium of traffic, and the great depot of so many finny treasures, it gives employment to thousands. 
It surrounds nations with the most secure barrier of defence; its salubrious breezes refresh and cool the air.- Used as a bath, it invigorates and strengthens the invalid; taken internally as a medicine, its qualities are of the most potent nature ; and although it serves as a sink for corruption and all manner of filthiness, such are its purifying and renovating powers, that it not only remains clean, wholesome, and uncontaminated itself, but furnishes us with a large proportion of an useful ingredient to preserve our food from putrefaction!

The bottom of the sea also abounds with a variety of vegetable productions, while its waters are stocked with creatures innumerable, both small and great; a consideration of these, however, we must defer for succeeding chapters, and will conclude the present in the words of Bishop Horne:- "The last use I shall mention which we are to make of the sea, is, that which the Holy Spirit himself hath so frequently made of it in the Scriptures, viz. to consider it as an emblem of the world, and of what is passing therein. Under a smiling, deceitful surface, both conceal dangerous rocks and quicksands, on which the unskilful mariner will strike and be lost. Both abound with creatures pursuing and devouring one another; the small and the weak becoming a prey to the great and powerful; while in both there is a grand destroyer, a leviathan, taking his pastime, and seeking the perdition of all.

"In the voyage of life we may set out with a still sea and fair sky; but ere long, cares and sorrows, 
the storms of affliction, shall overtake us. At God's word, either to punish us or to prove us, from some quarter or another, whence perhaps we least expected it, the wind ariseth and lifteth up the waves. We are carried sometimes up to heaven with hope, sometimes down to the deep with despair."

\section{CHAP. XI.}

\section{SEA PLANTS.}

"With wonder mark the moving wilderness of waves, Magnificently dreadful ! - Where at large

Leviathan, (with each inferior name

Of sea-horn kinds, ten thousand, thousand tribes,)

Finds endless range for pasture and for sport."

The bottom of the sea, as we have observed, abounds with a variety of vegetable productions. Before turning our attention more immediately to the animated inhabitants of the great abyss, we shall, therefore, take a cursory glance at these sub-marine gardens, woods, and meadows; and the first thing that strikes our attention, is the remarkable difference in the conformation of Sea and Land Vegetables; for although they agree in possessing the concomitant parts of roots, stalks, and branches, yet it must be immediately observed, that instead of being hard and brittle like the latter, the largest and strongest of the former are furnished with an extraordinary degree of tenacity, yet evince a power of 
flexible clasticity that is astonishing; so much so, that bend them into any form, or twist them into an hundred shapes, while they adhere in their native freshness, to the rocks, still they recover their natural shape and position without danger of breaking.

The roots of sea-plants are not constructed for penetrating deep into the soil, but they are wonderfully fitted for taking firm hold of the rocks or stones upon which they vegetate, and, instead of being disturbed by the tossings of the tempest, these seem rather to acquire vigour by the severity of the weather. The long and broad leaves of these plants are excellently formed for imbibing moisture from the surrounding element; their horizontal position, extreme pliability, and oval shaped branches, fit them admirably for the peculiar situations in which they are placed, while the clammy, glutinous moisture, with which they are covered, no doubt serves (besides other important purposes,) to prevent them from being injured by the continual action of the water; so that, in the words of an admirable writer, whom we have already more than once quoted, "we see from this, and numberless other instances, what a diversity there is in the operations of the great Creator's hand. Yet every operation is an improvement, and each new pattern has a peculiar fitness of its own. The herbs and trees (he also adds) which flourish on the dry land, are maintained by the juices that permeate the soil, and fluctuate in the air. For this purpose they are furnished with leaves to collect the one, and with roots to attract the other; whereas the sea-plants, 
finding sufficient nourishment in the circumambient waters, have no occasion to detach a party of roots into the ground, and forage the earth for sustenance. Instead, therefore, of penetrating, they are but just tacked to the bottom, and adhere to some solid substance, only with such a degree of tenacity as may secure them from being tossed to and fro by the random agitation of the waves."

There are two striking peculiarities in sub-marine vegetables, which deserve our notice. Several of them are furnished with a number of appendages in the form of globes or bladders; and, instead of an uniformity of colour, these are found to be diversified with a dissinilarity of tints The former, however, from emitting a loud noise when broken, we have reason to conclude may possibly serve the purpose of air-vessels to the plants, and we need not go far to have the mystery solved, why they are made to differ so much in colour from each other.

Let us attend to the operations of yonder angler, and behold with what eagerness the unsuspecting fish, guided by the eye, rushes on the deceitiul bait ; if we can, therefore, for a moment harbour the sup. position that it is by the eye the finny tribes are, in a great degree, directed in their movements, and knowing, as we do, that some of them delight in vegetable food, we must see at once the propriety of such a variety in the colour of the carpet that covers the bed of the ocean, and the wisdom in the contrivance of its different hues. Without dwelling on the several uses of the vegetable productions of the great 
deep, we will briefly observe, that, besides serving as articles of food to so many of the watery regions, particularly to those of the Shell kind, which abound chiefly among them, these afford, among their intricate and perplexing labyrinths, a safe retreat for the weak from the strong; a commodious lorigement for a variety of shell.fish, and convenient recesses for numbers of the finny tribes to betake themselves to, for the purpose of depositing their spawn; and to these who make use of their leaves on the occasion, these plants seem to be admirably adapted to the glary matter which covers their substance, not only preventing the eggs from being easily washed off before they are hatched, but affording, in all likelihood, an immediate supply of nutricious food for the young, before they are fitted for any thing more gross ; and this may be the reason, as well as the safety which their concealment insures, why so many of the weak and smaller fry are found among them.

These few specimens may serve to show in what respects sea vegetables may be of use in the economy of nature; and we will just notice two or three of the many instances in which they may be said more directly to contribute to the service of man.

The utility of the Sponge, (an article which takes its rise from those rocky beds, ) in several of our most useful arts and manufactures, is well known. The sea weed, made into kelp, forms a principal ingredient in the composition of soap and glass; and is. found on our rocks and shores in great abundance. After being spread out and dried in the summer 
months, it is raked together and burnt in those hollows which we observe on the beach. The ashes form what is called kelp, which is used in the composition of soap and glass, as well as in the alum works. Soap is an article too well known for its cleansing quality to need description; and without the aid of glass, to what miseries and inconveniences must we be exposed, without taking into consideration the darkness that must still have hung over our mental horizon, had it not been for the invigorating powers of those magical instruments that have brought a new creation to our notice! But of all the uses to which sea regetables can be, applied, there is not one so valuable as that to which they may be converted, when in a state of putrescence, in the form of manure, for promoting the interests of agriculture and vegetation upon land.

How surprising that these pliant productions of the bed of the ocean, when worn out, or in a state of decay, should possess the amazing qualities of rendering more fertile our fields and meadows, of causing the barren tracts to bring forth, and of renovating the exhausted powers of the cultivated districts! On this strange circuit of reproduction, we cannot say, " out of the eater cometh forth meat, and out of the strong came forth sweetness;" but we have abundant reason to remark, that out of death came forth life, that out of putrefaction came forth vitality! 


\section{Animal Flowers.}

Half removed from the objects we have just been considering, we observe, on our way to those of a higher order, a number of curious productions in the form of fleshy excrescences among the rocks and stones; some with their heads drawn close together, and others spread out at top in all the luxuriance of a full blown flower. These, on account of their firm adherence to a particular spot; and apparent want of sensibility, might be taken for vegetables; but, upon minute examination, they will be found to constitute part of that superior class, or uniting link between the vegetable and animal creation, that we had occasion to mention in a preceding chapter upon Quadrupeds, under the appellation of Animal Flowers. Let us attend to the operations of one of them, and we shall soon discover, that what at first wore the appearance of a still, inanimate, full-blown flower, has something of a living and active principle in it. Touch its diverging rays or filaments, and see how they contract; but in this you may say it does no more than the sensitive plant ; make, however, another experiment, and put a shell-fish on its orifice, behold how it extends itself to receive it, with what efforts it sucks it in, and how the under part of the body swells as it forces the food into the stomach. It is not, however, capable of digesting the shelly substance, and see with what artifice it disgorges it, after having stript it of its contents. These are certainly not the properties of mere vegetables.-But M 2 
what is that other one about? It has put forth in ariay all its little fleshy horns or feelers; with some of them it has laid hold of an insect, which it is in the act of conveying to its mouth; it soon is made to disappear in the aperture, and the dilating of the under extremity, or stalk of the flower, plainly evinces its progress downwards; these are certainly the functions of animal life, and from these and such like actions, what at first might appear as nothing more than vegetables, have justly been denominated Animal Flowers; while, from their being capable of propagation by cuttings, and of being muitiplied by divisions, they may, with equal propriety, be designated Salt-water, or Sea Polypuses, and be reckoned among the wonders of the Almighty in the deep.

That these substances resemble polypuses, by the singular property of being multiplied and grafted by slips, experience has put beyond a doubt. The reproductive power of the Barbadoes animal flower is prodigious. Many people coming to see these strange creatures, and occasioning some inconvenience to a person, through whose grounds they were obliged to pass, he resolved to destroy the objects of their curiosity; and that he might do so effectually, caused all the holes, out of which they appeared, to be carefully bored and drilled with an iron instrument, so that we cannot suppose but their bodies must have been entirely crushed to a pulp; nevertheless they appeared again, in a few days, from the very same places. 


\section{CHAP. XII.}

SHELI-FISH.

"In shelly armour wrapt, the lobster seeks Safe shelter in some bay, or winding creek; To rocky chasms the dusky natives cleave, Tenacious hold, nor will the dwelling leave."

IF the wonderful productions we have just been contemplating, may be considered as part of the connecting link between the vegetable and animal kingdoms, the lowest gradation of this species may be accounted that which unites the animal to the fossil class; but what a prodigious variety of these exist, from the humble oyster, which vegetates in its shell, to the ponderous Tortoise that grazes the aquatic meadow, or the wondrous Lobster, that shoots with rapidity across the gulf

The Lobster, indeed, may be well styled wondrous. According to Sturm, it is one of the most extraordinary creatures that exists. "An animal, (observes this writer,) whose skin is a shell, and which it casts off every year, to clothe itself with new armour; an animal, whose flesh is in its tail and legs, and whose hair is in the inside of its breast; whose stomach is in its head; and which is changed every year for a new one, and which new one begins by consuming the old. An aninal which carries its eggs within its body, till they become fruitful, and then carries them outwardly under its tail; an animal which can throw off its legs when they 
become troublesome, and can replace them with others; and lastly, an animal whose eyes are placed in moveable horns. So singular a creature will long remain a mystery in the human mind. It affords new subject, however, to acknowledge and adore the power and wisdom of the Creator.

The distinguishing appendage of this class, and that from which they derive their name, is the hard crustaceous covering in which their bodies are enveloped; and how admirably fitted are they by this natural bulwark for that particular station in which Providence has placed them: for how could such soft and tender bodies have been otherwise defended and protected from injury among the many rugged and uneven masses where their habitations are assigned, and how could they escape from their numerous enemies, had they not the power of withdrawing and shutting themselves up on the approach of danger, within their shelly covering? But besides this, there are several things remarkable in cach individual species of this order, which demonstrates the whole to be fitted in the best possible manner for their various situations, habits and propensities, and to be the workmanship of the same Being whose wisdom and goodness are so conspicuously displayed in his other works.

The Limpet, stationed as a sentinel on the top of the rock, and oft exposed to the mid-day's heat when the tide is, out, as well as to the continual tossings and agitations of its waves when it is covered, is safely lodged in a little cone, impervious to the most 
penetrating rays of the sun, and so firmly cemented to the rock by means of the broad muscular surface he presents, that neither storm nor tempest can prevail to loosen his grasp, or make him relinquish his firm hold. The Muscle is not provided by nature with such a strong and firm sheet-anchor, but she is taught to supply the defect by a rt, and to spin to herself cables, by which she can be moored in security to her favourite spot. The Periwinkle does not attach itself so firmly as either of these, nor has she the means or the power to do so ; but her stony habitation is almost proof against accident, and she can roll about in safety, hermetically sealed up unider her scaly covering. The Cockle burrows deep in the sand or mud, and its edges are notched, in order to enable it to clasp more firmly together. The Nautilus, which can exist either as a diver or swimmer, and lives sometimes at the bottom, and some. times on the surface of the ocean, has a power of contracting and drawing itself into its shell when it has occasion to descend to the bottom, and of unfolding and expanding its oars and sails, when it has an inclination to sport on the surface. The Cutler, or Razor fish, never creeps, but penetrates perpendicularly into the sand; and how nic ely is its long and slender shell formed for this purpose! The Crab is provided with. claws and feet for scrambling about, but amongst such rugged precipices, and with so many enemies to encounter, it must often be at the expence of a limb; and, lo! it is endowed with the singular property of shaking of 
and reproducing a new one at pleasure. Nature has given this singular power to these creatures, for the preservation of their lives, in their frequent quarrels. In these, one crab lays hold of the claw of another; and crushes it so that it would bleed to death, had it not the power of giving up the limb in the strange manner described by naturalists. If one of the outer joints of a small leg be bruised, and the creature be laid on its back, it shews uneasiness at first, by moving it about, afterwards it holds it quite still, in a direct and natural position, without touching any part of the body, or of the other legs with it. Then, on a sudden, with a gentle crack, the wounded part of the leg drops off; the effect will be the same with the great leg, only it is thrown off with greater violence. Having got clear of the injured part, a mucus now overspreads the wound, which presently stops the bleeding; and a small leg is by degrees produced, which gradually attains the size of the former. Lobsters have also the power of reproducing an injured leg; and this accounts for their being so often found with limbs of unequal size:- the small leg must be a new one, which has not attained its full growth.-The Lobster is admirably formed for either running or swimming, and can bound with such a spring to her hole in the rock when frightened, that she enters it with velocity through an opening barely sufficient, to appearance; for her body to pass. And the Pholas, though not furnished with an instrument apparently calculatëd for boring and scooping out stones, is endowed with 
such a fund of patient perseverance, that it is enabled to penetrate into these eallous substances by the application of a fleshy member, resembling a tongue. With this soft and yielding instrument, the indefatigable and persevering Pholas, perforates marble and the hardest stones; and when small and naked, it has effected an entrance, it then enjoys a life of security and ease, existing upon sea water, that enters at the aperture, and increasing its habitation as it increases in size.

The Instinctive Sagacity of the crustaceous tribe also claims our attention We have already remarked, that the little Nautilus is furnished with an apparatus for either diving or swimming. But who taught the Nautilus to sail ?-and yet, without the instinctive knowledge how to make use of them, of what use would be either her sails or oars?-these, however, are not given her in vain, for she evinces a knowledge in the art of navigation, which is supposed to have been copied by some of the early mariners, and the example she aftords has been held out by the poet as still deserving imitation :

" Learn of the little Nautilus to sail,

Spread the thin oar, and catch the driving gale."

The natural sagacity of the Nautilus, in the use of his instruments of motion, is thus beautifully delineated by the descriptive pen of Hervey; " The dexterous inhabitant (whose shell forms a natural boat,) unfurls a membrane to the wind, which serves . him instead of a sail. He extends also a couple of arms, with which, as with two slender oars, he rows 
himself along. When he is disposed to dive, he strikes sail; and, without any apprehension of being drowned, sinks to the bottom. When the weather is calm, and he has an inclination to see the world, or take his pleasure, he mounts to the surface, and self-taught in the art of navigation, performs his voyage without either chart or compass; is himself the vessel, the rigging, and the pilot."

When the sea is calm, numbers of these animals are said to be seen sailing on the surface; but at the approach of a storm, they fold in their legs, and swallowing as much water as will enable them to sink, they plunge to the bottom, where they no doubt remain in a place of security during the raging of the tempest, and when they wish to rise, they void this water, and so decreasing their specific gravity, quickly ascend to the top, where, by means of their tails, answering the purpose of helms, they can steer themselves in any direction.

Sea Tortoises, without any teacher but nature, are instinctively taught to lay their eggs on the sea shore, and cover them with sand; and no sooner are the young hatched and fitted for their journey, than they leave the place of their nativity, and run towards that element which Providence has destined for their abode; so that the poet may well say:

"Reason progressive, instinct is complete; Swift instinct leaps, slow reason feebly climbs. Brutes soon their zenith reach; their little all Flows in at once; in ages they no more Could know, or do, or covet, or enjoy." 
When the young Lobsters leave the parent, they betake themselves to hiding places in the smallest cliffs in the rocks; but no sooner do they find themselves incrusted with a firm shell, than they sally out in quest of plunder. When the time of moulting, or changing the shell draws near, this animal again betakes itself to a retired situation, where it remains in security during its defenceless state; and after losing the shell, (which both crabs and lobsters do annually,) and before a new one is formed, the animal is in a very naked and defenceless state, exposed to the dog-fish, and a multitude of other depredators. In this situation they do not, however, long continue; for the new covering is formed, and completely hardened, in little more than forty-eight hours; and no sooner does it find itself covered with its new suit of armour, than it appears again on the stage, lively and active as before. The common Crabs herd together in distinct tribes, and keep their separate haunts. The Soldier Crab is not provided by nature with a shell attached to his body, but she has inspired him with instinctive sagacity to take up his abode in the first empty one he can lay hold of, suitable to his purpose, and to change it for another when it grows incommodious. When it has overgrown, or otherwise has occasion to change the shell, the little soldier is seen busily parading the shore, but still dragging its old habitation along, unwilling to part with one, until it has found another still more convenient for its purpose It is seen stopping at one shell, turning it, then going on to 
another, looking at it a while, then slipping its tail from the old habitation to try on the new. This is sometimes found to be more inconvenient, in which case it quickly returns to its old shell, and goes in quest of another more roomy and commodious. But it is not till after many trials and frequent combats, that the soldier sometimes finds himself completely equipped; for there are frequent contests betwixt two of this species, for some welllooking and commodious shell; and it is from this circumstance, perhaps, the soldier-crab derives its name. When two of them meet with the same ob. ject, each strives to take possession; they strike with their claws, and bite each other till the weakest is obliged to yield. It is then that the victor takes possession, and parades in his new conquest, backwards and forwards upon the strand, before his envious antagonist. The Land Crabs of the West Indies (which also may be reckoned among the natives of the deep,) are represented as living in a kind of orderly society, and regularly once a year marching down from the mountains to the sea, in order to deposit their spawn; and after the little creatures are hatched under the sand, they also are observed as regularly quitting the shore in crowds, and slowly travelling up towards the mountains

These creatures commence their expedition in the months of A pril and May. At that time the whole ground is covered with this numerous band of adventurers. The sea is the place of their destination, and to that they direct their march. No geometrician 
could send them by a shorter course. They never turn aside to the right or to the left, if they can possibly avoid it, whatever obstacles intervene. If they meet with a house, they will attempt to scale the walls, in order to keep their ranks; and if the country be intersected by rivers, they wind along the course of the stream. They are commonly divided into three battalions, of which the first consists of the strongest and boldest males, that, like pioneers, march forward to clear the route, and face the great"est dangers. They are often obliged to halt for want - of rain. The main body is composed of females, which never leave the mountains till the rain is set in, and then descend in regular order, in columns of fifty paces broad, and three miles deep; and so close that they almost cover the ground. Three or four days after this, the rear guard follows, a straggling and undisciplined tribe, consisting of males and females; but neither so robust nor so numerous as the former. The night is their chief time of proceeding; but if it rains by day, they do not fail to profit by the occasion. When they are terrified, they march back in a disorderly manner, holding up their nippers, with which they sometimes tear off a piece of the flesh of an assailant, and leave the weapon where they inflicted the wound. They even try to intimidate their enemies, by clattering their nippers together, which, considering their number, must have a powerful effect. When they have arrived at the shore, which sometimes takes three months, they prepare to cast their spawn, by eagerly going to the 
edge of the water, and letting it wash several times over their bodies. At the expiration of some days, spent on the land, after this washing, they again seek the shore; and shaking off the spawn into the water, leave it there. The sea, to a great distance, is black with the eggs, and shoals of hungry fish attend, and devour a considerable quantity of them; those that escape are hatched under the sand; and soon after, millions at a time of these little crabs are seen quitting the shore, and making their way slowly to the mountains.

When the Tellina has occasion to move, she puts herself into a certain position, which occasions her to spring out, with considerable force, to a distance. When the Scallop finds herself deserted by the tide, it jerks itself forward by opening and shutting its shell in a singular manner. When the Razor shellfish finds itself deceived by the fisherman, when he decoys it from its subterraneous habitation by a sprinkling of salt, and has time to retreat, no such attempt will succeed a second time. When pait of the legs of the Sea Hedge-hog are at work, carrying him forward, the horns that are nearest in that direction are busily employed in making soundings or feeling the way. The Muscle, when slie has commenced spinning her cable, will make a trial of a thread, by drawing it out strongly towards her, before she proceeds to stretch out a second; and these cords, which she spins with so much art, are, in reality, as serviceable to them as cables are to a ship. There are frequently a hundred and fifty of these 
little cables employed in mooring a muscle; each cable is scarcely two inches long, but they are all spun by herself, and the tongue is the instrument which not only produces these numerous threads, but serves also instead of arms and legs on other occasions The Limpet, when she has occasion to unmoor, finds means to disengage herself without any great effort, and to move from her place by the same muscle by which she adhered so firmly to her anchorage. Even Oysters are said not to be destitute of the power and the instinctive sagacity to turn them. selves round when thrown irregularly into a vessel of water, so that the concave shells may remain downmost, in order to retain their favourite liquor.

\section{Uses of Shell-fish.}

From the number of animals which prey upon insects, it was inferred, that the principal object the Creator had in view in the formation of these, was the subsistence of many of the larger orders of creatures; so, from the numerous herds of shell-fish, which, in a great degree, resemble insects, and every where abound among the beds of the ocean, and the extraordinary digestive faculties of the finny tribes, we have reason to conclude, that the former were principally intended and brought into existence for food to the latter. We will, however, mention a few particulars in which the crustaceous tribes may also be said to be otherwise servic cable. 
The Hawk's-bill Turtle is valued on account of its shell, from whence our most beautiful snuff. boxes, and other trinkets, are said to be former. The Green Turtle, as a wholesome and highly delicious food, has become such a valuable article in commerce, that our West India vessels are now generally fitted up with conveniences for importing them alive. The Land Crab is said to be regarded as a delicacy in Jamaica; and it is even asserted that the slaves are often entirely fed upon them. Among the shell-fish on the Waterford coast, the Murex, which gave the Tyrian purple, is said to exist. We need not mention in what estimation the Lobster, the Crab, and other shell-fish, are held among ourselves; and the delicacy of flavour which makes the Oyster prized as an article of food. In the Oyster, also, is found that beautiful substance called Mother of Pearl; but as the pearl fishery is one of the most destructive employments (the art of war excepted, in which the human species can be engaged, it is much to be lamented that what is principally used in the formation of trinkets should continue to be procured at the expence of so much human misery.

The pearls are searched for by Divers, educated to it as a profession; they descend from fifty to sixty feet, each bringing up a net full of Oysters. The pearl is most commonly attached to the inside of the shell, but is most perfect when found in the animal itself.

The exertion undergone during this progress is so violent, that, upon being brought into the boat, the Divers discharge water from their mouths, ears and 
nostrils, and frequently blood; this does not, however, hinder them from going down in their turn, and the poor creatures will often make from forty to fifty plunges a day. But the violence of the exertion (by which, although the most robust and healthy are generally chosen for this employment, yet they seldom survive it five or six years, ) is not the only thing the Pearl-divers have to dread; they are also. exposed to the attacks of the sharks, who, if they are not successful in every attempt to extinguish at once the vital spark, and so put an end to a life so little to be envied, frequently deprive these unhappy beings of a limb, and suffer them only to escape from their jaws in a mutilated state!-Read this, ye dashing fair ones! and think, as ye enter the ball-room under a profusion of glittering ornaments, that, to procure that costly bracelet, an unhappy fellow creature was doomed to the slavery of the diamondmines; and that beautiful pearl was procured at the peril of another's life.-And all this while so many of the transcendent beauties of creation, placed by the Almighty within our reach, pass unregarded.But this is of a piece with the general conduct of man, who is ever apt to lose the substance in grasp. ing at the shadow. 


\section{CHAP. XIII.}

\section{FISHES.}

"Who can old Ocean's pathless bel explore, And count her tribes that people every shore?"

"From icy oceans, where the whales 'I'oss in foam their lashing tails."

Ir the Ostrich, the Emu, and the Cassowary, were remarkable for their size, and claimed our first attention among the feathery tribes, in consequence of their apparently constituting part of that link which unites the quadruped to the volatile race, the Whale deserves our immediate notice on entering among the finny tribes; not only on account of its enormous bulk, which has occasioned it, in its movements, to be compared to a mountain in motion, but for the resemblance that it bears to the four footed class of animals in its internal structure, and that superior in. stinctive sagacity which it displays in its conjugal attachment, and care of its offspring. In bulk, the Whale may be said to exceed every animal of which we have any certain description. They are in the - arctic regions at present from sixty to ninety feet long; but formerly, when the captures were less frequent, and they were not so much thinned before arriving at a larger growth, they were said to be found of the enormous length of two hundred and fifty feet; and in the Indian Seas they are still seen one hundred and fifty feet in length. Yet, notwithstanding 
- its amazing bulk, this creature must not be considered as a huge unwieldy mass; for, according to La Cepede, it swims at the rate of thirty-three feet in a second, and it is computed that it might circumnavigate the globe, in the direction of the equator, in forty seven days, even allowing it to rest by night during that time! It is believed to be extremely long lived; and the method of catching these huge animals is said to be one of the boldest enterprizes of man. As the whale fishing has, however, been . so fully described in a variety of publications, within the reach of the greater part of our readers, we shall pass it over for the present. But, large as the whale is, what is its size in comparison with the Kraken? if such an animal exists; which is said to be "a mile and a half in circumference; - that, when it appears above the water, it resembles a parcel of small islands and sand-banks, on which fish disport themselves, and sea-weeds grow ;"-and that, "when he sinks, which he does gradually, a dangerous swell succeeds, and a kind of whirlpool is actually formed in the water."

Far from being disposed to set bounds to the power of the Almighty, by denying the possibility of the existence of such an animal, we would conclude in the words of Goldsmith, that " to believe all that has been said of those animals would be too credulous, and to reject the possibility of their existence, would be a presumption unbecoming mankind."

In the internal conformation of its parts, and in a few of the external ones of the Whale, there is such 
a similarity to those of quadrupeds, that Linnæus has. placed it in the same class; to which its claim, and that of the other cetaceous fishes, seem, indeed, little inferior to that of the Seal, where the last gradation, in that order of animals, may be said to end.

In its instinctive tenderness, the Whale is, indeed, entitled to our admiration; but, as we shall have occasion to speak more fully on that subject by and by, we will, for the present, proceed to the consideration of the general

\section{Structure of Fishes.}

In attending to these, we will soon observe that, if the body of a bird is shaped in the most convenient manner for making its way through the air, a no less extraordinary degree of divine wisdom is evident in the conformation of the finny inhabitants of the deep to that element in which they exist. To make these creatures buoyant and flexible, yet firm to oppose the strongest currents, the great Creator has constituted them of yery different materials, and of a different construction from other animals. To enable them to traverse with ease and swiftness the watery regions, the greater part of them have the same external form, sharp at each end, and swelling in the, middle. To preserve them from being hurt by the action and temperature of the surrounding fluid, as well as to enable them to glide more smoothly through it, many of these are covered with a coat of scales, others with a fat oily substance, and the whole 
with a slimy glutinous matter, supposed to be secreted from the pores of their bodies. A protuberant eye would have been inconvenient, and easily injured by moving in such a dense medium; but, to prevent this, the eyes of fishes are sunk in their heads, and the cornea made flat, while the defect of vision, that must have inevitably ensued in consequence, had they been formed like those of other animals, is provided against by the spherical form of the crystalline humour. As their progression is performed in a different way from that of any of the tribes we have already noticed, they are provided with instruments peculiar to themselves, and are enabled to poise their bodies, and push swiftly along by means of their fins and tail. Not being provided with hands or feet to lay hold of their prey, or with talons or bills to tear it to pieces, Nature has provided them with mouths capable of great extension, when they have occasion to seize on their victims, yet so formed, that when shut up close, they terminate in a point; in which an opening is scarcely distinguishable. What a tremendous chasm, for instance, does the mouth of a Shark present when exterided to receive a human carcase, of which this voracious monster has given instances of being extremely fond, and yet, when closed, it appears but a continuation of that long snout with which this fish, (reckoned among the swiftest of swimmers) like an arrow pierces the watery element.

In the absence of necks, which would make the head too apt to be turned aside when making their way against a stream, the whole bodies of fish are 
so formed as to be easily turned with a slight stroke of the tail; for, when a fish desires to turn, a blow from the tail sends it about in an instant; and when it strikes both ways, the motion is progressive, and enables it to dart forward with an astonishing velocity.

One distinguishing appendage peculiar to the finny tribe, and which is found in the bodies of all spinous or bony fish, is the air bladder, by means of which they can make themselves more or less buoyant, and rise or fall in the water at pleasure. "This," as Dr. Paley observes, " affords a plain and direct instance, not only of contrivance, but strictly of that contrivance which we denominate mechanical. It is a philosophical apparatus in the body of an animal. The principle of the contrivance is clear; the application is also clear" The rising and sinking of a fish in the water, so far as is independent of the strokes of the fins and tail, can only be regulated by the specific gravity of the body. When the bladder, contained in the body of the fish, is contracted, which it probably possesses a muscular power of doing, the bulk of the fish is contracted along with it ; whereby, since the absolute weight remains the same, the specific gravity, which is the sinking force, is increased, and the fish descends; on the contrary, when, in consequence of the relaxation of the mus- cles, the elasticity of the inclosed, and now com. pressed air, restores the dimensions of the bladder, the fish becomes proportionally lighter, and rises in the water. 
If the attributes of the Deity are so conspicuously displayed in the general structure and conformation of fishes, they are no less so in the infinity of their number and sizes; in the provision made for at once keeping up the number of this most numerous of all classes, and preventing the sea from being overstocked; and in that peculiarity of form and structure, so essentially necessary in the different species.

In this mighty reservoir it may emphatically, in deed, be said, "there are creatures innumerable, both small and great." Linnæus, however, reckons upwards of four hundred species; but it is extremely probable, that numbers are concealed in the vast extent and profundity of the ocean, which have never yet been exposed to human observation. But who can count the numbers in each species? For who can attempt to calculate the numbers in those prodigious shoals that tinge the sea with their colour, without taking into consideration "those scaly herds, and that minuter fry, which grace the sea-weed, or stray through the coral grove?" and what a diversity and variety of sizes do they assume, from the massy whale that sports at large in the Greenland seas, to those minute creatures which enter our creeks, and take up their abode in our harbours!

Yet, notwithstanding the prodigious numbers of some of these animals, and the stupendous size of others, as we observed before, they are all conveniently lodged and fed; which is the more surprising, if we take into consideration the amazing fecundity of some, and the longevity of others of these crea. 
tures. It is asserted of the Herring, that if suffered to multiply unmolested, and its offspring to remain undiminished during the space of twenty years, it would shew a progeny many times greater in bulk than the whole earth!- that a single Codfish will produce at a birth, if they escape depredation, a number equal to that of the inhabitants of England!The Flounder is said to produce above a million at a time, and a Mackarel not less than five hundred thousand; and, in regard to the longevity of fishes, several are said to live upwards of an hundred years. How, then, it may be asked, are those myriads of subjects of the watery kingdom kept within due limits? How comes it to pass, that the mighty basin is not overstocked? And how are its numerous tenants provided with food? This must be principally owing to the prevalence of the predatory system among fishes; for, numerous as are the draughts taken from the bosom of the ocean for the service of man, they can bear no proportion to the number that are left behind. But the sea, like the land, abounds not with a profusion of vegetables, so as to be sufticient for the support of all, nor even the greater part of its inhabitants, many of which are known to be of the most greedy and voracious natures It was absolutely necessary, therefore, that they should devour one another, and the experience of ages has proved, that great as the increase of these creatures is, and has been, it has never as yet been more than enough; that the balance has hitherto been pretty equally kept up, and that while the astonishing pro- 
lific powers of the finny tribes have been found sufficient for keeping up a constant supply, and making up for every waste, yet there will always be found a requisite number of hungry mouths to devour the overplus. A single Pike has been known to devour one hundred Roaches in three days. Whatever is possessed of life, seems the most desirable food of fish. Some of the smallest feed upon worms and spawn; others, whowe mouths are large, seek larger prey, it matters not of what kind, or whether it is or is not of their own species. Those with the largest mouths pursue almost every thing that has life; and often meeting each other in fierce opposition, the fish with the largest swallow comes off victorious by devouring its antagonist.

In regard to the particular construction of fishes, we will briefly remark, that the Whale has often occasion to ascend to the surface of the water for the purpose of breathing, and it has a tail peculiarly constructed to enable it to do so. His coat of blubber may be absolutely necessary to make his body equiponderate in the water, and to keep his blood warm; while in the absence of offensive weapons he is possessed of extraordinary agility, and by a stroke of his tail can deal destruction to his pursuer. The strength of this fish lies chiefly in the tail. A boat has been cut down, from the top to the bottom, by means of this formidable instrument, though the gunnel on the top was of tough wood. Another has had the stern-post, three inches thick, cut off smooth, 
without so much as shattering the boat, or drawing the nails of the boards.

The Cod, the Haddock, the Whiting, and others, whose principal element is in the middle region of the ocean, have an air-bladder to raise and depress them at pleasure; while the Scate, the Thornback, and others, that grovel mostly at the bottom, are destitute of this wonderful instrument. The Nar-whale, being a harmless and peaceable animal, may probably make use of the horn, which rises from its brow, for the purpose of breaking the ice, or disengaging the plants, on which it feeds, from the bottom of the sea. The Sword fish will not fail to attack even the Whale himself; and with what a fearful and dangerous weapon is he armed for the purpose! Of all the inhabitants of the deep, the Shark is the fiercest and most voracious, and in celerity of movement surpasses most, if not all, of the finny race ; but, to counterbalance powers, and an appetite for destruction, that might thin the ocean, there is a strange singularity in the projecting of his upper over his under jaw, so that he is obliged to turn in order to take hold of his prey, and while he is doing so his victim often makes its escape. Crabs, Lobsters, Whilks, Muscles, and other shell fish, are the food of the Wolffish; and for the purpose of effecting the destruction of such well-defended prey, this animal is provided with teeth remarkable for their strength. The Flying-fish has many enemies in both elements, but it is provided with instruments by which it can betake itself either to the water or the air, as occasion may 
require. In the tropical climates these fishes, when hotly pursued, are seen springing by hundreds out of the water, and sometimes throw themselves on board of ships in order to escape their varions assailants. The predaceous fishes that swim in the ocean, and all the birds of prey that range its surface, seem to be combined against it. It is no wonder, therefore, that the beneficent Author of nature has endowed a fish, exposed to so many enemies, with a twofold power to escape.

The structure of the Sucking-fish enables it to attach itself furmly to the bodies of animals; that of the Ammodytes, or Sand-eel, particularly the head, is most excellently formed for piercing into the sand. The flatness of the Scate and Flounder enables them to cover themselves up in the sand or mud, when they lie in wait for their prey; and the Turbot is said to be provided with a skin or membrane, which he draws over his eyes when he has occasion to stick fast at the bottom in stormy weather. The Globefish is beset with prickles like a hedge-hog, and bids defiance to all hirds of prey. The Torpedo benumbs on a sudden, and renders impotent whatever fish it assaults: it is said also to strike the fisherman's arm, when he attempts to lay hold of it, with a temporary deadness. "The instant," says Kempfer, "I touched it with my hand, I felt a terrible numbness in my arm, and as far up as my shoulder. Fven if one treads upon it with a shoe on, it affects not only the leg, but the whole thigh upwards." The 'Torporific Eel imparts a sensation similar to that which 
is experienced from electricity. The Cuttle-fish is furnished with a liquid magazine of an inky colour, to darken the waters when pursued by an encmy. The Galley-fish is protected by the caustic quality of the substance with which its legs are smeared. The abhorrent appearance of the Sea Orb is sufficient to disgust men from handling it, and more so to deter them from partaking of its poisonous quality by way of food. And it is not improbable but the hideous form of the Sea-devil, and other monsters of the deep, may have been stamped upon them by nature (which does nothing in vain,) for similarpurposes.

\section{The Instincts of Fishes.}

Fishes, it is said, appear inferior to beasts and birds in acuteness of sensation and instinctive sagacity ; but how is this reconcileable with that tenderness, care, and solicitude, (which nothing can exceed,) which the common Whale evinces for her young? She suckles and nurses them with the greatest affection, takes them with her wherever she goes; when pursued she carries them on her back, and supports them with her fins; when wounded she will not relinquish her charge, and when obliged to plunge, in midst of her agonies, will clasp them more closely, and sink with them to the bottom. Mr. Waller, in his beautiful poem of "The Summer Islands," relates a sto$r y$, in which the maternal tenderness of the Whale is most affectingly displayed. A whale and her cub had got into an arm of the sea, where, by the defec- 
tion of the tide, they were entirely enclosed. The people on shore beheld their situation, and drove down upon them in boats, with such weapons as could be hastily collected. The animals were soon severely wounded, and the sea tinged with their - blood. After several attempts to escape, the old one forced over the shallow into the depths of the ocean; but, though in safety herself, she could not bear the danger that awaited her young one; she therefore rushed in once more where the smaller animal was confined, and, as she could not carry it off, seemed resolved to share its danger. The tide, however, coming in, both were enabled to escape from their enemies, after sustaining a number of wounds.

The fidelity of whales to each other is also said to exceed even what we observe in birds; and Goldsmith relates an instance, in which a female whale being wounded while her attached partner was reclining by her side, on beholding the object of his tenderness falling a victim to the harpooners, he stretched himself on her body, and participated in her fate.

It is curious to remark what sagacity the finny tribes display in seeking out the most proper places for depositing their spawn. The Salmon on her journey up the river, will suffer no obstacle that she can possibly surmount to oppose her progress to the place of her destination; and in order to attain it, will spring over cataracts several feet high. In going upwards she will keep at the bottom where the current is weakest, and when she returns, will avail herself of its strength at the top, by swimming near its surface! 
The migration of different kinds of fishes is truly astonishing; and it is pleasing to remark, that it is when fat and in season for eating, that they are taught so instinctively to throng our bays and creeks, while they disperse to the remotest quarters of the globe when lean and emaciated. "Who," in the words of the celebrated Hervey, "Who bids these creatures evacuate the shores, and disperse them. selves into all quarters, when they become worthless and unfit for our service? Who rallies and recalls the undisciplined vagrants, as soon as they are improved into desirable food? Who appoints the very scene of our ambush to be the places of their rendezvous, so that they come like volunteers into our nets? Surely the furlough is signed, the summons issued, and the point of re-union settled by a Providence, ever indulgent to mankind, ever studious to treat us with dainties, and load us with benefits." Not only do the Herrings, the poor man's feast, visit our shores at stated periods, and solicit us by their numbers to partake of the bounties of Providence, but the Pilchard, the Mackerel, the Lamprey, the Tun. ny, and the Salmon, are regular in their migrations. At the time the I and Crabs of the West Indies arrive upon the coast to deposit their eggs, numerous fishes of different kinds punctually attend, as if timely advised of the exact period when they might expect their annual supply, and greedily devour many of the eggs before they are hatched.-Fishes, in order to be fed, have been taught to assemble at the side of a pond by the sound of a bell. Dr. George Serger asserts, that having taken a walk with some 
friends in the fine gardens of the Archbishop of Saltzburg, the gardener conducted them to a very clear piece of water, in which no fish were at first to be seen, but that the man had no sooner rung a little bell, than a multitude of trout came together from all parts of the pond, to take what he had brought them, and disappeared as soon as they had eaten it up.

The Lamprey makes holes in the gravelly bottom of the river previous to depositing her ova. The SeaDog, in a storm, is said to conceal her young under her belly. A curious circumstance has been observed relative to the young Sharks, that when pursued, they will, on the appearance of danger, take refuge in the belly of the mother. It is asserted by Pliny, that the Fishing-Frog hides itself in muddy water, and makes use of a singular artifice to secure her prey. The Ink Fish seems to be well informed of the use she ought to make of her natural bottle, and - when pursued, discharges its contents in the way of her foe. The aborescent Star fish, like the Spider, spreads out her net in order to entangle her unwary victim. And the little Thresher, in order to get the better of his formidable antagonist, tumbles neck over heels, and falls down with astonishing force on the back of the Whale, while his ally, the Swordfish, wounds him fiom underneath.

\section{The Uses of Fishes.}

Although it has been said, that to preserve their own existence, and to continue it to their posterity, 
fills up the whole circle of their pursuits, and that a ceaseless desire of food seems to be their ruling impulse, yet we are not to consider Fishes as insulated creatures, unconnected with the general concerns and affairs of the world; as merely formed for the propagation of their kind, and to " pursue and be pursued, each other's prey." No; these also act an important and most essential part in the great theatre of the universe; and woe be to the inhabitants of the earth, did multitudes of fishes not abound in its waters. We have already hall occasion to notice the necessity of a speedy decomposition of the parts of putrescent bodies on land, and notwithstanding the saline quality of its waters and perpetual agitation which prevents them for a time, the bad effects of such accumulated loads of filth and nastiness, as are continually pouring into the sea, must soon be apparent, were it not for those numerous herds of fishes, which in every quarter glide with rapidity through the liquid expanse, and catch and devour almost every thing of a digestible nature that comes in the way. For this purpose, that amazing fecundity may have been bestowed upon them, and for this purpose, those voracious appetites given, that, however remote the situation, or disgusting the substance, that enters the watery element, it might quickly meet an eye eager to catch it, and a living tomb to swallow and strip it of its noxious qualities.

As an article of food the finny tribes are greatly to be prized, and it is matter of thankfulness, that the benefits they impart are most extensively diffus- 
ed; for while our lakes, and rivers, and streams, abound with these living treasures, the ocean conveys them in myriads to the ends of the earth, and presents the bounties of an indulgent parent to his numerous children, however scattered among the isles of the sea ; and if the Turbot has been styled for its exquisite relish the Pheasant of the waters, the Sturgeon, even in pickle, has been denominated a luxury, and while the Salmon is held in much esteem by the great, the poor have reason to praise the Almighty for an abundant supply of cheap, wholesome, and nutritious food, in those prodigious shoals of Herrings and Pilchards which visit our coasts.

When the great colony of Herrings set out on their migrating journey from the Polar seas, it is composed of such numbers, that if all the horses in the world were loaded with them, they could not carry the thousandth part; and when the main body approaches the coast, it is generally divided into distinct colums of five or six miles in length, and three or four in breadth!

Vast shoals of Pilchards (a small species of Herring) appear about the middle of July, off the coast of Cornwall; and Mr. Pennant was assured by Dr. Borlase, that on the fifth of October, 1767, there was at one time enclosed and caught in St. Anne's Bay, no less than 7000 hogsheads of Pilchards, each hogshead containing 3500 fishes!

Nor have we less reason to be thankful for the incalculable number of Cod, and other white fish, which are drawn from the ocean; and for those in- 
exhaustible stores of cartilaginous flat fish, which furnish the labourer with his cheap repast.-In 1806, five hundred and seventy-seven ships, carrying about 64,667 tons, and navigated by $4,336 \mathrm{men}$, were employed bv the British Government, to export the produce of the fisheries on the banks of Newfoundland, where the principle cod-fisheries are. The vessels used in the fishery, are from 100 to 150 tons burden, and catch from thirty to forty thousand fish each; 10,000 persons being employed about this fishery, in catching, salting, and drying the fish, which are sent to all parts of Europe and the WestIndies. These fisheries are said to bring in to the proprietors a revenue of several millions yearly; and they will probably remain in an inexhausted and inexhaustible source of treasure, when the richest mines are wrought out. Happy ordination of infinite goodness and unerring wisdom, that while the monstrous and unwholesome tribes are thinly scattered or hid from our sight in the great abyss, the wholesome and nutritious kinds abound in such numbers, and are brought, as it were, to our very doors!

Even the great Greenland Whale, which abounds in such numbers in the northern ocean, is said to furnish the inhabitants of those countries, which border on his haunts, with a delicious luxury in the article of food. The Porpoise was a royal dish even so late as the reign of Henry VIII. and the negroes are said to be fond of the flesh of the voracious Shark.

- The Whale is well known on account of its importance in furnishing such a supply of oil and 
whalebone. Every Whale yields, on an average, from sixty to one hundred barrels of oil; which, with the whalebone, a substance taken from the upper jaw of the animal, must render these creatures very valuable in a commercial point of view. From the Cacholet we derive that valuable commodity spermaceti; and ambergris, the sweetest of perfumes, is also frequently found in this animal. The skin of the Shark is converted into shagreen. From a spe. cies of the Sturgeon, we are supplied with isinglass. From the Beluga-fish we derive that delicious composition called caviare, and also the Beluga-stone. The hide of the Huso is so tough and strong, that it is employed for ropes in carts and other wheel carriages.

As some of the volatile race seem to be formed to please us with the beauty of their plumage, and delight us with the melody of their song, so a few of the finny tribe are so exquisitely formed and beautifully embellished, that they appear more calculated for our pleasure and pastime, than for any intrinsic value in another point of view. We do not here merely allude to the little gold and silver natives of China and $\mathbf{J}$ apan, which are trained and domesticated to sport in our ponds, and amuse us with gambols in our gardens, but to the Dorado and Gilt head, which glide in the ocean, and the beautiful Dragonet, which shines resplendent in the deep. These, also, on some interesting occasions, may contribute their mites towards the comforts of man. Gazing on these from the side of the vessel that conveys him 
far from his native home, the solitary exile may be made, for a while, to forget his private woes; and the sporting of these may serve to beguile the tedious moments that mark the slow progress of the lonesome passenger, returning from captivity to the circle of his friends, or to the agitated bosom of her he loves.

Thus, if we have had reason to admire the wisdom, the power and the goodness of the great Creator, as they are manifested in some of the inanimated pages of the Book of Nature, and to contemplate, as we have gone along, with sentiments of admiration and gratitude, the benefits we derive from the internal structure and outward form of the earthfrom the numerous appendages and vegetable productions by which the dry land is covered-and from the wonderful phenomena and beneficial properties of the ocean; we have no less cause to be filled with admiration at the bright display of the wisdom and goodness of the Creator, as they shine conspicuous in the inhabitants of the great deep.

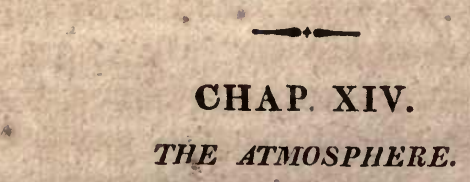

_ "To Hrm, ye vocal gales

Blow soft, whose spirit in your freshness breathes!"

"We view his kind, hís life-preserving care,

In all the wondrous properties of air."

From the earth let us ascend into the regions of the air, and take a view of that invisible fluid that 
surrounds our globe as with a garment, gravitates to its surface, enters into its pores, revolves with it in its diurnal motion, and cireles along with it in its annual course.

The Air is one of the most heterogeneous mix. tures imaginable. "In it," says Goldsmith, " all the bodies of the earth are continually sending up a part of their substance by evaporation A thousand sub. stances that escape all our senses we know to be there; the powerful emanations of the loadstone, the effluvia of electricity, the rays of light, and the insinuations of fire." Such are the various substances through which we move, and which we are continually taking in at every pore, and returning again with imperceptible discharge. Yet, notwithstanding the multitude of discordant particles of which the atmosphere is composed, it is made wonderfully to. harmonize in point of utility; and is wisely contrived, admirably framed, and excellently constituted, for the various purposes it was intended to perform, in the world of nature and of art.

That the air is a fluid is obvious, from its possessing so many properties in common with other fluids; yet, in one respect, it is wisely made to differ from all others, being incapable of freezing by the greatest degree of cold. Was it not for this singular quality of the atmosphere, what dreadful effects must have been the consequence. Life and animation must long ago have ceased, before the frigid blasts of the north, and when winter first shook his hoary locks; the great pulse of nature must have stood still. 
Another wonderful property of the air is its invisibility; for, although it can be heard in the howling of the tempest, and felt in the pressure of the gale, and notwithstanding the number of bodies that continually mix with its substance, it is still too fine to be seen by the sharpest eye.

Every object around us is visible, except the air; and happy it is for us that it is so; for, had it been otherwise, farewell to all the delightful prospects that charm the eye; farewell to all the bright beauties of creation. Nature must have put on a sombre aspect, and, instead of those delightful regions of light and cheerfulness in which we are placed, our habitations would have been surrounded by the doleful shades of a dusky covering, and environed with a mantle of darkness and despair.

But, although the atmosphere is of itself invisible to the sight, it is the happy medium of light and heat. The air is found to moderate the rays of light, to dissipate their violence, and to spread an uniform lustre over every object. Were the beams of the sun to dart directly upon us, without passing through this protecting medium, they would either burn us up at once, or blind us with their effulgence; but, by going through the air, they are reflected, refracted, and turned from their course a thousand different ways, and thus are more evenly diffused over the face of nature. But this is not all; for, by means of the air, the beams of the sun are not only rendered tolerable, and the rays of light more copiously diffused throughout creation, but the advantages of heat and light are 
lengthenèd and prolonged. By the reflective property of this fluid, which must always be in proportion to its density, the heat of the sun, although duly attempered, must be more sensibly and uniformly felt nigh the surface of the earth, than in the higher regions of the atmosphere; while, to its refractive quality, we are beholden for the twilight, or that surpris. ing phenomena of nature, by which we enjoy the real presence of the sun when he is actually below the horizon. For the better understanding of this, let any person put a shilling into a basin, and then retire until he can just observe its outer edge visible over the inner edge of the vessel; in that position let some person fill up the basin with water, the whole shilling, by being seen through a denser medium, will instantly become visible to the person who could only before observe its onter edge.

Were it not for the reflective quality of the air, by which, indeed, the light is parted, we would behold the sun in his splendour, and observe a brightness in that part of the heavens in which he happened to be, but, on turning round, how cheerless would be the prospect! there darkness visible would reign in the heavens, although the stars and planets would glimmer at noon day; and were it not for the refractive property of this fluid, by which the oblique rays of the great luminary are broken off from a straight. course, and turned towards the earth, the transition from the horrors of night to the light of day must have been instantaneous, and, instead of those beneficial harbingers, by which the outgoings of the morn- 
ing and evening are made to rejoice, and the long and dismal nights of the polar regions stript of their horrors, the optic nerves would have been overpowered by the sun rising in all its glory, and the moment he sunk beneath the horizon, the bewildered traveller left to grope in the dark.

Although the air cannot be frozen, or perceived by the eye, for the wise reasons already noticed, yet it is capable of being condensed and rarified to an astonishing degree: so much so, that the air in a house may be compressed so as to be made to enter a cavity not larger than the eye of a needle, and the contents of a nut-shell so expanded as to fill a sphere of unknown dimensions. If an empty bladder, with its neck tied close, is laid before the fire, the heat will so rarify the small quantity of inclosed air, as to make it extend the bladder to its full dimensions, and if not then timously removed, will at last break it with the report of a gun. Sir Isaac Newton thinks the air capable of diffusing itself into above a million of times more space than it before possessed. By these remarkable properties of the air, together with its weight and elasticity, it is admirably fitted for some of its most essential uses, and, perhaps, none more so than for the business of animal respiration; for, in this act, so necessary for the prolongation of life, the air, by its weight and condensing power, is forced and compressed into the lungs, while, by its elastic and expanding property, it is thrown out again in the act of breathing. 
Perhaps some of our readers may be surprised at the bare mention of the weight of a substance, which has been proverbially compared to a trifle for its lightness, and they nay wonder still more when we speak of its elasticity, when they have been taught to consider it an unresisting medium; but what will such think when we boldly assert, that we are literally plunged into a sea of air, and of such gravity and pressure, as to be equal, on the body of a man of moderate size, to the weight of 20,000 lbs? "Tremendous consideration," says the reflective Hervey, " should the ceiling of a room, or the roof of a house, fall upon us with half that force, what destructive effects must ensue! Such a force would infallibly drive the breath from onr lungs, or bieak every bone in our bodies; yet so admirably has the divine wisdom contrived this aërial fluid, and so nicely counterpoised its dreadful power, that we receive not the slightest hurt; we suffer no manner of inconvenience; we even enjoy the load. Instead of being as a mountain on our loins, it is like wings to our feet, or like sinews to our limbs. Is not this common ordination of Providence, thus considered, something like the miracle of the burning bush, whose tender and combustible substance, though in the midst of flames, was neither consumed nor injured?"

But how are we to account for this miraculous preservation?-It is owing to the elasticity or spring of the internal all within all bodies, which, although small in proportion, is wisely made to balance, resist, 
and equiponderate that which is without, notwithstanding the height of its column.

The elasticity and resistance of the air, perhaps, cannot be demonstrated by a more simple experiment than by pressing with the hand on a bladder. with which it is confined; and the weight and pressure of the atmosphere may be explained without the aid of the air-pump, or other philosophical instrument, merely by taking a common saucer, filled with water, and turning down a teacup into it, with a piece of flaming paper inside. As the fire destroys the internal air in the cup, a sort of vacuum will take place, and the pressure of the outward air on the water in the saucer will make it disappear and fill up.

Although, in casting our eyes upwards, we do not observe any boundary to the vast expanse, we are not to consider that the atmosphere is unlimited. On the contrary, we are taught, by the most rational cal. culation, that if it extends much beyond forty-five or fifty miles, it becomes so exceedingly rare, as to be unfit for the purposes for which the lower regions are so well adapted. The atmosphere, at the height of fifty miles, is said to be so rare, that it has no sensible effect on the rays of light At the height of forty-five miles it loses the power of refraction; at forty-one miles it is supposed to be rarified to that degree as to occupy three thousand times the space it does here; and Dr. Gregory observes, that it is generally agreed that there are no clouds at the height of four or five miles. 
It is seldom, indeed, sufficiently dense at the height of two miles to be able to bear up the clouds; so that, to whatever perfection our modern aëronauts may bring the art of balloon-navigation, there is not the smallest probability of their being able to escape from the earth to another planet. The atmosphere has its limits as well as the ocean; and not only are those massy bodies that are made to move in the lower: parts of this great outwork of our globe confined by laws, firm as chains of adamant, but the thinnest vapour, the minutest atom, the most subtile effluvia that ascends the higher regions, and gain, as it were, the outskirts of creation, are checked in their career by the powerful manclate of the Creator, and forced to return and execute his orders.

Happy, indeed, for the world, is this ordination; for, if the philosophic axiom be true that things must continue as at the beginning, with respect to the quantity of matter contained in the universe, and that, if it were possible that a single atom could be lost, the harmony of creation would be destroyed, what direful consequences must ensue, were the daring spirits of adventurous men not confined by unalterable laws, and the imperceptible atoms which float in the atmosphere not laid under restraint by that command which says to the troubled waves of the ocean, " $\mathrm{Hi}$ therto shalt thou come, and no farther."

\section{The Uses of the Atmosphere.}

We have already mentioned several of the uses of this invaluable and all-pervading fluid, in point- 
ing out some of its most remarkable peculiarities; and all we have now to do is, to notice a ferv, and but a very few more, of the many unspeakable blessings and advantages derived from this necessary appendage, which the bountiful Benefactor of the human race has attached to our globe.

The air, in a peculiar manner, may be said to constitute the very essence of which life is mäde. When the Lord created man of the dust of the ground, he breathed into his nostrils the breath of life, when man became a living soul; and the experience of all ages amply testifies, that when men cease to breathe, which is performed by means of the air, they cease to live. Many days, it has been observed, we might live, or even whole months, without the light of the sun, or the glimmering of a star; whereas, if we are deprived only for a few minutes of this aërial support, we sicken, we faint, we die. How thankful, then, ought we to be, that of this indispensable necessary of life no person can deprive us. The treasures of the earth, the verdure of the ficlds, and even the refreshments of the stream, often contribute to the luxuries of the great, while the less fortunate can only behold them as humble spectators; but, in the words of an eminent naturalist, "the air no limitations can bound, nor any landmarks restrain. In this benign element, all mankind can boast an equal possession; and for this we have all equal obligations to Heaven."

It is equally beneficial to all the branches of the animal creation; for, although some creatures dwell 
in the very bowels of the earth, or swim in the unmeasurable depths of the sea, yet it has been demonstrated by experiment, that no sooner are they totally deprived of air than they cease to live. By the same air, also, that preserves animal life, flame is fed and cherished. We all know the utility of fire, and the many inconveniences to which we would be exposed, were we deprived of that necessary element; but without air, in vain would the faggots be piled in a heap, in vain would we apply the lighted torch. Every attempt to set the hearth in a blaze, in order to render our habitations more comfortable during the chilling damps of winter, and every effort to dispel the midnight gloom by the cheering candle. would prove abortive. Take but away the surrounding air, life expires, and the lighted taper goes out in darkness; for even an ordinary candle is said to consume about a gallon of air in a minute.

Plants are also dependent on the air for support and nourishment, and they cannot possibly exist without it. They are continually imbibing fresh nutriment from the atmosphere It is this wondrous fluid that helps to transfuse vegetable vigour into the trunk of the mighty oak, and gives a blooming gaiety to the spreading rose.

And how wisely is its consistence calculated for answering these important purposes! It is neither ton thick nor too thin; too gross nor too attenuated. It rushes with ease into our lungs, in order to inflate them in the act of respiration; it forces its way into the most minute tubes of the vegetable tribes. In 
fact, as Mr. Derham observes, it is a subtile and penetrating matter, "fit to pervade other bodies, to penetrate into the inmost recesses of nature; to excite, animate, and spiritualize; and, in short, to be the very soul of this lower world"

But what is vêry remarkable, this wonderful fluid, so necessary for the existence of bodies, is also made use of as a most powerful agent in the hand of Providence for their destruction. It is a chaos containing all kinds of menstrua, and consequently possessing powers for dissolving all bodies, by which means many things, which would prove nuisances to the world, are put out of the way, and reduced to their first principles

The air, as well as being the medium of light and rision, is also the great vehicle of sound, serving to convey to the ear, by its undulating motion, all that diversily of noise and modulation of tone, necessary to warn us of impending danger, or attract our attention and regard. "As I walk across the streets of London," observes Mr. Hervey, "with my eye engaged on other objects, a dray, perhaps, with all its load, is driving down directly upon me; or, as I ride along the road, musing and unapprehensive, a chariot and six is whirling on with a rapid career, at the heels of my horse. The air, like a vigilant friend in pain for my welfare, immediately takes the alarm; and while the danger is at a considerable distance, despatches a courier to advertise me of the approaching mischief. The air wafts to our senses all the modulations of music, and the more agreeable 
entertainments of refined conversation. When Cleora tunes her song, or the nightingale imitates her enchanting voice; - when wisdom takes its seat on Mitio's tongue, and flows in perspicuous periods and instructive truths amidst the chosen circle of his acquaintance; - when benevolence, associated with persuasion, dwell on Nicander's lips, and plead the cause of injured innocence or oppressed virtue;when goodness, leagued with happiness, accompany Eusebius into the pulpit, and reclaim the libertine from the slavery of his vices; disengage the infidel from the fascination of his prejudices; and so affectionately, so pathetically, invite the whole audience to partake the unequalled joys of pure religion-in all these cases the air distributes every musical variation with the utmost exactness, and delivers the speaker's message with the most punctual fidelity"

The air is also made highly subservient to the sense of smelling. "It undertakes (says the same author) to convey to our nostrils the extremely subtile effluvia which transpire from odoriferous bodies. Those detached particles are so imperceptibly small that they would elude the most careful hand, or escape the nicest eye; but this trusty depository receives and escorts the invisible vagrants without losing so much as a single atom, entertaining us, by this means, with the delightful sensations which arise fiom the fragrance of flowers ; and admonishing us, by the transmission of offensive smells, to withdraw from an unwholesome situation, or beware of pernicious food." 
Thus does the air administer to the senses of seeing and smelling. Happy, however, ought we to account ourselves, that, so often charged with noisome effluvia and noxious vapour's, it does not render these susceptible to the taste; and although it certainly is a body corporeal, and may at times be felt, yet, its resistance in ordinary cases, when it is unagitated and unconfined, is so undistinguishable as to occasion no inconvenience.

The region of the atmosphere is the great thoroughfare to the feathery creation; it is, if we may so speak, the king's highway for the fowls of heaven, where they perform their lengthened journeys with expedition and safety, and range and expatiate beyond the reach of danger. It is by this element, also, that the inhabitant of the waters is enabled to work his little philosophical engine with effect; for, without the aid of this subtile fluid, the empty vesicle would have remained a piece of useless lumber

We cannot as yet say, there go the balloons, as if. the atmosphere, like the sea, had become the established medium of commerce and travelling; but the art has already attained to such a degree of perfection, as render it not improbable that a voyage in the air will be regarded one day, by the generality of mankind, with less awe than was evinced by those who first witnessed the adventurous navigator push his bark out of sight of land, beyond the pillars of Hercules

As all the rivers run into the sea, and deposit their contents in its capacious bosom, so do all the exha- 
lations that arise from terrestrial bodies ascend into the atmosphere. To this capacious alembic take their flight, not only the aqueous vapours that proceed from the sea, the rivers, and moist places of the earth, but the steam or smoke of things melted or burnt; the perspiring fumes of whatever enjoys life; and the effluvia they emit when deprived of it, and in a state of putrescence. How then, it may be asked, is this heterogeneous mass preserved from corruption, and purified from its ofiensive qualities? For, if by respiration, flame, and putrefaction, air is rendered unfit for the support of animal life, there can be no doubt, as Dr. Paley observes, by the constant operation of these corrupting principles, the whole atmosphere, if there were no restoring causes, would come at length to be deprived of its necessary degree of purity.

Among these causes the Doctor mentions vegetation, and agitation with water, both of which have been proved by experiment to have the effect of atmospherical restoratives; for a sprig of mint, corked up with a small portion of foul air, placed in the light, renders it again capable of supporting life and flame; and the foulest air, shaken in a bottle with water, for a sufficient length of time, recovers a great degree of its purity. Here we see the salutary effects of storms and tempests-the yesty waves, which confound the heaven and the sea, are doing the very thing, but upon a larger scale, which was done in the bottle. And, in as far as the lower regions are concerned, these, on account of their wide extension, 
must be attended with most beneficial consequences; but as the sea, for its purity, is not dependent on any one cause, so the atmosphere, besides these external restoratives, will be found to contain, in its own bosom, a correcting principle, which developes itself by its salutary operations, as we shall soon have occasion to notice, in speaking of some of the most remarkable of the phenomena of the atmosphere.

\section{CHAP. XV.}

\section{PHENOMENA OF THE ATMOSPHERE:}

"Of what important use to human kind,

To what great ends subservient is the wind?

Where'er the ærial, active vapour flies,

It drives the clouds, and ventilates the skies;

Sweeps from the earth infection's noxious train,

And swells to wholesome rage the sluggish main!"

\section{The Wind.}

Sometimes there is a profound calm; every wind is hushed; not a zephyr breathes over the face of creation, and not a breeze disturbs the glassy expanse of the lake; but the appearance is deceitful and short-lived; all on a sudden the wind is heard rustling among the branches-it gathers strength as it proceeds, and grows up into the majesty of a storm. Now the raging tempest spends its fury; houses are 
swept from their foundations; navies are rent from their anchors; trees are torn up by the roots. This we eall wind; and whether its effects appear in the fury of the gale, the violence of the hurricane, the impetuosity of the whirlwind, the dryness of the harmattan, the deleteriousness of the sirocco, or the mortifying influence of the samiel, it becomes us not to repine at the dispensations of the Almighty, or account those the most deplorable evils, which are wisely sent us for the best of purposes.

We have already noticed the bad effects that would accrue, were it not for the agitation of the ocean; but more dieadful would be the consequences,

Did neither air nor ocean feel the wind.

Motion is the soul of the universe; it is as necessary in the air as in the ocean, and both are no less indispensable than the motion of the sap of plants, and the circulation of the blood in animals.

It is, however, happily so ordered, that where putrefaction in a state of quiescence would soon prevail, wholesome breezes and salutary gales alternately spring up, to sweep destruction from the aërial fluid, and where heat is felt to an alarming degree, the atmosphere extends its airy wings to fan a fainting world.

"This principle, as Dr. Gregory observes, we find realized on a great scale in what are called the trade winds, which blow constantly from east to west, near the equator. The sun rises in the east Q 2 
and sets in the west, consequently the air will be heated gradually from east to west, and the wind will blow in that direction." The same cause, this author remarks, will explain "the land and sea breezes in the tropical climates ;" and the monsoons, though the theory of them be more complicated, originate in the same cause

And as it is not only necessary that there be a continual agitation kept up in the ocean, by means of the tides and currents, but, in order to prevent its waters from being contaminated by those numerous loads of filth which are, from all quarters, poured into it, it is also requisite that it be furnished with something of a correcting nature, which it has in its saltness. So in the atmosphere, besides the perpetual motion kept up in it by means of the winds, and the beneficial consequences proceeding from vegetation and the agitation of the waters, there must be also some correcting quality, especially prevalent in the upper regions, where a number of the most noxious particles, and a considerable quantity of vitiated effluvia, must ascend, perhaps beyond the reach of the other purifying agents. This, it is probable, is the chief cause of the electric fluid, which, although it is found to pervade the whole mass of creation, is supposed to be much more copious in the upper than in the lower parts of the atmosphere.

In the lower regions of the firmament, indeed, the tremendous noise of the thunder is heard, and the vivid lightnings are seen to flash; but these only hap. pen on extraordinary occasions, or where their pre- 
sence is absolutely necessary to restore the equilibrium of the lower tracts, in the same manner as the tempest is sometimes sent to agitate, in an uncommon degree, the surface of the ocean; but far more frequent, we may suppose, is the busy working of the lightning in the higher regions of the air, although it may be concealed by the density of its lower extremities at times from our view. The glancing of the wild fire, as the vulgar style it, and the playful skip. ping of the aurora borealis, give us sufficient intimation, that, in the silent hours of rest and repose, the great Supreme faints not, neither is weary, but is busily employed in the unceasing operations of his providence, when our senses are locked in midnight slumbers, and refreshing sleep stretches her balmy wings over a fatigued world.

Besides these, which may be called the principal, there are also a number of other fiery meteors. Fireballs, in all the glare of terrific magnificence, are sometimes seen to rush across the hemisphere. Fall. ing stars are observed to shoot with astonishing rapidity. The Ignis-fatuus, Will with-the-wisp, or Jack-with-a lanthorn, as it is called, glides along by the sides of hedges or ditches in moist situations, and sometimes takes up his abode among the graves of the dead, or is seen in the neighbourhood of dunghills; but these, as well as the fiery Dragon, the skipping Goat, the Dart and the Lamp, with every other appearance that the unsubstantial and airy form may assume, may all be accounted for on the principles of electricity. 


\section{Watery Meteors.}

In the regions of the air, a variety of watery meteors are formed. Here are fogs, the creation of those collections of vapours which chiefly rise from fenny, moist places. These become more visible as the light of day decreaseth, and, uniting with those that rise from the waters, so as to fill the air with their humid particles, are called mists. Sometimes, especially in the summer months, our morning walks sparkle with pellucid drops, and transparent globules hang pendant from every leaf, in the form of pearly dew.

In the atmosphere, the balancings of the clouds are preserved, till these swimming lakes are commis. sioned to discharge their contents, not in deluging torrents, confined to particular spots, but in refreshing showers, widely spread abroad in the form of drops of rain. Here, too, that wonderful phenome. non snow takes its rise, which is said to be composed. of such vapours as are frozen while the particles are small; and hail, which is rain frozen, as hoar frost is said to be of the dew. Water-spouts may be reckoned among the number of watery meteors; but, having already been noticed in a preceding chapter, (chap $\mathrm{x}$.) we shall pass them over, and proceed to the consideration of a few of the most remarkable

\section{Celestial Appearances.}

The wonderful and beautiful colours which we ob. serve in the clouds, is owing to their particular situ- 
ation to the sun, and the different modifications under which they reflect his light. The various appearances and fantastic figures they assume, probably proceed from their loose and voluble texture, revolving into any form by the force or activity of the winds, or by the electricity contained in their substance.

But, of all the celestial appearances we can behold, what can be compared to the beauty of the rainbow? What a majestic and stupendous arch does this wonderful phenomenon present to our view, and how beautifully is it tinged in regular order, by all the primogenial colours in nature!

Yet, this gorgeous arch is instantaneously erected, and at no expense: the commission is sent forth, and it springs into existence, merely by the operation of the sunbeams on the watery particles that float in the atmosphere The rainbow, it must be observed, is always seen in an opposite direction from the sun, and that it is occasioned by the reflection and refraction of his rays, at a certain angle or distance from the eyc of the spectator, must be evident to every person who has tried the experiment of the silly boy in the fable, and gone in pursuit of the treasures at the end of it.

Sometimes, too, we have lunar rainbows; but these shine with inferior lustre; and what more can we expect fiom the reflected light of a body, such as the moon that shines itself by reflection? Halos are supposed to be occasioned by the refraction of the light of the sun or moon on the frozen particles that surround them in frosty weather; and what are called 
parhelia, or mock-suns, and paraselenes, or mockmoons, are only representations by the reflection of the face of the true sun or moon from some of the clouds, which are placed at a convenient distance to produce the effect.

\section{The Uses of Atmospheric Phenomena, Meteors, \&c.}

Without entering upon the vast utility of the winds in the world of art, with the many purposes to which they are made subservient and applied, in navigation, agriculture, manufactures, trade and commerce; or recapitulating what we have already said respecting their vast import in the preserving the equilibrium and salubrity of the atmosphere, we will briefly observe, that the wind may be said to act the important part of Nature's great husbandman, by scattering abroad the productive principles of a multitude of plants; and, instead of that imaginary water bearer which the ancients traced out among the stars, the eye of modern philosophy has discovered, in the operations of the wind, a real Aquarius in the heavens, bearing about his precious treasures, and dispensing them where most wanted.

Electricity is, indeed, a most powerful agent in nature, and we are probably but acquainted, as yet, with a small proportion of its wonderful effects; but, from what we do know, we have reason to conclude that the benefits to be rerived from this all-pervading principle are numerous as the appearance it puts on; 
are infinite as its extent. Since the phenomena produced by this fluid have been observed with attention, the true cause of thunder and lightning seems to be ascertained. As the motion of light is almost instantaneous, and that of sound is at the rate of a league in forty pulsations, the distance of thunder may be easily ascertained; for, if we can count thirteen pulsations between the flash and the sound, the thunder will be about a mile off. A means, however, has been invented, by which houses, ships, and other buildings, may be secured from its ravages, and places of the greatest safety, in thunder-storms, pointerl out; but what are the evils experienced from thunder storms, when put in competition with the advantages to be derived from them? What would the atmosphere, it may be observed, become, but for the winds? But, notwithstanding the blessings derived from those wholesome ventilations, what would become of the atmosphere itself, were it not for the loud-roaring thunder, the forked lightning, and all the other varieties of electrical phenomena, which purge the air of those noxious substances that are continually mixing with it, and purify, by fire, the upper regions, where so many light, inflammatory substances, are arrested in their course?

There appears to be a continual circulation going on in the atmosphere, by which the inflammable air, generated between the tropics, is made to ascend, by its lightness, to the upper regions, where, by the motion of the earth, it is urged to the poles; hence, the inflammatory exhalations continually arriving and 
taking fire as they approach, are made to form those beautiful appearances called northern and southern lights, which, although they are oft invisible by the thickness of the weather, at other times amuse the inhabitants, even of our climate, in clear frosty weather; and these merry dancers, as the vulgar call them, are no doubt of infinite service to the people of the polar regions, by imparting a lengthened, if not uninterrupted supply of that light and cheerfulness, of which they would otherwise be deprived during their protracted winter.

Were it not for the beneficial operations of the electric spark, which is always ready at the command of its Maker, to kindle these combustible materials before they become sufficiently accumulated to involve the whole in one universal conflagration, the world, it is probable, would long ere now have been destroyed by fire. There is no occasion (according to the opinions of some theorists) for calling in the aid of a comet to complete this work of destruction. The Almighty has only to suspend the operations of his fiery meteors, and the elements will soon become sufficiently inflammatory to catch fire by a single spark; so that, in fact, those terrific monitors of the gazing crowd, instead of being certain indications that an incensed Deity is about to inflict the effects of his hot displeasure on a guilty world, according to the language of philosophy and the whispers of religion, are rather convincing tokens that " His mercy is not yet clean gone, that the Lord has not forgotten to be gracious." 
The use of fogs and mists on the tender herbs, in the absence of rain, is well known to the grazier and agriculturist; and so sensible was the good man of the land of $U z$, of the importance of what some may reckon among the inferior kinds of watery meteors, (although it is the surest and most universal which the wise Ruler of the world makes use of to render the earth fruitful) that, when he asks the question, "Has the rain a father?" he does not forget to add, "Who has forgotten the drops of the dew?"

From the clouds proceed not only those fertilizing showers that drop down fatness, and the windy currents that, to a surprising degree, agitate the air in warm climates, but, by intervening between the earth and the scorching rays of the sun, they serve as screens to protect from injury the grass and tender herbs, and also act the part of conducting mediums, by which the electric fluid is conveyed not only from the atmosphere to the earth; and fiom the earth to the atmosphere, but from one end of the heavens to the other.

Of all the blessings poured out of the treasures of Providence, there is none, perhaps, of which man is more sensible than that of rain. What an alteration on the face of the earth does a seasonable shower produce! No wonder that the Psalmist, when contemplating such a scene, breaks out in such language as this: "Thou visitest the earth and waterest it: thou makest it soft with showers: thou blessest the sprinkling thereof: the little hills rejoice on every side: the pastures are clothed with flocks: the val- 
lies also are covered over with corn ; they shout for joy, they also sing." Nay, the very manner in which this blessing is made to descend, claims at once our admiration and gratitude; for, in general, the rain descends in gentle showers, but, in the case of thunder, there is an exception, when it pours down with impetuosity and in torrents; but let it be remarked, that here it acts the part of a life-preserver; for, when once wet, our clothes become excellent conductors to carry off the electric fluid to the earth.

Even frost and snow have their uses. Hail is known to cool the air in summer; and experience has demonstrated, that " nature could not give a better covering than snow to secure the corn, the plants and trees, from the effects of cold in winter; and if a frost succeeds after a ploughed field has been well watered by the autumnal rains, the particles of the earth dilute and separate, and the spring then completes the making the earth light, moveable, and fit to receive the kindly influence of the sun and fine weather."

Water-spouts at sea seem to proceed from the same cause as whirlwinds upon land, and if these serve the purpose of carrying up the superabundance of the electric fluid from the earth to the atmosphere, as is with good reason supposed, their utility, in the economy of nature, must be apparent.

With regard to those illusory appearances that we behold in the heavens, do they not teach us in a language plain, evident, and forcible, how easily we may be deceived by our senses, and of the conse- 
quent importance of placing our actions under the guidance of that reason which distinguishes man from the brute creation, and was kindly given him as a lamp to his feet, and a light to his path?

'Tis Reason our Great Master holds so dear;

'Tis Reason's injured rights His wrath resents;

'Tis Reasons's voice obey'd His glorious crown;

To give lost Reason life, He poured his own.

\section{CHAP. XVI.}

CHANGES OF THE SEASONS, AND VICISSITUDËS OF DAY AND NIGHT.

"These, as they change, Almighty Father these Are but the varied God. The rolling year Is full of Thee !"

The Earth, surrounded by the Atmosphere, remains not at rest ; for, as we observed in a preceding chapter, the latter is made to revolve with the former in its diurnal motion, and to circle with it in its annual course.

Before procecding farther in our researches, we will therefore, turn our attention for a few minutes to this two-fold motion of the earth, which although it would not, but for external objects, be perceptible to our senses, is rendered extremely important, on account of the beneficial effects it produces. 
"Of all the effects resulting from this admirable scene of things," says Bonycastle, "nothing can be more pleasing and agreeable to a philosophic mind, than the alternate succession of day and night, and the regular return of the seasons. When the sun first appears in the horizon, all nature is animated by his presence; the magnificent theatre of the universe opens gradually to our view, and every object around us excites ideas of pleasure, admiration, and wonter. After riding in all his brightness through the vault of heaven, he is again hidden from our sight; and we are now presented with a new spectacle of equal grandeur and sublimity. The heavens are on a sudden covered with innumerable stars; the moon, rising in a clouded majesty, unveils her peerless light; whilst the silent solemnity of the scene, fills the mind with sentiments and ideas beyond the power of language to express.

"Variety is the source of every pleasure; and the bountiful Author of Nature, in the magnificent display of wisdom and power, has afforded us every possible means of entertainment and instruction.What a pleasing succession of scenes results from the gradual vicissitudes of the seasons! Summer, Winter, Spring, and Autumn, lead us insensibly through the varied circle of the year; and are no less pleasing to the mind, than necessary towards bringing to maturity the various productions of the earth. Whether the sun flames on the tropic, or pours his mild effulgence from the equator, we equally rejoice in his presence, and adore that Omniscient 
Being, who gave him his appointed course, and prescribed the bounds which he can never pass."

But how is this pleasing and useful variety produc: ed?-How is this perpetual succession of Day and Night, of Spring and Summer, of Autumn and Winter, kept up? It is by means simple, but evidently striking, to the man of science and discernment. By the revolution of the earth on its axis, once in twentyfour hours, we have the alternate succession of day and night;-by its annual circuit round the sun, together with the inclination of its poles (lying always in the same direction) to the plane of its orbit, we experience all that variety of season, which is so indispensibly necessary for the springing up, ripening, and in gathering of the fruits of the earth.

By this constitution of things, that part of the earth's surface which is turned towards the sun, must have the largest share of his visible presence at the time; hence, when the earth is south of that luminary, the inhabitants of the regions north of the equator, must have their summer; and, on the contrary, those who dwell in the southern latitudes, must have their winter: but reverse the case, and suppose the earth in that part of her orbit which is north of the sun, and the inhabitants between the equator and south pole must have their longest days, while those who dwell on the opposite side, of course must have their shortest. At the equinoctial points; the axis of the earth being parallel to the sun, and neither turned in to, nor out from him, it necessarily follows, that at those precise times, and no other, 
the days and nights must be equal throughout the globe; for the instant that the north pole gets beyond the vernal equinox in spring, it emerges into the sun's light, and the people who inhabit the arctic regions, have six months of perpetual day; while those at the south pole, or contrary extremity of the earth, have an equal duration of protracted night. At the opposite season of the autumnal equinox, the reverse takes place. In the intermediate spaces between the poles and the equator, the inhabitants experience all that vicissitude of light and shade, to which their situations expose them; and which, in the absence of a globe, may be tolerably well illus. trated by suspending a large wooden bowl from the hand, and making it revolve round a lighted candle, with its axis inclined a little to one side, and pointing always in the same direction. If, at the same time, this bowl could be made to turn incessantly round on its axis in the progress of its revolution, it would afford a pretty accurate idea how the vicissitudes of day and night are produced.

Let us attend a little to some of the beneficial consequences of this " ever varying, ever changing scene." Spring is characterized as the season of the renovation of nature ; in which animals and vegetables, excited by the kindly influence of returning warmth, shake off the torpid inaction of winter, and prepare for the continuance and increase of their several species. "A soft and pleasing languor, interrupted only by the gradual progression of the regetable and animal tribes towards their state of 
maturity, forms the leading character of Summer. In Autumn the promise of the spring is fulfilled. The silent and gradual progress of maturation is completed, and human industry beholds with triumph the rich production of its toil. The unvarying symptoms of approaching Winter now warn several of the winged tribes to prepare for their aërial voy. age to those happy climates where no deficiency of food or shelter can ever distress them; and, about the same time, other fowls of hardier constitutions, which are contented with escaping the iron winters of the arctic regions, arrive to supply their place. From the fall of the leaf, and withering of the herb, an unvarying, death-like torpor oppresses almost the whole vegetable creation, and a considerable part of the animal, during this entire portion of the year: but this state is not always to continue; it is a time of renovation and refreshment:- a time shall come, when many that sleep in the dust shall awake, and shine forth gloriously at the return of spring.

Day is the season of labour and activity; Night is the time for rest and repose. Man goeth forth to his labour in the morning, and returns to recruit his exhausted powers in the evening; and what an admirable provision for this purpose is sleep, which introduces a most welcome vacation, both for the soul and body, during which the exercises of the brain, and the labours of the hands, are at once discontinued.

These are some of the inestimable blessings derived from the changes of the seasons, and the alter- 
nate succession of day and night; but to man they speak also a moral lesson.

"s Behold, fond man!

See here thy pictur'd life; pass some few years Thy flow'ring Spring, thy Summer's ardent strength, Thy sober Autumn fading into age, And pale concluding Winter comes at last, And shuts the scene. Ah! whither now are fled Those dreams of greatness! Virtue sole survives, Immortal, never-failing friend of man."

46 Each night we die, each day are born anew."

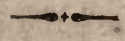

\section{CHAP. XVII.}

\section{THE MOON.}

"As when the moon, refulgent lamp of night, O'er heaven's clear azure sheds her sacred light, Then shine the vales; the rocks in prospect rise; A flood of glory bursts from all the skies."

From the earth and the atmosphere we will now ascend in our speculations, and, in our way to regions more remote, turn aside a little and consider the Moon.

The first thing that strikes our attention in viewing this resplendent luminary, is the opacity of her substance, and diversity of her shades. The Moon is not, of herself, a luminary, but shines by the bor- 
rowed or reflected light of the sun, and her face, instead of being too dazzling to behold, presents, like the earth, a dark unequal surface, pleasantly diversified with hills and vallies, mountains and cavities. Seas and lakes have also been exhibited as adorning this body, by the constructors of some maps of the moon; but the powerful glasses of Dr. Herschel are said to have dissipated such delusions; and, as it appears from the clearness of her disk, and the circumstance that, when any star approaches her, it retains its lustre till it touches the very edge, and then vanishes in an instant; that the moon has no atmosphere, there is the less probability that there are lakes and seas, from which clouds and other atmospheric phenomena are formed.

\section{The Phases of the Moon,}

And the circumstance of her having always the same face turned to us, are very rationally accounted for as follows:-The moon is known to have a twofold motion; the one she performs round the earth in the time of a lunar month, and the other she performs round her own axis in exactly the same period. By the latter motion, she naturally behoves to turn al. ways the same face to the earth; and, by the former, her various phases are produced. When that part of the moon which is illuminated by the sun, is turned wholly towards the earth, we then see one of her sides, round and fully enlightened, and in that situation we say we have a full moon; when the side 
illuminated is turned from us, by being between us and the sun, she becomes totally invisible, and then we have the change; when, shortly after, the enlightened part re-appears, we call it the new moon; and when it exhibits a half-enlightened aspect, the moon is said to be in her first or last quarter, according to the time of her age. These appearances, with all the intermediate stages, will be pretty correctly represented by moving the bowl, formerly alluded to, round the flame of a candle, when suspended by a string, and observing in what manner the light is reflected from its surface, according to the various positions in which it is placed in the course of its circuit,

\section{Eclipses.}

There are no phenomena better understood by modern astronomers than the nature of eclipses; and so far is there from being any thing supernatural or mysterious in them, that were the orbit of the moon perfectly parallel, or in the exact plane of the earth, there would be an eclipse of the moon at every full, and of the sun at every change; for there is not a doubt that an eclipse of the moon is occasioned by the dark body of the earth happening to be in a line between the sun and the moon, when the moon is in a direction opposite to the sun; while an eclipse of the sun is caused by the dark body of the moon passing between the earth and the sun, when she is in that part of the heavens. That eclipses do not more frequently happen, arises from the orbit of the 
moon being wisely made to incline to that of the earth at a small angle; by which, although they sometimes take place, it is so unfrequent, as not to exceed, at the average, four in the year ; and of these, two only may be expected visible at any particular place.

\section{The Harvest-Moon.}

In the path which she describes in the heavens, the moon is made to rise every day later than she did on the preceding; but the exact period between the time of her rising differs so considerably in different seasons of the year, that although in the spring she is an hour and twenty minutes later in rising one day than she was on the preceding, the difference in autumn is so inconsiderable, as scarcely to be perceived for several days together. No sooner does the sun set towards the middle of September, than the moon immediately rises in her glory for several days, by which the day is considerably lengthened out in that most important of all seasons; and Nature, as it were, points to the husbandman to make the best of his time in cutting down and securing his crops before the equinoctial gales and storms of winter set in. This wonderful phenomenon, although too little attended to by us, has been distinguished, in different ages of the world, by different appellations, accord. ing to the favourite occupations and pursuits in which mankind happened to be engaged at the time; being first called the Hunter's, then the Shepherd's, and now the Harvest-Moon. 
About the equator, where there is no variety of seasons, the moon rises, with the greatest regularity, about forty-nine minutes later every day than on the preceding; but as we advance north or south from that line, and get in a more variable climate, the little difference in the rising of the Harvest Moon becomes more perceptible. At the polar circles, where the mild season is very precarious, and of short duration at that advanced season of the year, the autumnal full-moon rises at sunset, from the first till the third quarter; and, at the poles, where the sun is half a year below the horizon, the winter full-moon shines constantly from the first to the third quarter.

In these respects the moon, that faithful companion and attendant on the earth, may be said to proportion her services to the emergency of the occasion; but even in the ordinary aid she affords, in the absence of sunshine, her influences are of infinite advantage. The Hebrews, the Greeks, the Romans, and, indeed, the ancients in general were wont to assemble, at the time of the new moon, to discharge the duties of gratitude and devotion. The oldest measure of time, taken from the revolutions of the heavenly bodies, is supposed to be a month; and when the king of the Pelew Islands entrusted his son to the care of Captain Wilson, he inquired how many moons would elapse before he might expect his return.

By the dark, opaque, and unequal surface of the moon, the light of the sun is reflected to the earth, after that superb and glorious luminary has left our 
hemisphere to visit other climes; and what a tran. scendantly magnificent spectacle does a moonlight scene present, independent of the incalculable blessings it is made to produce. How welcome are the harbingers of this bright luminary to the toiling traveller, when almost fainting under his unremitting, but fruitless exertions, to gain the goal of his journey before the close of the day. How comfortable to the bewildered mariner as he ploughs the deep on an unknown coast; and how cheerful to the lonely shepherd, as he tends his fleecy charge in the otherwise deep gloom of some sequestered valley, or tunes his midnight pipe among the solitary tops of his native mountains. Even on the mighty ocean the moon extends her influence; the waves of the sea are swollen and lifted up by the energy of her power; and it is far from being improbable, that what has such an effect upon this great fluid mass, may not also make some very important and sensible impressions on that atmosphere, in whose agita: tions and changes we are so much interested.

\section{CHAP. XVIII.}

THE SUN.

"Great source of day! best image here below Of thy Creator, ever pouring wide,

From world to world, the vital ocean round;

On nature write with every beam His praise."

From the earth and its companion, the moon, we will now direct our attention to yonder radiant orb, 
which fills the heavens with his rays, and cheers the earth with his presence The Sun is, indeed, a most glorious luminary; and is, without doubt, the most perfect image of his great Creator that we can behold aniong inanimate beings; and, indeed, so nigh, in one respect, does he resemble his Maker, that of the Sun it may be said that he, also, is

"Too glorious to be gaz'd on in his sphere."

It is no wonder, then, that the fallen reason of idolatrous nations " should mistake so fair a copy for the adorable original," and that philosophers should be divided so much in their opinions respecting his substance. In one thing, however, even from the imperfect glance we have been able to procure of this glorious body, it is found to differ from, and to fall infinitely short of, its Creator; for the Sun has his spots, while He, who made the Sun, is

"Light itself,

Pure, spotless, uncreated light, ineffable."

According to Dr. Gregory, " the sun is very generally considered as composed of the matter of light and heat, whether these are to be regarded essentially the same or not:" but he is careful how he expresses himself, even in this cautious manner of declaring his sentiments ; for he adds, "perhaps it will be speaking more correctly to say, that he is the source of both, and that he both warms and enlightens the bodies which surround him." The sun is, 
indeed, the great fountain of light and heat, and it is amazing to think with what rapidity of motion he sends forth his rays to illumine and cherish the world; for so great is the distance of this bright body from us, that, were the motion of light no swifter than a cannon ball, it would take, according to the computation of philosophers, thirty-two years in arriving at the earth; and, were it no swifter than sound, it would take upwards of seventeen years; but light flies with such incredible velocity that it arrives at the earth in about seven or eight minutes, being at the rate of no less than 200,000 English miles in a second of time. By this means the inconvenience that would result from a slower progress of light is obviated, and the kindly effects of this inestimable and indispensable blessing are conveyed to us in an instant.

The rays of the sun are not sparingly dispensed, nor come to us as from a niggardly hand. The rays of light are copiously diffused, and in sufficient abundance to chase away the most minute vestige of the shades of night. 'The extension of light is a most valuable property of that great and invaluable bless. ing; for it is by it that we are enabled to see bodies at a distance during the day, and, by the same operating cause, the mariner, during the hours of darkness, observes the fiery beacon glimmering from afar.

The heat of the sun is also most potent in its operations. With ease it penetrates into the bowels of the earth, and finds its way into the most secret recesses of nature; so that, in the expressive language of Scripture, "there is nothing hid from the heat 
thereof." But, indeed, what could possibly exist without it? The sun may be truly styled the grand enlivening principle of the universe; without his infuence, the crimson tide behoved to stagnate in the veins of animated beings; "the trees could never break forth into leaves, nor plants spring up into flowers;" we would no more behold the meadows mantled over with green, nor the vallies standing thick with corn; or, to speak in the beautiful language of a prophet, "No longer would the fig-tree blossom, nor fruit be in the vine: the labour of the olive would fail, and the fields would yield no meat: the flocks must be cut off from the fold, and there would be no herd in the stall." It penetrates the beds of metal, and finds its way to the place of sapphires. In short, the beneficial agency of this magnificent luminary is inexpressible.

The sun is also the fountain of cheerfulness. While all nature is enlivened by his presence, it is also - cheered by his gifts. "Truly," says Solomon, "the light is sweet, and a pleasant thing it is for the eyes to behold the sun." And the author of " The Spectator" has well observed, that the sun has a particular influence on the mind of man, and making the heart glad; for a proof of which, he refers us to a consideration of the natural world, when this luminous globe withdraws his rays, for a few moments, by an eclipse

The human mind delights in variety; and one great cause that produces cheerfulness in the heart of man, as he walks abroad and contemplates the 
face of nature, is no doubt that diversity of light and shade, of colour and hue, that in every direction salutes his eye. In this respect, also, the sun may be said to be the fountain of cheerfulness, as it is certainly the cause of colour. The sun is the great limner of nature, whose beautifying rays paint creation. "The blushing beauties of the rose, the modest blue of the violet," as Groldsmith observes, "are not in the flowers themselves, but in the light that adorns them. Odour, softness, and beauty of figure, are their own; but it is light alone that dresses them up in those robes which shame the monarch's glory."

The sun may, therefore, also be well styled the fountain of colour; and, bat for this, what disadvall. tages would we labour under, notwithstanding the beneficial distribution of light and heat! In that case, we would not only be unable to distinguish objects at a distance, and to perceive the colour of tho raiment of our nearest friends, but be incapable of observing any difference of complexion between the ink that flows from our pen, and the paper on which we write. Without this discriminating property of light, no pleasing variety would overspread the great carpet of nature; the same unvaried hue, in every direction, would meet our eye; the same dull uniformity would every where prevail.

Such are some of the beneficial consequences that result from the sun, with respect to the earth. We shall now consider him in another and a more exalted light, as the centre of the Solar System.

\section{s 2}




\section{CHAP. XIX.}

\section{TILE SOLAR SYSTEM.}

"Obscrve how regular the planets run,

In stated times their courses round the sun :

Differ ent their bulk, their distance, their career, And diff'rent much the compass of their ycar;

Yet all the same eternal laws obey,

While Go D's unerring finger points the way."

From the consideration that, by the laws of nature, all the lesser heavenly bodies are made to revolve round the greater, in the same manner that the moon is made to move round the earth, it was to be expected that the sun, the centre of a system in which so many planetary and cometary bodies were made to move within the sphere, or verge, of his attraction, would be a body of very considerable magnitude; and that he is said to be of such an extent, that his solid bulk is computed to be sixty-four millions of times bigger than the moon, a million of times bigger than the earth, or five hundred times greater than all the other planets put together!

From what we ourselves experience of the benefits of this luminary, we have reason to conclude, that the sun is placed in the most convenient situation in the heavens, and at the most suitable distance from each of the respective bodies which move around him; and that, however nigh or remote their courses may be to the common centre, or however slow or rapid in their movements, the inhabitants of all those bo. 
dies which are inhabited, will have forms and powers no less suited to their situations than ours,

"And constitutions fitted for that spot,

IVhere Providence, all-wise, has fix'd their lot."

The sın, although generally considered as fixed, is known, by his spots, to make a revolution on his axis in somewhat less than our month, and is likewise said to be agitated by a small motion round what is called the centre of gravity of the Sular System His motion, however, is so comparatively small, that he may, indeed, be said to be fixed, with respect to

\section{The Planets.}

Of the planets which have yet been diseovered, the first, or nighest the sun, is Mercury His diameter is computed to be less than the half of that of the earth, and his year is not quite so long as three of our months: the light and heat of this planet are supposed to be about seven times greater than the earth receives; yet he is said to move at the rate of more than 109,000 miles in an hour! Being so nigh the sun, Mercury is seldom seen; but when he is, it is a little after sunset, and before sunrise, and he appears to emit a bright white light

The diameter of Venus is somewhat less than that of the earth, and her year is not quite eight of our months. In the heavens she moves next in order to Mercury, and, notwithstanding she is supposed to 
be surrounded by an atmosphere like the earth, her light and heat are said to be twice as much as ours. Like the sun, this brilliant planet has her spots ; like the moon, she has her phases, and she moves at the rate of upwards of 80,000 miles an hour! Venus appears in the heavens the brightest of all the planets, and, according as she is situated, is sometimes called the Morning, and sometimes the Evening Star. What is called the transit of Venus, is the passing of this planet over the sun's face, which happens only twice in about one hundred and twenty years.

Next to Venus comes our Earth, attended by her constant companion, or satellite, the Moon. The diameter of the Earth nay be computed to be about 7,964 miles, her distance from the sun ninety-five millions of miles, and, moving at the rate of 68,000 miles an hour, she completes her annual revolution in 365 days and somewhat less than six hours, all the while whirling round on her axis, once in twenty. four hours, with such velocity that the inhabitants of the equator are carried round at the rate of 1,045 miles, and those in the latitude of London about 64.4 miles in an hour.

We have already explained several of the phenomena resulting from the motion of the Earth; but there is one astronomical fact we will here mention, which may sound strange in the ears of some of our readers, viz. that we are actually nigher the sun in winter than in summer! Were it not for this, it is presumed that the severity of our winters (being chief- 
ly occasioned by the obliquity of the sun's rays, as they, at those seasons, fall on our atmosphere) would be rendered still more intolerable and severe.

The magnitude of the Moon is said to be about one-fiftieth of that of the Earth, about which she moves at the distance of 236.847 miles, and completes her revolution in somewhat less than twenty- eight days, travelling at the rate of 2,270 miles an hour.

Mars, whose diameter is little more than one half of our Earth, moves next her in the order of the planets: he completes his revolution in something less than 687 of our days; so that his year is nigh twice the length of ours, while his light and heat are considered to be not quite the half of what we enjoy: Mars revolves at the rate of 55,223 miles an hour, and appears in the heavens of a dusky red colour.

What are called the New Planets are to be found between the orbits of Mars and of Jupiter; but as so little is yet known respecting them, we shall just mention their names, with the dates of their disco. veries:-Ceres was discovered by M. Piazzi in Sicily, on the 1st Jan. 1801; Pallas was discovered by Dr. Olbers, of Bremen, on the 28th of March, 1802; Juno was discovered by Mr. Harding, of Lilienthal, Bremen, 1st Sept. 1804; and Vesta was discovered by Dr. Olbers, 29th March, 1807. These being so very small, in comparison with the others, Dr. Herschel does not deign to denominate them planets, but Asteroids. 
But very different is the case with Jupiter, which is the largest of all the planets, and adorned by his belts, attended with his glorious reinue of four moons, comes next in order in the heavens. The magnitude of this stupendous planet is, indeed, said to be no less than 1400 times larger than the earth: his year is something less than twelve of ours, and he moves at the rate of 29,894 miles in an hour. In. consequence of his distance from the sun, his light and heat are computed to be only about one twentyseventh of what the earth receives, but the former of these may be compensated by the number of his moons; by one or more of which, there is scarcely any part of this planet but what is enlightened during the whole night, except his poles, and there is no saying, but what has the appearance of Jupiter's belt, may be something of an atmospheric nature, so constituted as to imbibe, and considerably increase, the heat of the sun's rays. Jupiter, in the heavens, appears to the eye next in magnitude to Venus.

Beyond the orbit of Jupiter moves Saturn, attended by a retinue of no less than seven satellites or moons, and having his body surrounded by an interior and exterior ring. Although the diameter of this planet is not so large as Jupiter, his magnitude is said to be no less than 966 times that of the earth, and, moving at the rate of 22,072 miles in an hour, he completes the revolution of his wide circle in a period not much less than thirty of our years.

The light and heat which he receives from the sun, are computed to be about one hundredth part of what 
the earth receives; but, to compensate for this, besides the rings and moons already mentioned, the disk of this planet has been observed to be crossed by zones or belts, which may be analogous to, and answer the purposes of, those of Jupiter. Saturn is visible to the naked eye, and shines in the heavens with a pale, feeble light.

The Georgian, or Georgium Sidus, is the remotest of all the planets yet discovered, and was brought to notice so recently as the 13th of March, 1781, by that indefatigable astronomer, $\mathrm{Dr}$ Herschel. Six satellites have already been discovered attending on this distant planet Its magnitude is supposed to be upwards of eighty times that of the earth, and its periodical revolution performed in something more than eighty three of our years. Through a telescope of a small magnifying power, the Georgian appears like a star of the sixth or seventh magnitude, and is only visible to the naked eye, in the absence of the moon, in a clear night.

These planets, with their attendant satellites and other appendages, are carried round the sun in elliptical orbits, differing but little from circles; by which means the temperature of their seasons must be wisely proportioned, and pretty equally kept up. To prevent too frequent eclipses, they move not in the same planes; and that they may not interfere with each other, they revolve all in the same direction, from the east away westerly. The greater part of them are known, and the whole are supposed to turn round on their axis in the same manner that our earth 
does, by which means they must also be favoured with the alternate succession of day and night; and as the revolution of the satellites of Jupiter is known to a nicety, there can be no doubt but those planets, which have such attendants, are equally benefitted by them. Of the spots of Venus and of Mars, the belts of Jupiter and rings of Saturn, we can say little; but let it be remembered that we are surround. ed by an atmosphere, the appearance of which may not easily be accounted for by the inhabitants of those distant bodies. That the planets are inhabited, we have every reason to believe, from the provision that is made for their comfort, and other analogy they bear to our own inhabited globe. It is true, that our views and discoveries respecting those distant orbs, must be imperfect and limited in this present state; but what we know not now, we may, perhaps, know hereafter; although it is not to be supposed that our finite capacities, even in a more exalted state and enlarged sphere of vision, shall ever be able fully to eomprehend the mighty works of the Creator of the Universe, or utter forth all His praise.

\section{CHAP. XX.}

\section{COHETS.}

"Hast thou ne'er seen the comet's flaming flight ?"

Besides the planets and their satellites, there are other bodies called Comets, which revolve round the sun in very eccentric ellipsis, and in all manner of 
directions. These comets, in one part of their orbit, called the perihelion, approach very near the sun, and appear all in a blaze: this appearance, however, they gradually lose, as they fly off, with inconceivable rapidity, to the opposite part of their orbit, called, by astronomers, their aphelion; there they are totally divested of their luminous tail, and, being at such an immense distance from the sun, it is concluded they must experience a degree of cold, of which we can have no adequate conception. There are a variety of opinions as to the number of comets belonging to our system: Riccioli enumerated 154; others assert that 450 had been seen previous to 1771 : the tables of Berlin estimate them at 700 , and some have even supposed that there are millions. And, as these bodies appear but seldom, and their stay is so short, it is not surprising that so much ignorance should prevail respecting them. It is, however, now sufficiently ascertained, that these, like the planets, shine not by their own, but by a reflected light; and, were it not for the sun, these bodies, instead of alarming our fears by their glaring magnificence, would move unseen and unheeded by us; for, however naturalists may have differed respecting the composition of their tails, it seems now to be pretty well understood that they possess nothing fiery or combustible in them, and may, with more propriety, be likened to the mild radiance that proceeds across the street from the illuminated glass in an apothecary's window in a dark night, than to any thing of a baneful or pestilential nature. 
There is one thing to be remarked with regard to the tails of comets, that they appear always in a direction averted from, or contrary to, the sun; and this certainly, with the circumstance of the stars being visible through them, gives colouring to the supposition that they are nothing more than merely a condensation of the solar rays, by the refracting power of the comet and its atmosphere.

With regard to the purposes for which comets were created, "all is doubt, uncertainty, and conjecture." Some have supposed they are the means, appointed by the Almighty, for putting a period to the planetary world; others have imagined that comets, in their several revolutions, gradually approach the sun, till at last they fall into it, and become a supply of fuel to that luminary; and some of the learned world, Dr. Mavor remarks, are of opinion, that they are places of future punishment for tormenting the damned with eternal vicissitudes of heat and cold; " but when, on the other hand," as the Doctor goes on, "we reflect on the infinite power and goodness of the Deity, the latter inclining, the former enabling him to make creatures suited to all states and circumstances; that matter exists only for the sake of intelligent beings; and that, wherever we find it, we always perceive it pregnant with life, or subservient to that purpose; when we consider the numberless species, the astonishing diversity of animals, in earth, air, water, and even on other animals ; every blade of grass, every tender leaf, every natural fluid, swarming with life, and every one of these enjoying such 
gratifieations as the nature and state of each require; when we further reflect that, some centuries ago, a great part of the earth was judged uninhabitable, till experience undeceived us; the torrid zone, on account of excessive heat; and both the frigid zones, on account of excessive cold; it scems highly probable, that such numerous and large masses of durable matter as the comets are, not however, dissimilar to our earth, destitute of beings capable of contemplating with wonder, and acknowledging with gratitude, the wisdom, symmetry, and beauty of the creation, which is more plainly to be observed in their extensive tour through the heavens than in our confined circuit: yet, however difficult it may be for us, circumstanced as we are, to discover their particular designation, this is an undoubted fruth, that, wherever the Deity exerts his power, there, also, he manifests his wisdom and goodness."

If, in addition to these judicious remarks of the learned Doctor, we take it into consideration that the vast rapidity of their movements, when in their perihelion, or part of their orbit nighest the sun, and the comparatively slow progress they make as they recede from him, till their motion is so languid as to be scarcely perceptible at their aphelion, or farthest distance from him, may not suffer these bodies to undergo such an alternate extreme of heat and cold as would otherwise have been the case, the probability is still the greater that comets are inhabited, especially if we make a proper allowance for the powerful effect of such an atmosphere as they may 
be surrounded with, for attempering the sun's rays as they fall more directly or obliquely upon it. And we have an example of this in what we ourselves experience in winter, when our situation is nearer to the sun than it is in summer.

But whatever uses these eccentric bodies are of otherwise, the astonishing courses that the comets perform in empty space, suggest to our minds an idea of the vast distance between the sun and the nearest fixed stars, of whose attractions all the comets must keep clear, in order to return periodically and move round the sun, and, consequently, of the infinite greatness of that Being, who has stretched out the heavens like a curtain, and afforded such ample scope for all those numerous orbs. "I cannot forbear re. flecting," says the author of the Guardian, " on the insignificance of human art, when set in comparison with the designs of Providence. In the pursuit of this thought, I considered a comet, or, in the language of the vulgar, a blazing star, as a sky-rocket discharged by a hand that is Almighty. What an amazing thought is it to consider this stupenrlous body traversing the immensity of the creation with such a rapidity, and, at the same time, wheeling about in that line which the Almighty had prescribed for it! How spacious must the universe be, that gives such bodies as these their full play, without suffering the least disorder or confusion by it! What a glorious show are those beings entertained with, that can look into this great theatre of nature, and see myriads of such tremendous objects wandering through those 
immeasurable depths of ether, and running their appointed courses! Our eyes may hereafter be strong enough to command this magnificent prospect, and our understandings able to find out the several uses of these great parts of the universe; in the meantime, they are very proper objects for our imagination to contemplate, that we may form more extensive notions of infinite wisdom and power, and learn to think humbly of ourselves, and of all the little works of human invention."

\section{CIIAP. XXI.}

THE FIXED STARS.

"This prospect vast, what is it ?-Weigh'd aright,

'Tis Nature's system of Divinity;

And ev'ry student of the night inspires.

"Tis elder scripture writ by God's own hand."

What a glorious prospect does night unfold when she draws aside her sable curtains, and displays to the contemplative mind the azure canopy of the heavens bedecked with stars! We need not wonder at the expression of the poet:

“ Devotion! daughter of Astronomy!

An undevout astronomer is mad!"

For who can take even the most transitory glance of these glowing beauties, on a fine frosty evening, 
without feeling something of that indescribable impulse which every good man must feel when casting his eyes to the nocturnal heavens? "Something, like magie," says the pious Hervey, "has struck my mind, on a transient and unthinking survey of the etherial vault, tinged throughout with the purest azure, and decorated with innumerable starry lamps. I have felt, I know not what powerful and aggrandizing impulse, which seemed to snatch me from the low entanglements of vanity, and prompted an ardent desire for sublimer objects." What, then, must be his sensations, who, by means of the "sight-invigorating tube," and the lights of philosophy, is led to explore the upper regions of this celestial canopy, which the Creator has so distinctly marked with the wonders of his power!

The first thing that strikes a superficial observer, is the apparent multitude of these heavenly hosts; but this will be found to be an illusion, and probably is occasioned by their twinkling, and th? confused manner in which, by their distance, they are made to appear; for, strange as it may sound in the ears of the unlearned, the stars that are visible in our hemisphere to the naked eye, even in the most favourable weather, do not amount, in any one time, to one thousand. But let it not be imagined that, in mentioning this, we mean to derogate from the glory of the Almighty, as it is revealed in the heavens, or by any means wish to insinuate that the number of the stars is within the sphere of our finite powers and capacities to calculate. - No; as the more we descend 
downwards in our researches among the animalcule creation, the more evident traces of divinity we discover; so the more we extend our discoveries upwards into the regions of the universe, the more do we observe of the glory of God.

'i'he heavens, indeed, declare the glory of God in a most emphatic manner; and the important invention of the telescope, aided by modern improvements, has brought systems and worlds to light, that were not dreamt of by the ancients. The heavens of Thales and Hipparchus were poor and thinly sown, indeed, when compared to fliose of Tycho, Brahe and Flamstead; but what were even these to what the wonderful instruments of Dr. Hersehel has brought to notice? Every new discovery of this indefatigable astronomer has tended to the glory of his Maker, and every increase of magnifying power has served to confirm the sublime truth, that " the stars of heaven cannot be numbered"

The Milky Way, or that white, luminous tract, which we observe in the heavens, is found to derive its appearance from the number of stars of which it is composed. No less than forty little stars are said to be in the Pleiades alone; and in the constellation of Orion, a number has been discovered, by far exceeding what can be observed by the naked eye in the whole heavens.

From an attentive examination of the stars with a good telescope, many which appear perfectly formed or single, to the naked eye, have been found to consist of two, three, or more stars; and Dr. Herschel, 
by the help of his glasses, is said to have discovered near 700 such stars. Besides these, the Doctor has observed other appearances in the heavens, which he calls Nebuloe or cloudy stars; being apparently surrounded by a faint, luminous substance, of considerable extent; of these he has given us a catalogue of 2000, which he has described, and is of opinion that the starry heavens are replete witl: nebulo.There are also several little whitish spots which appear magnified, and more luminous, when seen through telescopes, yet without any stars being distinguishable in them.

When, to these grand, magnificent, and numerous appearances in the heavens, we add those wandering stars, or planetary bodies we have just been considering, which, according to the appearances they put on, are denominated as stars of different magnitudes, together with that host of cometary orbs which occasionally appear and disappear from our hemisphere, who can forbear exclaiming:

“ This gorgeous apparatus! this display!

This ostentation of creative power!

This theatrc; - what eye can take it in?

By what divine enchantment was it rais'd?

How boundless in magnificence and might !"

The fixed stars are so called to distinguish them from the planets, and other wandering bodies, that move among them; for, in respect to these, they seem to be fixed, and, with regard to each other, they do not appear to change place. Thus, while the pla. 
netary bodies are not to be found in precisely the same place for any two successive days together, the stars, for instance, in the constellation of Ursa Major, or the Great Bear, have not been observed to alter their situation, with respect to each other, since the creation of the world. But there are few rules without exception; and here it must be observed, that new stars have been discovered, which were unknown to the ancients, and many of those which appeared in old catalogues are not now visible, while numbers seem gradually to vanish, and others appear to have a periodical increase and decrease of magnitude.

All the fixed stars, however, have an apparent motion round the heavens once in twenty-four hours; for, although that of the star nighest the pole, and consequently called the polar star, be so imperceptible as to be scarcely distinguished, yet, even that star appears to move in a very small circle; and this imaginary motion is occasioned by the same cause as produces the rising and setting of the sun; viz. the revolution of the earth on its axis.

Though the number of the fixed stars, visible to the naked eye, fall infinitely short of what a superficial observer might be apt to imagine, yet, from the great resemblance they bear to each other, and the confused manner in which they appear at such vast distances, it was found necessary, by the ancient astronomers, to class and arrange them under various figures and resemblances, to which they gave the names of several persons and things; and these ima. 
ginary likenesses, many of which, individually, obtained the names of persons celebraced in antiquity, were in general called constellations.

The distances of the fixed stars from the earth is supposed to be very great; so much so, that were a cannon ball discharged from the nearest of them, it is computed that it would take $7,000,000$ years before it could reach the earth. So far, indeed, are these luminous orbs removed from us, that their mag. nitude cannot be increased by the best magnifiers; and, notwithstanding the great extent of the earth's orbit or path round the sun, a fixed star does not appear to be nearer to us when the earth is in that part of its orbit nearest to it, than it seemed to be when the earth was at the greatest distance, or 190,000,000 of miles farther removed from the star.

Dr. Bradley calculates the nearest fixed star from the earth to be 40,000 times the diameter of the earth's orbit, and the distance of Draconis from the earth to be 400,000 times that of the sun, or $38,000,000,000,000$ miles!

As to the size of the fixed stars, some idea may be formed from the vast distance at which they are * visible. Were the sun removed to as great a distance from us as we are from the nearest of these stars, it is not probable that he would appear greater to us, and the different apparent magnitudes of the stars is supposed only to arise from their difierent distances. Indeed, from a comparison of the light afforded by a fixed star to that of the sun, it has been concluded that the fixed stars do not differ materi- 
ally, in magnitude, from that luminary; and, as it is impossible that these bodies can shine from such a distance with a reflected light, it has also been concluded, that the fixed stars must be of the same nature of the sun, and, like him, shine with their own native lustre.

\section{The Uses of the fixed Stars.}

's Ask for what end these heavenly bodies shine;

Earth for whose use?-Pride answers, 'tis for mine!'?

"But do these worlds display their beams, or guide

Their orbs, to serve thy use, to please thy pride?

'Thyself but dust, thy stature but a span,

A moment thy duration-foolish man!"

"As well may the minutest emmet say,

That. Caucasus was rais'd to pave his way;

The snail, that Lebanon's extended wood,

Was destin'd only for his walk and food:

The vilest cockle, gaping on the coast

That bounds the ample seas, as well may boast

The craggy rock projects above the sky,

That he in safety at its feet may lie;

And the whole ocean's confluent waters swell,

Only to quench his thirst, or move and blanch his shell.",

As every part of the vast machine of the universe seems wisely made, in some degree or other, subservient to the whole, notwithstanding the vast distances of the stars from the earth, it would be extremely improper to deny that they may be, to a certain extent, useful to man. How often do they serve 
to cheer the gloom of the midnight sky, when neither sun nor moon appears. In the early ages, those who went down to the sea in ships had scarce any other sure guide for their wandering vessel. They still serve to direct the benighted traveller in his so. litary journey; and, by means of the revolutions of the stars, the ploughman, even had he no other directory, would know exactly when to plough his fields and sow his seeds. But if, as we have seen, the stars bear such a striking analogy to the sun in their magnitude, their nature, and some of their properties, have we not reason to conclude that they have far more important offices to fulfil than merely to be useful, in a few respects, to man? that they, also, like the sun, are each the centre of its respective system? But where does this reasoning lead us? for, if the stars are suns, and centres of other sys. tems than that to which our earth belongs, does it not naturally follow that there must be other worlds revolving around them? and if other worlds, must they not also be inhabited? This is a humiliating lesson to the sons of pride, who have indulged the thought that every thing in the universe was intended chiefly for their use; but it is not to be supposed that the Omnipotent Creator, who has not a leaf or irop of water unpeopled, should have left such immense bodies destitute of inhabitants. "It is surely much more rational to suppose them the abodes of intelligent beings ; of beings endowed with capacities of knowing, loving, and adoring their Creator; provided and blessed with every object conducire 
to their happiness; many of them, perhaps, in a far greater state of purity than the inhabitants of our earth; in possession of superior degrees of bliss; and all under the direction, indulgence and protection, of infinite wisdom and goodness;" so that the poet is correct in his reasoning:

"What read we here?-Th' existence of a God?

Yes; and of other beings, man above;

Natives of æther! sons of higher climes !"

In this view of the subject, what a grand and mag. nificent spectacle does the starry heavens present! What lofty and enlarged ideas must it give of the Deity, to suppose every star which we behold a sun, and each sun the centre of its respective system, of planets and comets moving within the sphere of its attractive energy, and irradiated by its beams! Must not such a consideration inspire us with the grandest and most sublime ideas of that Being, who has not only formed, but launched forth, those numerous orbs into the immensity of space, and who preserves them in the greatest order and regularity, so that there is not the least danger, nor the smallest possibility, of their running into confusion? But, to stretch our imagination still farther beyond the boundaries of the visible creation, and to suppose other stars, and consequently other suns and systems of inhabited worlds, moving in the same beautiful order and regularity beyond these, how awful the thought! how overwhelming the consideration! What an august, what an amazing conception does this give of the works 
of the Creator! Thousands of thousands of suns multiplied without end, and ranged all around us at immense distances from each other, attended by ten thousand times ten thousand worlds, all in rapid motion, yet calm, regular, and harnonious, invariably keeping the paths prescribed them; and these worlds, doubtless, peopled with myriads of beings, formed for endless progression in perfection and felicity!

"Not only this which we by custom call

Our world, the stars embellishing the skies Are worlds alike, th' Almighty rules them all, And all at first from matter's mass did rise."

Thus we see, that the great Creator of the Universe, like gold well tried in the furnace of the refiner, rises more august, more grand, more sublime, more inexpressible, beyond what our finite capacities can conceive, or our tongues express, the more we extend our researches into nature; - that " the works of the Lord are indeed great, in proportion as they are sought out of all them that have pleasure therein;" while man, an atom of an atom world, dwindles into insignificance as he becomes sensible of his own imperfections and weakness; and even the most devout and diligent student of nature, while he is forced to exclaim as he contemplates the won. ders of the skies, "The heavens declare the glory of God, and the firmament sheweth his handy work," is also obliged, from a sense of his own littleness, when put in competition with those mighty orbs, to 
GOOK OF NATURE LAID OPEN.

adopt the following beautiful sentiment: "When I consider the heavens the work of thy fingers; the moon and the stars which thou hast ordained; what is man that thou art mindful of him, and the son of man that thou visitest him :" 


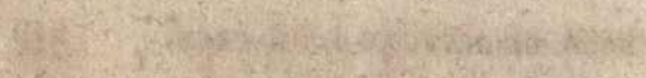

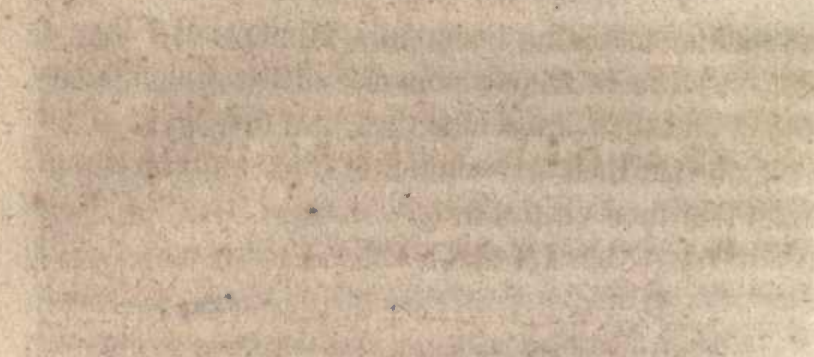

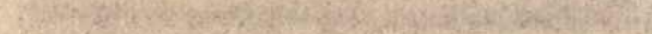

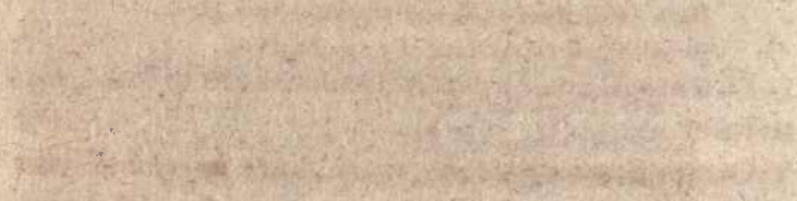

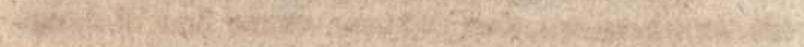
3.6.

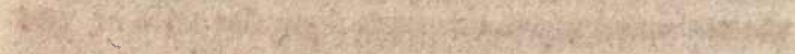

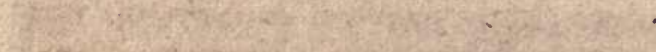

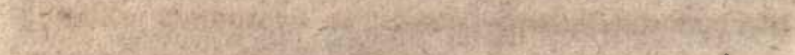

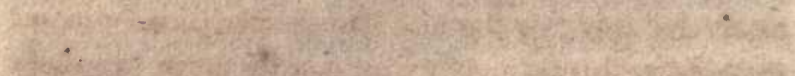

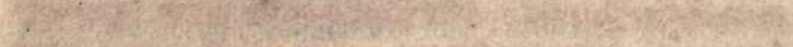

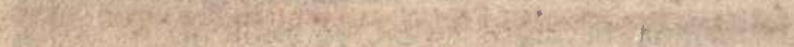
1.5 - 20 a

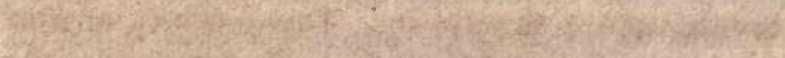

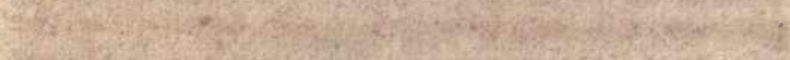

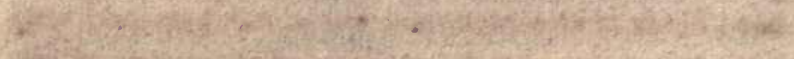

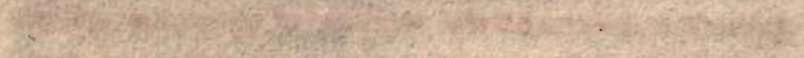

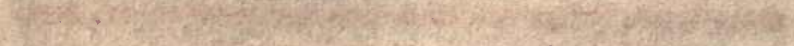

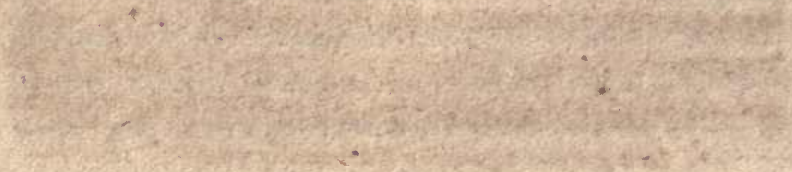




\section{NATURAL, APPEARANCES}

\section{IN JANUARY.}

"Stern Winter's icy breath, intensely keen, Now chills the blood, and withers every green.

Bright shines the azure sky serenely fair, Or driving snows obscure the turbid air."

CrFinzed nations in general have agreed to date the commencement of the year on the first of January, within a few days after the winter solstice, or shortest day, which takes place on the 21 st or $22 d$ of December. In-the month of January, the weather, in the British islands, is commonly either a clear, dry frost, or fog and snow, occasionally intermingled with rain. Nothing can be more wonderful than the elfecis of frost, which, in the spac of a single night, stops the running stream in its course, and converts the lake, that was curled by every breeze, into a firm plain. This property of frost. produces a beneficial effect to the farmer; for the hard clods of the ploughed fields are loosened and broken to pieces by the swelling of the water within them when it freezes, and thus the earth is prepared for receiving the seed in spring; while,

"The frost-concocted glebe,

Draws in abundant vegetable sonl,

And gathers vigour for the coming year." 
Numerous natural phenomena are produced by frost. Water from the clouds, freezing slowly, crystallizes in little icy darts or stars, forming, by their assemblage, the beautiful flakes of snow. Its whiteness is owing to the smallness of the particles into which it is divided; for ice, when pounded, becomes equally white. Snow is very useful by protecting the plants it covers from the severity of the frost.Hailstones are drops of rain, suddeniy congealed into a hard mass, so as to preserve their figure. They often fall in warmer seasons of the year, as even then the upper regions of the atmosphere are very cold. When dew or mist freezes, as it frequently does on every object on which it falls, it becomes hoar frost, producing figures of incomparable beauty and elegance.

As the cold of this inclement season advances, the birds collect in flocks, and, rendered bold by want, approach the habitations of man. The wild quadrupeds, also, are driven from their accustomed haunts; hares enter the gardens to browse on cultivated vegetables, and, leaving their tracks in the snow, are frequently hunted down, or caught in snares.

The domestic cattle now require all the care and protection of the farmer. Sheep are often lost in the sudden storms by which the snow is drifted into hollows, so as to bury them a considerable depth beneath it; yet they have been known to survive many days in this situation. Cows receive their subsistence from the provision of the farm-yard; and early lambs 
and calves are kept within doors, and tended with nearly as much care as the farmer's own children.

"Now shepherds, to your helpless charge be kind;

Bafle the raging year, and fill their pens

With food at will; lodge them below the storm,

And watch them strict; for, from the bellowing east,

In this dire season, oft the whil lwind's wing

Sweeps up the burden of whole wint'ry plains

At one wide wait, and o'er the helpless flocks,

Hid in the hollow of two neighbouring hills,

The billowy tempest 'whelms."

The plants, at this season, are defended by nature from the effects of cold. Those called herbaceous, which die down to the root every autumn, are safely concealed under ground; and the shrubs and trees that are exposed to the open air, have all their soft and tender parts closely wrapped up in buds, which, by their texture, resist the effects of frost, and are hence aptly termed the winter quarters of the young shoots How admirable is the economy of Nature!

The carth, at this season, may now be compared to a mother who has been robbed of those children. from whom she had the best hopes. She is desolate, and deprived of the eharms which varied and embellished her surface; however; she is not robbed of all her children; here and there some vegetables are still to be seen, which seem to defy the severity of the winter; here the wild hawthorn shows its purple berries, and the laurestina displays its blossoms in clusters, crowned with leaves which never fade. The yew-tree rises like a pyramid, and its leaves 
preserve their verdure. The ivy, evergreen, still creeps along the walls, and clings inmoveable, while the tempest roars around it. The laurel extends its green branches, and has lost none of its summer ornaments; and the humble box shows here and there, in the midst of the snow, its evergreen branches.

\section{FEBRUARY.}

"Now shifting gales with milder influence blow,

Clond o'er the skies, and melt the falling snow;

The soften'd soil with fertile moisture teems,

And, freed from icy bonds, down rush the swelling streams."

THE earlier part of this month may still be reckoned winter; though the cold generally begins to abate. The days are sensibly lengthened, and the sun has power enough gradually to melt away the snow and ice. Sometimes a sudden thaw comes on, with a south wind and rain, which at once dissolves the snow. Torrents of water then descend from the hills; every little brook and rill is swelled to a large stream; and the ice is swept away with great violence from the rivers. The frost, however, returns for a time; fresh snow falls, often in great quantities; and thus the weather alternately changes during most part of this month.

Various signs of returning spring occur at different times in February. The woodlark, one of the earliest and sweetest of our songsters, often begins his 
note at the very entrance of the month. Not long after, rooks begin to pair, and geese to lay. The thrush and chafinch then add to the early music of the groves. Moles go to work in throwing up their hillocks as soon as the earth is softened. Under some of the largest, a little below the surface of the earth, they make their nests of moss, in which four or five young are found at a time. These aninials live on worms, insects, and the roots of plants. They do much mischief in gardens, by loosening and devouring flower-roots; but in the fields they do no other damage than rendering the surface of the ground unequal by their hillocks, which obstruct the scythe in mowing. They are said, also, to pierce the sides of dams and canals, and let out the water; but this can only be an accidental occurrenee, attended with their own destruction.

Many plants emerge from under ground in $\mathbf{F e}$ bruary, but few flowers yet adorn the fields or gardens. Snow-drops, in general, are fully opened from the beginning of the month, often peeping from the midst of the snow.

"Already now the snow-drop dares appear, The first pale blossom of the unripen'd year; As Flora's breath, by some transforming power, Had chang'd an isicle to a flower;

Its name and hue the scentless plant retains, And winter lingers in its icy veins."

The alder-tree discloses its flower buds; the catkins of the hazel become very conspicunus in the 
hedges; and young leaves appear on the gooseberry and currant-bushes. The farmer, as soon as the ground is sufficiently thawed, ploughs his fallows, sows beans and pease, and rye and spring wheat.

“ Joyous th' impatient husbandman perceives Relenting nature, and his lusty steers

Drives from their stalls, to where the well-us'd plough

Lies in the furrow, loosen'd from the frost ;

There, unrefusing, to the harness'd yoke

They lend their shoulder, and begin their toil, Cheer'd by the simple song and soaring lark. Meanwhile, incumbent o'er the shining share, The master leans, removes the obstructing clay, Winds the whole work, and sidelong lays the glebe. While through the neighbouring field the sower stalks, With measur'd step, and lib'ral throws the grain Into the fruitful bosom of the ground."

The husbandman, also, at this season, sets his early potatoes, drains his wet land, dresses and repairs his hedges, lops his trees, and plants those kinds which love a wet soil, as poplars and willows; and, with.

_ "Fancy fir'd, anticipates their growth."

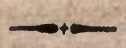

Winter in the Polar Regions.

Nor are the symptoms of returning spring confined to the inhabitants of our temperate climate ; they also begin, towards the middle of this month, to be sensibly felt by those of the icy regions of the north. 
Their winter, however, is very different from ours. The single night of the country about Spitzbergen begins about the 30 th of October. The sun then sets, and never appears till about the 10th of February. A glimmering, indeed, continues some weeks after the setting of the sun: then succeed clouds and thick darkness, broken by the light of the moon, which is as luminous as in England, and, during this long night, shines with unfailing lustre. The cold strengthens with the new year, and the sun is ushered in with an unusual severity of frost. By the middle of March the cheerful light grows strong; the arctic foxes leave their holes, and the sea-fowls resort, in great multitudes, to their breeding places. The sun acts no more after the 14th of May. The distinction of day and night is then lost.

But, to make up for the want of sunshine in such a long and tedions winter, the wisdom and goodness of God has amply provided, by furnishing, in addition to the light of the moon, the northern inhabitants of our globe with such a copious display of the aurora borealis, or what the common people here call streamers.

In Shetland, these northern lights, which the natives call merry dancers, are the constant attendants of the clear evenings, and prove great reliefs amid the gloom of the long winter nights. They commonly appear at twilight, near the horizon, of a dun colour. approaching to yellow, sometimes continuing in that state for several hours, without any apparent motion; after which they break out into streams of 
stronger light, spreaciing into columns, and altering? slowly into ten thousand different shapes, varying their colours, from all the tints of yellow, to the most obscure russet. They often cover the whole hemisphere, and then make the most brilliant appearance. Their motions, at these times, are most amazingly quick, and they astonish the spectator with the rapid changes of their form. They break out in places where none were seen before, skimming briskly along the heavens. On a sudden they are extinguished, and leave behind a uniformly dusky tract. This again is illuminated in the same manner, and as suddenly left a dull blank. In certain nights they assume the appearance of vast columns, on one side of the decpest yellow, on the other declining away till it becomes undistinguished from the sky. They have generally a strong, tremulous motion, from end to end, which continues till the whole vanishes. In a word, we, who only see the extremities of these northern phenomena, have but a faint idea of their splendour and their motions.

In Siberia there is one species of the aurora borealis, which regularly appears between the north-east and east, like a luminous rainbow, with numbers of columns of light radiating from it. Beneath the arch is a darkness, through which the stars appear with some brilliancy. There is another kind, which begins with eertain insulated rays from the north, and others from the north-east. They augment little by little till they fill the whole sky, and form a splendour of colours rich as gold, rubies, and emeralds ; 
but the attendant phenomena strike the beholders with horror; for they crackle, sparkle, hiss, make a whistling sound, and a noise even equal to artificial fireworks.

In Hudson's bay, moreover, the firmament, in winter, is not without its beauties. The night is enlivened by the aurora borealis, which spreads a thousand different lights and colours over the whole concave of the sky, not to be defaced even by the splendour of the full moon; and the stars are of a fiery redness.

\section{Wonders of the North.}

As we advance into these dreary regions, we meet with those picturesque objects which attract and captivate the most incurious eye. In the icy seas, and particularly at Spitzbergen, (which is the largest of that group of frozen islands which go under that name, or that of New Greenland) the forms assumed by the ice are extremely pleasing. The surface of that which is congealed from the sea water is flat, even and hard, resembling white sugar, and is capable of being slid upon. The greater pieces, or fields, are many leagues in length: the smaller are the meadows of the seals, on which those animals, at times, frolic by hundreds. The motion of the smaller pieces is as rapid as the currents; the greater, which are sometimes two hundred leagues long, and sixty or eighty broad, move slowly and majestically. They often fix for a time, immoveable by the power 
of the ocean, and then produce, near the horizon, that bright, white appearanee, called, by the mariners, the blink of the ice. These float in the sea like so many rugged mountains, and are sometimes five or six hundred yards thick; but the far greater part is concealed beneath the water. These are continually increased, in height, by the freezing of the spray of the sea, or of the melted snow which falls on them. Those which remain in this frozen climate receive. continual growth; others are gradually wafted, by the northern winds, into southern latitudes, and melt, by degrees, by the heat of the sun, till they waste away, and disappear in the boundless element.

The collision of the great fields of ice, in high latitudes, is often attended with a noise that, for the time, takes away the power of hearing any thing else; and the meeting of the lesser fields is attended with a grinding of unspeakable horror. The water which dashes against the mountainous ice freezes into an infinite variety of forms, and gives the voyager ideal towns, streets, churches, steeples, and every shape which imagination can frame.

The icebergs or glaciers of the north-west of Spitzbergen, are among the capital wonders of the country. Frost sports with these icebergs, and gives them majestic, as well as other most singular forms.Masses have been seen assuming the shape of a gothic church, with arched windows and doors, and all the rich tracery of that style, composed of what an Arabian tale would scarcely dare to relate, of crystal of the richest sapphirine blue. Tables with 
one or more feet, and often immense flat-roofed temples, supported by round, transparent columns, of cerulean huc, float by the astonished spectator. These icebergs are the creation of ages, and receive annually additional heights, by the falling of snow and rain, which often instantly freezes, and more than repairs the loss by the influence of the melting sun.

Such are part of the wonderful phenomena of the polar regions; and the best improvement we can make of such awful and terrific scenes, is to compare them with what we daily behold at home, and learn contentment with that spot, where Providence, all. wise, has fixed our residence.

" One of the great arts to escape superfluous un. easiness," says a celebrated writer," is to free our minds from the habit of comparing our condition with that of others, on whom the blessings of life are more bountifully bestowed, or with imaginary states of delight and security, perhaps unattainable by mortals. Few are placed in a situation so gloomy and distressful as not to see, every day, beings more forlorn and miserable, from whom they may learn to rejoice at their own lot.

"A native of England, pinched with the frosts of December, may lessen his affection for his own country by suffering his imagination to wander in the vales of Asia, and sport among woods that are adways green, and streams that murmur; but if he turns his thoughts toward the polar regions, and considers the nations to whom a great portion of the year is darkness, and who are condemned to pass week 
and months amid mountains of snow, he will soon recover his tranquillity; and, while he stirs his fire, or throws his cloak about him, reflect how much he owes to Providence that he is not placed in Greenland or Siberia."

\section{MARCH.}

"As yet the trembling year is unconfirm'd, And winter oft at eve resumes the breeze, Chills the pale morn, and bids his driving sleets Deform the day. ${ }^{2}$

THE greatoperations of nature, during this month, seem to be to dry up the superabundant moisture of February, thereby preventing the roots and seeds from rotting in the earth, and gradually to bring forward the process of evolution in the swelling buds; while, at the same time, by the wholesome severity of chilling blasts, they are kept from a premature disclosure, which would expose their tender contents to injury from the yet unsettled season.

The winds of March, boisterous and vehement to a proverb, are to be regarded, however, as particularly useful to vegetation; for those year's generally prove most fruitful, in which the pleasing appearances of spring are the most retarded. The importance of a dry season for getting the seed early and favourably into the ground, is expressed in the old proverb:

"A bushel of March dust is worth a king's ransom." 
The mellow note of the thrush, singing perched on the naked bough of some lofty tree, and the cooing of the ring-dove in the woods, are heard from the beginning of March. The rooks also are now in motion, building and repairing their nests; and it is highly amusing to observe the tricks and artifices of this thievish tribe; some to defend, and others to plunder, the materials of their new habitations. These birds are accused of doing much injury to the farmer, by plucking $n$ the young corn, and other springing vegetables; but some are of opinion that this mischief is fully repaired by their diligence in devouring the grubs of various insects, which, if suffered to come to maturity, would occasion much greater damage. For this purpose, they are frequently seen following the plough, or settling in flocks on newly turned up lands.

In the month of March, those birds which took refuge in our temperate climate from the rigour of the northern winters, begin to leave us, and return to the countries where they were bred. The redwing, fieldfare, and woodcock, are of this kind, and retire to spend their summer in, Norway, Sweden, and other parts of the north of Europe. Frogs, which, during winter, lie in a topid state at the bottom of ponds or ditches, now, enlivened by the warmth of spring, rise in vast numbers to the surface of the water, and make themselves heard to a sur. prising distance by their croakings. Those small, but beautiful fish, called smelts, or sparlings, proceed up the rivers in this month in order to spawn; bas $\times 2$ 
they are of so tender a nature, that the least mixture of snow-water in the river drives them back to the sea.

One of the most agreeable tokens of our approach of spring is, that about the middle of the month of March bees venture out of their hives. These admirable and useful insects appear to be possessed of uncommon foresight of the weather; so that their appearance in the morning may be reckoned a sure token of a fair day. As their food is the sweet juice to be found in the nectaries of flowers, their coming abroad is a certain sign that flowers are now to be met with. The gardens are adorned with the yellow and purple crocus; and, towards the end of the month, primroses peep out from beneath the hedges, while the most fragrant of all flowers, the violet, discovers itself by the perfume it imparts to the surrounding air. The peach, the nectarine, the almond, apricot and cherry-trees, come into full bud during this month; the sallow enlivens the hedges with its catkins full of dust; and the leaves of the honey. suckle are nearly expanded.

In the latter part of the month of March the equinox happens, when day and night are of an equal length all over the globe; or rather, when the sun is an equal time above and below the horizon; for the morning and evening twilight makes apparent day considerablv longer than night. This takes place again in September. The former is called the vernal, the latter the autumnal equinox. 


\section{APRII.}

"Now stormy skies with milder influence shine, And winter, banish'd, seeks the northern elime:

The earth, revived, a cheerful aspect wears -

The gentle bird returns - the fragrant flower appears."

ApriL generally begins with raw, unpleasant weather, the influence of the equinoctial storms still, in some degree, prevailing; but its vicissitudes of warm gleams of sun-shine and gentle showers have the most powerful effects in hastening that universal springing of the vegetable tribes, whence the season of spring derives its appellation.

Early in the month that welcome guest and har. binger of summer, the swallow, returns. The chimney or house swallow, known by its long, forked tail, and red breast, is first scen; and as this bird lives on insects, its appearance is a certain proof that some of that minute tribe of animals are come abroad from their winter retreats.

In this month the groves resound with the various melody of the birds.

"s The blackbird, woodlark, and the thrush, Unite with those of feebler voice;

Whose chants resound from bush to bush, To rouse all nature to rejoice.

Whilst nature seems to hear the sound, Flowers, herbs, shrubs, trees, put forth their heads, To ask, what have you, warblers, found

To make you sing-is winter fled ? 
Sweet ' yes ;' the nightingale replies;

- For I'm the harbinger of spring;

And to confirm the same,' she cries,

"Hark! don't you hear yon cuckoo sing ?",

The nightingale is heard soon after the arrival of the swallow. He sings by day as well as by night, but in the day-time his voice is drowned among the multitude of performers; in the evening it is heard alone: whence arises the common opinion that it sings only by night.

Birds are now busied in pairing, and building their nests, in which they exhibit the most admirable instinctive peculiarities.

"Some to the holly hedge

Nestling repair; and to the thicket some;

Some to the rude protection of the thorn

Commit their feeble offspring: the cleft trec

Offers its kind concealment to a few ;

Their food its insects, and its moss their ncsts: -

Others apart, far in the grassy dale

Or roughening waste, their humble texture weave:

But most in woodland solitudes delight,

In unfrequented glooms, or shaggy banks,

Steep, and divided by a babbling brook,

Whose murmurs sooth them all the live-long day,

When by kind duty fix'd."

Another of the most striking events of this month is the renewal of the note of the cuckoo, which is generally heard about the middle of April. This circumstance has commanded attention in all countries; and several rustic sayings, and the names of 
several plants which flower at that time, are derived from it.

The arrival of the cuckoo is regularly preceded some days by that of the wryneck, a small bird, singular in its attitudes and plumage, and which has a peculiar note or cry, easily distinguished by those who have once heard it. Other birds, which are seen among us only in the warmer months, as the redstart, whitethroat, and yellow wagtail, appear in April.

A considerable number of plants flower this month, and, with the blossoms of fruit-bearing trees and shrubs, form a very agreeable spectacle, as well on account of their beauty, as of the promise they give of future benefits.

\section{"Arabia cannot boast}

A fuller gale of joy than, lib'ral, thence

Breathes thro' the sense, and takes the ravish'd soul.

Full of fresh verdure and unnumber'd flowers,

The negligence of Nature, wide and wild,

Where, undisguis'd by mimic art, she spreads

Unbounded beauty to the roving eye."

\section{Reflections on Spring.}

His beauty walks, His tenderness and love.

Wide flush the fields; the softening air is balm ;

Echo the mountains round; the forest smiles;

And every sense, and every heart is joy."

What a wonderful revolution, indeed, in the universal aspect of Nature, does the return of this lovely 
season exhibit! After having been long bound up with frost, or overspread with snow, the earth once more displays all her variety of plants and flowers, is arrayed with the most beautiful and enlivening verdure, variegated with a numberless variety of hues, and exhales odours so exquisitely pure and fragrant, that every sense of every creature is awake to inexpressible delight.

None of the other seasons can vic with spring in loveliness and amenity. It has the same order among them that the morning has among the divisions of the day, and youth among the stages of life. It may be called the favourite season of harmony; for the warbling of the feathered tribes has been observed to have now a peculiar wildness and sweetness of melody. Nor is its sweet influence confined to the songsters of the groves: it pervades the whole animal creation.

\section{Its Influence on Man.}

In the opening of spring, and subsequent reno. vation of Nature, how very sensibly is the human soul exhilarated by that sense of pleasure which inspires the birds with melody, and the whole creation with joy. In this season, when we contemplate the smiling scenes around, those secret overflowings of gladness are diffused over the soul, which compose what Milton expressively calls "vernal delight," and which is often denominated, with no less beauty and propriety, "the smile of nature." What an ex- 
quisite sense of this does the virtuous philosopher experience! The creation, particularly in this lovely season, is a perpetual feast to the mind of a good man. From all that he beholds, he receives instruction and delight Providence has adorned the whole creation with such a variety of beautiful and useful objects, that it is impossible for a mind, not imbruted by mere sensual enjoyments, to contemplate the scenes around, without some of the sweetest internal sensations of which man can be susceptible. But when, to the delightful satisfaction which rural objects afford, we add an occasional attention to the studies of natural philosophy, our relish for the beauties of the creation is quickened, and rendered not only pleasing to the imagination, but to the understanding; and it is an unquestionable truth, that the man who extends his inquiries into the works of nature, multiplies, in some degree, the inlets to happiness. The philosopher is not content with the lolling murmur of brooks, or the enlivening melody of birds, with the shade of embowing woods, the verdure of fields, or the embroidery of meadows. He will reflect, on the contrary, on the infinite variety of benevolent purposes to which they are all subservient, and the wonders of that Divine Wisdom, of which they all exhibit such impressions. While the pleasures of the eye, in course, are heightened, his soul is exalted to that rational admiration which insensibly leads to love and adoration; and, while he "walks superior amid the glad creation, musing 
praise, and looking gratitude," with a kind of sacred ecstacy he exclaims :

"These are thy glorious works, Parent of Good, Almighty! Thine this universal frame, Thus wondrous fair: Thyself how wondrous then, Unspeakable!"”

While unusual sweetness thus inspires the whole creation with a purer joy, the moral philosopher is led to enquire into the natural effects of this delightful influence, not only on the frame, but on the heart of man. The affections, he is fond to imagine, are all attuned to benevolence, and each discordant passion soothed to serenity and peace.

With what a generous satisfaction, too, will humanity reflect on the restorative effects of spring! The convalescents, so lately wretched, so long oppressed by the heavy load of pain, and langour, and disease, now feel, as it were, a new creation; and sweet are the cheering sensations, sweet the unwonted joys, that now recall them to the exertions of strength, and the happiness of health.

\section{MAY.}

" Born in yon blaze of orient sky, Sweet May, thy radiant form unfold;

Unclose thy blue, voluptuous eye, And wave thy shadowy locks of gold. 
Warm with new life thy glitt'ring throngs,

On quiv'ring fin and rustling wing,

Delighted join their votive songs,

And hail thee goddess of the Spring."

MAY has ever been the favourite month of poetic description, as uniting all the soft beauties of spring with the radiance of summer; but this must be in more southern climes than ours; for with us great part of the month is yet too cold for a perfect enjoyment of the charms of nature, and abounds with chilling blights and nipping winds:-

"The blast that riots on the spring's increase."

The month of May, however, is profuse of beauty; the earth is now covered with the freshest green of the grass and young corn, and adorned with numerous flowers opening on every side The trees put on their leafy verdure; the hedges are rich in fragrance from the snowy bloom of the hawthorn; and the orchards display their highest beauty in the delicate blush of the apple blossoms.

The leafing of trees is commonly completed in this month. It begins with the aquatic kinds, such as the willow, poplar, and alder, and ends with the oak, beech, and ash. These are sometimes very thin of foilage even at the close of May.

Birds hatch and rear their young principally during this month. The patience and assiduity of the female during the task of sitting upon her eggs, cannot be too much admired; nor should the conjugal 
affection of the male be forgotten, who sings to his mate, and often relieves her fatigues by supplying her place: and nothing can exceed the paternal tenderness of both, when the young are brought to light.

Towards the end of May the bee hives send forth their earlier swarms. Nature directs them to march in a body in quest of a new settlement, which, if left to their choice, would generally be some hollow trunk of a tree; but man, who converts the labours and instincts of so many animals to his own use, provides them with a more secure dwelling, and repays himself with their honey.

The glow-worm shines at this period ; the females of which are without wings, and luminous; the males vice versa. They extinguish their lamps, or cease to glow, between eleven and twelve at night.

The cattle are now turned out to the pastures; milk becomes more copious; and the process of - cheese-making goes on in Cheshire, Wiltshire, Gloucester, \&c.

This is not a busy month to the farmer. He now weeds his crop, and looks forward to the reward of his industry and toil, in the approaching season.

" Be gracious, heaven! for now laborious man Has done his part."

\section{Chick in the Egg.}

The hen has scarce sat on the egg twelve hours, when we begin already to discover in it some linea- 
ments of the head and body of the chicken that is to be born The heart appears to beat at the end of the day; at the end of forty eight hours two vesicles of blood can be distinguished, the pulsation of which is very visible At the fiftieth hour an auricle of the heart appears, and resembles a lace, or noose folded down upon itself At the end of seventy hours we distinguish wings, and on the head two bubbles for the brain; one for the bill, and two others for the fore part and hind part of the head:- the liver appears towards the fifth day At the end of 131 hours the first voluntary motion is observed. At the end of 138 hours the lungs and stomach become visible:-and at the end of 142 , the intestines, the loins, and the upper jaw The seventh day, the brain which was slimy, begins to have some consistence. At the 190th hour of incubation, the bill opens, and the flesh appears in the breast;-at the 194th, the sternum is seen, that is to say, the breastbone. At the 210th, the ribs come out of the back, the bill is very visible, as well as the gall bladder. The bill becomes green at the end of 236 hours; and if the chick is taken out of its coverings, it evidently moves itself The feathers begin to shoot out towards the 24.0th hour, and the skull becomes grisly. At the 264th, the eyes appear. At the 288th the ribs are perfect At the 331st, the spleen draws near to the stomach, and the lungs to the chest. At the end of 355 hours, the bill frequently opens and shuts; and at the end of 451 hours, or the 18th day, the first cry of the chick is already 
heard: it afterwards gets more strength, and grows continually, till at last it sets itself at liberty, by - opening the prison in which it was shut up. Adorable wisdom of God! it is by so many different degrees that these creatures are brought into life. All these progressions are made by rule; and there is not one of them without sufficient reason. No part of its body could appear sooner or later, without the whole embryo suffering, and each of its limbs appear at the most proper moment. This ordination, so wise, and so invariable in the production of this snimal, is manifestly the work of a Supreme Being. -

\section{JUNE.}

" Now genial suns and gentle breezes reign, And summer's fairest splendours deck the plain ;

Exulting Flora views her new-born rose, And all the ground with short-lived beauty glows."

JUNe, in this climate, is what the Grecian poets represented May. It is the most lively month in the year. Summer has commenced, and warm weather is established; yet the heats rarely rise to excess, or interrupt the enjoyment of those pleasures which the scenes of Nature at this period afford. The trees are in their fullest dress; and a profusion of flowers is every where scattered around. 
One of the earliest rural employments of this month is the shearing of sheep; a business of much importance in various parts of the kingdom, where wool is one of the most valuable products, and yields much rústic mirth; as,

\section{"Rang'd in lusty rows,}

The shepherds sit, and whet the suunding shears.

The housewife waits to roll her fleecy stores,

With all her gay drest maids attending round.

One chief in gracious dignity enthron'd,

Shines o'er the rest, the pastoral queen, and rays

Her smiles, sweet beaming, on her sliepinerd king;

While the glad circle round them yield their souls

To festive mirth, and wit that knows no gall."'

England has for many ages been celebrated for its breeds of sheep; which yield wool of various qualities, suited to different branches of the woollen manufacture.

In the hedges the place of the hawthorn is supplied by the flowers of the hip, or dog-rose, the different hues of which, from a deep crimson to a light blush, and even pure white, form a very elegant variety of colour; and of some the smell is peculiarly fragrant Some time after the woodbine and honeysuckle begin to blow; and these, united with the rose, give our hedges their highest beauty and fragrance.

The several kinds of corn come into ear and flower this month; as do likewise the numerous species of grass. In Europe the principal kinds of corn are 
wheat, rye, barley, and oats; in Asia, rice; in Africa, maize, or Indian corn.

The latter part of June is the beginning of hayharvest for the southern and middle parts of the kingdom. This is one of the most busy and agreeable of rural occupations.

"Now swarms the village o'er the jovial mead."

Both sexes and all ages are engaged in it.

The fragrance of the new-mown hay, the gayety of all surrounding objects, and the genial warmth of the weather, conspire to render this a season of pleasure and delight.

"Ee'n stooping age is here; and infant hands Trail the long rake, or, with the fragrant load O'ercharg'd, amid the kind oppression roll;

While, heard from dale to dale, Waking the breeze, resounds the blended voice of happy labour, love, and social glee."

In this month appear the grasshopper, green bec. the, angler's May fly, the formidable gad fly, \&c.The angler's May fly is most short lived; emerging from the water in its aurelia state at six in the evening, and dying at eleven: they appear about the fourth of this month and continue a fortnight.

Now gooseberries, currants, and strawberries, begin to ripen Birds cease their notes, except the stone curlew, yellow-hammer, goldfinch, and golden.crested wren, now and then chirping. The 
cuckoo, also ceases, It is amusing now, an hour before sun set, to see the barn owl in search of field mice, and bringing one to its nest about every five minutes; and the fern owl, feeding on the fern chaffer, another interesting nocturnal bird.

On the 21st of this month is the summer solstice, or longest day; when the splendid sun

"Shoots full perfection thro' the swelling year."

The Dew.

The wise Ruler of the world, who watehes continually over his children, and provides for all their wants, makes use of more than one means to render the earth fruitful. But the most common means, the surest, and most universal, and that which men the least attend to, and are least sensible of its value, is dew. This inestimable gift of Heaven, which even in years of the greatest drought supports and preserves the plants from perishing, is those sparkling drops seen in such profusion morning and evening on the leaves of trees and plants. The dew does not fall from above, as was formerly imagined; it does not descend from the highest parts of our atmosphere; and still less is it the sweat of the stars, as superstition had supposed. This pretended ce. lestial origin has probably given rise to the folly of some alchymists who hoped to convert dew into gold. It is now generally allowed, that the dew is nothing but the sweat of the plants, and the moisture 
they draw from the earth. In order to be convinced of this, one need only cover a plant with a glass bell, and it will appear that the leaves collect in the night a greater quantity of dew drops than the leaves of the other plants which are exposed to the air. This certainly would not be the case if the dew fell from above, and if it did not rise from the ground. Nothing is more easy than to comprehend how it is formed; for nobody is ignorant, that the rays of the sun, and the heat which is cast on the earth, continually loosens a multitude of thin particles from off every thing ; some of which rise into the atmosphere, and the rest collect in the form of drops of water. This account of the dew explains to us, how it happens that it is sometimes hurtful, and sometimes not so. Its nature evidently depends on the quality of the vapours of which it is composed. The wind carries away the light exhalations as soon as they are formed, and prevents them from falling in drops. This is the reason that there is most dew when the air is very calm. By this wise plan of the Creator, the plants can vegetate and grow in countries even where there is no rain; for the soil of those parts being sandy, porous, and very moist underneath, the heat draws out a great quantity of dew, which supplies the place of ruin. 


\section{JULY.}

i Deep to the root

Of vegetation parch'd, the cleaving fields And slippery lawn an arid hue disclose;

Echo no more ieturns the cheerful sound Of sharp'ning scythe; the mower, sinking, heaps O'er him the humid hay, with flowers perfum'd."

JULY is the hottest month in the year. The direct influence of the sun, indeed, is diminishing; but the earth and air have been so thoroughly heated, that the warmth which they retain, more than com. pensates for the gradual diminution of the solar rays.

The effects of this weather upon the face of nature soon become manifest. All the flowers of the former month lose their beauty, and the whole plant hastens to decay Many plants, however, do not begin to flower till July.

While the animal creation seem oppressed with languor, during this hot season, and either seek the recesses of woods, or resort to pools and streams, to cool their bodies and quench their thirst, the insect tribe are peculiarly active and vigorous. These minute creatures are for the most part annual ; being: hatched in the spring, and dying at the approach of winter.

The excessive heats of this period of the year, cause such an evaporation from the surface of the earth and waters, that, after some continuance of dry weather, Iarge heavy clouds are formed, which at length let fall their collected liquor, in extremely co- 
pious showers, which frequently beat down the fullgrown corn, and sometimes deluge the country with sudden floods. Thunder and lightning generally accompany these summer storms.

The effects of the great heat on the human body are agreeably allayed, by the various wholesome fruits which Providence offers at this season for the use of man. Those which are now ripe are, of all, the most cooling and refreshing; as currants, gooseberries, raspberries, strawberries, and cherries. These are no less salutary and useful than the richest products of the warmer climates.

The luxury of cooling shades is now peculiarly grateful, and multitudes flock from all quarters to enjoy the invigorating effects of sea bathing; while others of the debilitated and valetudinarian tribe assemble at the medicinal well, in order to allay the feverish heat in their blood, or improve their constitutions, by drinking the cooling and reanimating draught at the spring

Potatoes and hops flower in this month. The jessamines and white lily now ornament the garden. Mushrooms appear. Frogs migrate from ponds. Hoary beetles appear. Bees kill and expel the drones Ants, for frugality, foresight, and industry proverbial, quit their nests to found new colonies. Ants are divided into male, female, and neuter.The neuters are labourers, without wings; males and females have wings. An ant hill is a large vaulted clia ber ard has three or four passages to it. In the centre of it is the old one, and the young 
worms and eggs ranged around. When opened in the winter, the labourers are in torpor They lay up no provision. They prey upon beetles, caterpillars, dead mice, rats, frogs, and juices from leaves, and when they meet with more than they can carry, they return to fetch their comrades to help them.

In this month the poultry moult. Young partridges are found among the corn, and first broods of swallows and martins congregate.

The farmer now gets home the products of the earth, particularly hay.

Hemp and flax are pulled this month. These plants are cultivated in various parts of Europe more than in England. The stalks of both are full of rough fibres or strings, which separated and prepared in a particular manner, become fit for spinning into thread. Of flax linen is made, from the finest cambrick to the coarsest canvas Hemp is chicfly used for coarse cloth; it is also twisted into ropes and cables.

In the southern parts of our island the corn harvest begins; and,

"Soon as the morning trembles o'er the sky, And, unperceiv'd, unolds the spreading day, Before the ripen'd field the reapers stand in fair array." 


\section{Thunder Storms.}

At a season wherein nature presents to our eyes none but pleasing, cheerful scenes, there are some people, notwithstanding, who still complain and murmur. Summer they say, would indeed be delightful, if storms did not come to disturb and banish all joy from their souls The fear of thunder and storms is chiefly owing to the opinion of their being effects of the wrath of heaven, and ministers of its vengeance. For if, on the contrary, we considered how much these storms contribute to purify the air from numberless noxious vapours, and to fertilize the earth; if we would take proper precautions against the terrible effects of lightning, the storms would cease to be so dreadful to us, and would rather inspire gratitude than terror. Alas! we should soon change our language, if God, provoked at our ingratitude and complaints, was to deprive us of the blessings we derive from thunder storms. It is true, that we are not capable of pointing out all the advantages which accrue from them; but the little we know is sufficient to fill our hearts with gratitude towards our great Benefactor. Let us represent to ourselves an atmosphere loaded with noxious and pestilential vapours which thicken more and more by the continual exhalations of earthly bodies, so many of which are corrupt and poisonous. We must breathe this air ; the preservation or destruc. tion of nur existence depends upon it. The salubrity or unwholesomeness of the air gives us life or death. 
We fecl how we are oppressed in the stifling heat of summer; with what difficulty we breathe; what uneasiness we experience! Is it not a great blessing, that we ought to be grateful for to God, when a salufary storm comes to purify the air from all noxious vapours; and by lighting up the saline and sulphureous particles, prevents their dangerous effects, cools the air, which recovers its elasticity, and restores to us our usual facility of breathing ? Were it not for storms, the dangerous exhalations would more and more increase, and be more and more corrupt. Men and animals would perish by millions. Which is then the most reasonable, to fear or to wish for storms? To murmur at the slight mischief they may sometimes occasion, or to bless God for the precious advantages they procure us? Let us add, that not only men and animals are benefitied by purifying the air, but that it is also very useful to the vegetables. Experience teaches us, that the rain which falls when it thunders is the most fruitful to the carth.

Observe also, that, during the greatest claps of thunder, most people prolong their fear without rea. son. Whoever has time to fear the natural consequences of lightning is already out of danger It is only the lightning which is fatal. When we have scen, and not been touched by it, and when the thunder does not come with it immediately, it is doubly foolish to turn pale or tremble at hearing a clap, or to stop the ears for fear of sound, which is no longer dangerous. The thunder tells us we have es. 
eaped the danger, and, at the same time, informs us at what distance it is; for the greater space of time there is between the clap of thunder and the flash of lightning, the more distant is the storm.

Such reflections as these may moderate the excessive fear we have of thunder. Instead of filling our minds with frightful and terrible idęas, let us accustom ourselves to consider, a storm as a sublime and great object. Instead of speaking of the misfortunes occasioned by thunder, let us reflect rather on the necessity and great use of storms.

\section{AUGUST.}

63 Fair plenty now begins her golden rcign,

The ycllow fields thick wave with ripen'd grain,

Joyous the swains begin their sultry toils,

And bear in triumph home the harvest's wealthy spoils."

Wh ат remained to be perfected by the powerful influence of the sun, is daily advancing to maturity. The farmer now sees the principal object of his culture, and the chief source of his riches, waiting only for the hand of the gatherer.

Rye and oats are usually first ripe; but this varies, and depends on the time of sowing. Sometimes all kinds of grain are fit for cutting at the same time.

Every fair day is now of great importance; for, when the corn is once ripe, it is liable to continual damage while standing, either from the shedding of 
the seeds, from the depredations of birds, or from storms.

This pleasing harvest scene is beheld in its perfection only in the open field countries, where the sight can take in at once an uninterrupted extent of land waving with corn, and a multitude of people engaged in the various parts of the labour. It is a prospect equally delightful to the eye and the heart, and which ought to inspire every sentiment of benevolence to our fellow creatures, and gratitude to our Creator.

The rural festival of harvest home is an extremely natural one, and has been observed in almost all ages and all countries. The jovial harvest supper cheer's the heart of the labourer, and prepares him to begin, without murmuring, the labours of another year; and now,

"Inwardly smiling, the proud farmer views

The rising pyramids that grace his yard, And counts his large increase."

This month is the season of another kind of harvest in some parts of England, which is the hop. picking. The hop is a climbing plant, sometimes growing wild in hedges, and is cultivated on account of its use in making malt liquors. It is planted in regular rows, and poles are set for it to run upon. When the poles are covered to the top, nothing can make a more elegant appearance than one of these hop gurdens. At the time of gathering, the poles . are taken up with the plants clinging to them ant? 
the scaly flowering heads, which are the part used, are carcfully picked off. Kent, Sussex, and Worcestershire, are the counties most famous for the growth. of hops.

Wall fruits now come in season; and,

$$
\text { "The sunny wall }
$$

Presents the downy peach, the shining plum, The ruddy, fragrant nectarine, and dark

Beneath his ample leaf the luscious fig."

Vipers bring forth their young, of the size of earthworms. Many insects appear; the flies visit the windows, and the bulls begin their shrill bellowing.

Swallows appear in the southern regions; rooks

- roost in their nests by night; lapwings and linnets begin to congregate; and the red-breast, one of the finest, though commonest of songsters, concludes the month by the renewal of his music.

\section{The Construction and Vegetation of Corn.}

The wisdom which appears in the construction and vegetation of corn is very striking. The leaves, for example, which surround it before it has attained its full growth, even those leaves have their use; and it seems as if the wisdom of the Creator had placed them round the blade for the same reason that an architect raises a scaffolding about a building, which, when the building is finished, he takes away. For as soon as the blade has attained its full length and consistency, the leaves which protected it dry up and 
fall off. Whole months pass away before the ear of corn ventures to appear and expose itself to the air ; but as soon as every thing is prepared for the formation of the blossoms and fruit, they all appear in a few days. With what skill, also, are the stalks and the ears of corn constructed! If the former were higher, the nutritive juice could not so well penetrate into them; if, on the contrary, the corn had been placed lower, the moisture would have made it spring up before it was reaped; birds and other animals would get at and destroy it. If the stem was weaker and smaller, the wind would break it; and if it was stronger and thicker, little aninals might lodge in it, birds would perch upon it, and pick out the grain.

\section{SEPTE MBER.}

¿6 Now soften'd suns a mellow lustre shed,

The laden orchards glow with tempting red;

On hazel houghs the clusters hang cmbrown'd,

And with the sportman's war the new-shorn fields resound."

THIs is, in general, a very agreeable month, the distinguishing softness and serenity of autumn, with its deep blue skies, prevailing through great part of it. The days are now very sensibly shortened; and the mornings and evenings are chill and damp, though the warmth is still considerable in the middle of the day. This variation of temperature is one cause why auturnn is an unhealthy time, especially in the warmer climates, and in moist situations. 
The labours of the husbandman have but a very short intermission; for, no sooner is the harvest gathered in, than the fields are again ploughed up and prepared for the winter corn, rye, and wheat, which are sown during this month and the next.

Not only the swallow-tribe, but many other small birds which feed on insects, disappear on the approach of cold weather, when the insects themselves are no longer to be met with.

On the other hand, some birds arrive at this season from still more northerly countries, to spend the winter with us. The fieldfare and red wing, whose departure was mentioned in March, return about the end of September. They feed chiefly on the berries with which our woods and hedges are plentifully stored all the winter.

The most useful fruit this country affords, the apple, successively ripens, according to its different kinds, from July to September or October; but the principal harvest of them is about the close of this month. They are now gathered for our English vintage, the cider-making, which, in sone counties, is a busy and important employment.

Pears, treated in the same manner, yield a vinous liquor called perry. These are the common drinks in the counties where they are chiefly made.

Partridge-shooting commences on the 14th of this month. Partridges feed on grain and other seeds scratched up; therefore live chiefly on the ground, making much use of their legs, and little of their wings. They pair early in the spring, the hen sit- 
ting twenty-two days, and the young coming forth full feathered, like chickens. When the young ones are attacked, the old ones exhibit wonderful instances of attachment, and even feign being wounded, to draw off the pursuers from the nest. They retire to the groves in the day time, to the open stubble in the night; and, when man begins his

"Falsely cheerful barbarous game of death,"

he obliges them, by pointers, to take wing, for the purpose of shooting them, or enclosing them in a net, when they remain on the ground; and it is highly admirable to observe

"How, in his mid-career, the spaniel, struck Stiff by the tainted gale, with open nose,

Outstretch'd and cautious, on the latent prey;

As in the sun the circling covey bask

Their varied plumes, and, watchful every way,

Thro' the rough stubble turn the secret eye."

In this month the snake casts his skin, parting by rolling itself in the grass, with its whole external cover; even the outer coat of the eyes scale off, and is left in the head of the slough like a pair of spectacles.

Hazel nuts are now gathered in our thickets and gardens in this month. The oak sheds its acorns, and the nuts fall from the beech, both of which are called mast.

The autumnal equinox, when day and night are again equal over the whole globe, happens about the 
23d of this month, and is often atterided with heavy storms of wind and rain, which throw down much of the fruit yet remaining on the trees.

At the end of the month the leares of many trees lose their given colours, and begin their grave autumnal tints, indicative of the approaching desolation of winter; which

" comes to rule the varied year,

Sullen and sad, with all her rising train,

Vapours, and clouds, and storms."

\section{Fruit.}

This is the happy season in which Divine Goodness lavishes all sorts of fruit upon us in great abun. dance. The charms of summer give place to more solid enjoyments. The boughs of the apple-tree bend under the weight of that golden fruit, the beauty of which is still heightened by its purple streaks. The meltirg pear, the plum sweet as honey, display their charms, and seem to invite the hand of their master. Should we not be unpardonable, if the sight of these blessings which we owe to the munificence of God, did not create in us grateful reflections, and by such means sanctify the pleasures of autumn?

There is hardly any food so swholesome as fruits. It was with a benificent view that Providence gave them to us in a season when they are not only pleasing and refreshing to us, but also excellent in a 
medicinal way. Apples come seasonably during the heat of summer, because they temper the heat of the blood, and cool the stomach and bowels. The plums have an acid sweetness, with an oily, softening juice, which may make them useful in many cases. They gently open the body, and correct the acrid humour's, which so often occasion inflammatory disorders. Nothing certainly is more delicious than fruit. Each sort has a peculiur flavour to itself. This variety renders them doubly pleasing to us. Thus, Grod, like a tender father, provides not only for the support of his creatures, but also for their. pleasure.

\section{Herrings.}

This is the season in which they fish for herrings on the coast of England and Scotland; by which means we receive a great quantity of these fish, which feed the poor as well as the rich during the whole year. Let us examine what is most important in the natural history of these fish. Innumerable shoals of herrings live in the Frozen Sea, near the Artis Pole; but at a cert in period they quit that place, and come in multitudes to the coasts of England and Scotland. It is not yet positively ascertained what may be the cause of this emigration. Some think it is to avoid whales and other great fish in the frozen seas; others imagine that the prodigious increase of the herrings obliges them to take these long voyages, and to divide into separate colo. 
nies, lest they should be in too great quantities to find sufficient food in the northern seas. Perhaps, also', it is the desire of propagation, and a peculiar instinct, which leads them to the places most favourable for the increase and preservation of their race. It is certainly these reasons in general that occasion such shoals of herrings to quit the north in the beginning of the year; for in the month of Mareh a wing of their army had already reached the coast of Iceland, and it is their western wing. The herrings are at this season so plentiful there, that by putting the shovel with which the sails are watered into the sea, there are great quantities of them taken up at a time. The eastern wing advances farther into the Baltic Sea. A part of it turns towards the North Cape, sails along the coasts of Norway, and enters through the southern straits into the sea. Another part gains the northern point of Jutland, then enters into the Zuider Zee, and from thence, passes again through the Baltic Sea, in order to return to the place from whence it set out. But the largest detachment of the eastern wing, is that which turns to the western coast, in order to turn directly to the Orkney Islands, where the Dutch go to catch them. Towards the 8th of June, the sea in those parts is full of herrings. They then direct their course towards Scotland and England, where they fill all the bays and mouths of the rivers with their fry. After having quitted England, they probably return to thei: own country. The prodigious multitude of these fish is surprising: one single herring 
lays at least ten thouaand eggs in the sea near the British coasts.

\section{OCTOBER.}

"Now stormy Winter, with her dusky train,

Frowns o'er the hill, and nurmurs in the plain;

The little birds the trembling forests fly,

And, led by nature, seek the southern sky."

Plants having gone through the progressive stages of springing, flowering, and seeding, have at this season brought to maturity the rudiments of a future progeny, which are now to be committed to the fostering bosom of the earth. This being done, the parent vegetable, if of the herbaceous kind, either totally dies, or perishes as far as it rose above ground; if a tree or shrub, it loses all its tender parts which the spring and summer had put forth. Seeds are scattered by the hand of nature in various manners. The winds, which at this time arise, disperse far and wide many seeds which are curio sly furnished with feathers or wings for this purpose. Other seeds, by the means of hooks lay hold on passing animals, and are thus carried to distant places. Many are contained in berries, which being eaten by birds, the seeds are discharged again uninjured, and grow where they happen to alight.Thus carefully has nature provided for the distribu. tion and propagation of plants. 
The gloom of the declining year, enlivened by the rich and bright colours of fading leaves,

" Now cheer the landscape in decay ;"

which to some are more interesting than the blossoms of spring, or the radiance and verdure of summer. Ripened berries in a great variety also at this season adorn the hedges and decorate the groves, as the hip, the haw, the sloe, the blackberry, \&c.

The common martin, whose nests hung under the caves of our houses, afford so agreeable a spectacle of parental fondness and assiduity, usually disappears in October. As this, though one of the smallest of the swallow kind, stays the latest, its emigration to distant climates is less probable than that of the others.

In most of the wine countries in Europe the vintage takes place in October. The grape is one of the latest fruits in ripening. When gathered, they are immediately pressed, and the juice is fermented like that of apples in making cider

This month is particularly chosen, on account of its mild temperature for the brewing of malt liquor designed for long keeping, which is therefore commonly called old October.

The farmer continues to sow his winter corn during this month; and wheat is frequently not all sown till the end of it. When the weather is too wet for this business, he ploughs up the stubble 
fields for winter fallows. Acorns are sown for young plantations at this time: and forest and fruit trees are planted.

The ground is now covered with spiders, the weaving gossamer; and the cold air condensing the vapour arising from the warm earth, causes thick and frequent fogs.

This month is the height of the hunting season; the weather being suitable, and the products of the earth housed,

"A Al, now, is free as air, and the gay pack, In the rough, bristly stubbles, range unblam'd;

No widow's tears o'erflow ; no secret curse

Swells in the farmer's breast, which his pale lips,

Tremblingly, conceals, by his fierce landlord aw'd;

But, courteous now, he levels ev'ry fence,

Joins in the ceremony, and halloos loud,

Charm'd with the rattling thunder of the field."

At the very close of the month, a few flowers still cheer the eye; and there is a second blow of some kind, particularly of the woodbine. But the scent of all these late flowers is comparatively faint.

\section{Migration of the Birds.}

This is the time when numbers of the birds, which, during summer, had lived and found food in our fields, woods, and gardens, are going to quit our climate for other countries. There are but few of them. which pass the winter with us: the rest leave us almost the whole winter. This migration is wonderful in all respects; and if we have not much attended 
to these creatures while they were with us, let us at least think of them now they are gone. Some birds, without taking their flight very high, and without separating from one another, drawing gradually towards the south, to seek the seeds and fruit they prefer; but they soon return back. Others, which are called birds of passage, collect together at certain seasons, go away in large bodies, and take their flight into other climates Some kinds of them are content with going from one country to another, where the air and food draw them at certain seasons. Others cross the seas, and undertake voyages of a surprising length.

These migrations of the birds cannot be too much admired. Certainly the difference of heat and cold, and the want of food, warn them to change place. But what is the reason that, when the air is so mild that they might remain in it, and that they find enough to eat, they still never fail to go at the appointed time? How do they know that they will find food, and the proper degree of heat, in other climates? What is the cause of their going all at the same time out of our countries as if they had unanimously fixed, be. forehand, their day of departure? How do they contrive, in dark nights, and without knowing the countries, to pursue their direct road constantly? These and other questions on this interesting. subject, are cmbarrassing, and have not yet been answered in a satisfactory manner, because we are not enough acquainted with the nature and instinct of these animals. We may, however, behold, in the migrations, 
the wise and beneficent directions of Providence. What wonderful means are made use of to preserve and give food to certain birds! With what tender care is their subsistence pointed out to them, when it fails them in some regions! Let us learn from thence, that every thing, throughout the vast empire of nature, is planted with infinite wisdom.

\section{The Winter Sowing Time.}

Great part of the food destined for us, and for many animals, is, at this time, deposited in the ground. The farmer has sowed his winter corn, and begins to enjoy rest from his labours. He will soon have the satisfaction to see his fields gradually covering with a beautiful verdure, and giving the promise of a plentiful harvest. Nature at first, indeed, works in secret, while the seed is opening; but its operations may be discovered by taking some of the grains out of the ground when they are beginning to shoot. Two days after the grain is put into the earth, it is swelled by the juices, and begins to shoot. The shoot is always at one of the ends of the grain; and that part of it which is next the outside of the grain, is the little root of the future plant. The corn, when sowed, generally begins, in twenty four hours, to pierce through the coat, and unfold itself. The root and stalk become visible. The root is first wrapped up in a bag, which it bursts open. Some days after, the other roots shoot out of their sides. The fifth or sixth day, a green stalk springs up above the 
ground. It remains some time in that state, till the fine season comes, when the ear of corn breaks out of the coats in which it had been inclosed and profected from cold and uncertain weather.

\section{NOVEMBER.}

"The lengthen'd night elaps'd, the morning shines Serene, in all her dewy beauty bright, Unfolding fair the last autumnal day. And now the nountain sun dispels the fog, And rigid hoar frost melts before his beam; And hung on every spray, on every blade Of grass, the myriad dew-drops twinkle round."

TuE preceding month was marked by the change, and this is distinguished by the fall, of the leaf. The whole declining season of the year is often, in common language, denominated the fall. There is some. thing extremely melancholy in this gradual process, by which the trees are stripped of their beauty, and left monuments of decay and desolation. This gradual death of vegetable nature, and quick succession of springing and falling leaves, suggests to the reflecting mind an apt comparison for the fugitive generation of men:-

"Like leaves on trees the race of man is found, Now green in youth, now withering on the ground;

Another race the following spring supplies,

They fall successive, and successive rise;

So generations in their course decay,

So flourish these when those are passed away !" 
The loss of verdure, together with the shortened days, the diminishing warmth, and frequent rains, justify the title of gloomy to the month of November; and other animals seem to symathize with man in feeling it as such.

Intervals of clear and pleasant weather, however, frequently occur; and it long continues,

"The pale, descending year, yet pleasing still."

In fair weather the mornings are somewhat frosty; but the hoar frost soon vanishes after. sun-rise.

High winds frequently happen in November, which at once strip the trees of their faded leaves, and reduce them to their winter state of nakedness. Flocks of wood pigeons, or stock doves, the latest birds of passage in their arrival, visit us in this month. Salmon now begin to ascend the rivers to spawn: their force and agility in leaping over cataracts and other obstacles to their ascent, are very surprising.

The farmer endeavours to finish his ploughing in the course of this month; then, laying up his utensils till the ensuing spring, he takes his cattle and horses out of the exhausted pastures into the yard or stable; puts his hogs up. to fatten; turns his sheep into the turnip-field, or, in stormy weather, feeds them with hay at the rick; and then, when

"The western sun withdraws the shorten'd day,

And humid evening, gliding o'er the sky,

In her chill progress, to the ground condens'd

The vapour throws ;" 
he seeks the cheerful fire-side, and even gloomy

November has its charms.

\section{The Fall of the Leaf.}

We now perceive the effects of approaching winter in the woods and gardens. Almost all the plants are losing their leaves, their chief ornament. The most natural way this can be accounted for is from the cold; for the leaves are no sooner covered with frost than they begin to fall in abundance, and all the vegetables are stripped of their clothing. It cannot be otherwise, as the cold causes the sap to stagnate in the plants. But the cold is not the only eause of the leaves falling; for they fall when it does not freeze the whole winter, and when the trees are even put into green-houses to preserve them from cold. It is therefore probable that other causes also contribute to strip the trees. But we must not suppose, that these fallen leaves are entirely lost, and of no - use Reason and experience teach the contrary. These leaves, which grow rotten when they are fallen, make manure for the ground. The snow and rain wash the salts out of them, and convey them to the roots of the trees. These strewed leaves, heaped together upon the young plants, preserve their roots. They cover also the seeds, and keep them warm and moist. This is more particularly observed in respect to the oak-leaves. They afford excellent manure, not only to the tree itself, but also to its - shoots; and are also very useful for forest-pasture, 
as they increase the growth of the grass on which they fall and rot. Leaves are spread in stables instead of straw, and make a good litter for cattle, or are mixed with common dung. This mould is particularly useful in gardens, where they make layers of it, which assist greatly the growth of fruit and young trees.

Thus fallen leaves have their uses in administering to the comforts and necessities of man, while to his mind the fall of the leaf is an emblem of this life, and the frailty of all earthly things.

\section{The Beginning of Winter.}

The sun is now taking leave of the world. Every thing is changed with us. The earth, which was lately so beautiful and fruitful, is now becoming gradually barren and poor. We no longer behold that fine enamel of the trees in blossom; the charm of spring, the magnificence of summer, those different tints and shades of verdure in the woods and meads, the purple grapes, nor the golden harvests which crowned our fields. The trees have lost their clothing ; the pines, the elms, and oaks, bend with the force of the northern blasts The rays of the sun are too feeble now to warm the atmosphere or earth. The fields, which have bestowed so much upon us, are at last exhausted, and promise no more this year. But in the midst of these melancholy prospects, let us still observe, that nature faithfully fulfils the eternal law prescribed to her, of being 
useful at all times and seasons of the year. Winter draws nigh ; the flowers are going; and even when the sun shines, the earth no longer appears with its usual beauty. Yet the country, stripped and desart as it is, still presents to a feeling mind the image of happiness. We may recollect with gratitude to Heaven, that the fields which are now barren were once covered with corn and plentiful harvest. It is true, that the orchards and gardens are now stripped, but the remembrance of what they bestowed upon us may make us content to bear the northern blasts which at present we feel so sharp. The leaves are fallen from the fruit trees; the grass of the ficld is withered; dark clouds fill the sky, and fall in heavy rains. The unthinking man complains at this, but the wise man beholds the earth moistened with rain, and beholds it with a sweet satisfaction. Though the earth has lost its beauty and exterior charms, and is exposed to the murmurs of those it has nourished and cheered, it has already begun: again to labour secretly within its bosom for their future welfare.

\section{DECEMBER.}

"No mark of vegetable life is seen,

Save the dark leaves of some rude ever-green;

No bird to bird repeats his tuneful call,

Save the lone red-breast on the moss-grown wall!"

THE changes which take place in the face of na. ture during this month, are little more than so many 
advances in the progress towards universal gloom and desolation. The day rapidly shortens, and the weather becomes foul and cold.

In our climate, however, no great and continued severity of cold usually takes place before the close of the month.

Several of the wild quadrupeds now take to their winter concealments, which they either seldom or never quit during the winter. Of these, some are in an absolutely torpid or sleeping state, taking no food for a considerable time; others are only drowsy and inactive, and continue to feed on provisions which they have hoarded up. In this country few become entirely torpid.

Bats retire early to caves and holes, where they remain the whole winter, suspended by their hind feet, and closely wrapped up in the membranes of the fore feet. As their fond is chiefly insects, they can lay up no store for the winter, and therefore must. be starved, if nature did not thus render food unnecessary for them. Dormice also lie torpid the greatest part of the winter, though they lay up stores of provision. A warm day sometimes revives them; when they eat a little, but soon relapse into their former sleepy condition.

Squirrels, and various kinds of field-mice, provide magazines of food against winter, but are not known to become torpid. The badger, the hedgehog, and the mole, keep close in their winter quarters in the northern regions, and sleep away great part of the scason. 
The only vegetables which now flourish are the numerous tribes of mosses, and the lichens, or liverworts. Lichens cover the ditch-banks, and other neglected spots, with a leather-like substance, which in some countries serves as food both to men and cattle. The rein-deer lichen is the greatest treasure

- to the poor Laplanders, who depend upon it for the support of their only species of domestic cattle during their tedious winters.

On the 21st of December happens the shortest day; when the sun is not quite eight hours above the horizon in these islands. About fifteen degrees to the northward the sun does not rise at all, and a continued night lasts weeks or months, according to the distance from the north pole. But, on the contrary, to the countries near the south pole, it is at this period perpetual day; and every where to the south of the equator it is summer. As our summer advances, their winter approaches.

The festival of Christmas seasonably cheers this comfortless period. Great preparations were made for it in the country, and plenty of rustic dainties provided for its celebration, according to the rules of ancient hospitality; and

"Frequent in the sounding hall they wake The rural gambol."

Thus the old year steals away unlamented, and scarcely perceived; and a new one begins with 
lengthening days and brighter skies, inspiring fresh hopes and pleasing expectations, that

"All this uniform uncolour'd scene Shall be dismantled of its fleecy load, And flush into variety again."

\section{The Advantages of Winter.}

The frost and cold of winter prevent many hurtful vapours in the higher regions of the atmosphere from falling upon us, and even purifies the air. Far from being always bad for our health, it often strengthens it, and preserves the humours from putrefaction, which a constant heat would certainly occasion. If the vapours which collect in the atmosphere were always to fall in rain, the earth would be too soft and wet, our bodies would be too full of humours, and too much relaxed; whereas the cold braces and promotes the circulation of blood. We are told by travellers, that in Greenland, where the ground is covered with mountains of ice, and where in winter the days are only four or five hours long, the air is very wholesome, clear, and light : and, except a few complaints in the chest and eyes, occasioned partly by the quality of the food, they have seldom there the disorders so common in Europe.

As man, though active by choice, and though labour is necessary to him, is still glad to interrupt his employments to taste the sweets of sleep, so also our nature yields to the change of seasons, and takes a pleasure in it, because in reality it contributes towards 
our welfare and happiness. Behold our ficlds and gardens!- they are indeed buried in snow; but this is necessary, in order to preserve them from the cold, as well as to prevent the grain from corrupting. The ground requires rest, after having yielded in the summer all wewant for the winter. If our present support had not been provided for, if in this severe season we were obliged to cultivate the earth, there might be some foundation for our complaints. But all our wants are supplied, and we enjoy a repose suitable to the season. 


\section{CONCLUSION.}

Having endeavoured to point out the changes on the face of nature, during the varying year, we shall conclude our labours with the following impressive extract from St. Pierre.

"We have attempted, in the course of this work, "\%* says this amiable writer, "to treat of the harmonies of the sun and moon with animated beings; but these harmonies are inexhaustible. All animals, in short, have the phases of their life regulated by those of the sun and moon. Scarcely does the orb of day sink nder the horizon, when all animals are struck with lethargy, with the exception of those to whom night is the season of excursion. The wakefulness of the latter proves, as well as a number of other effects of nature, that sleep is not a mere mechanical result of the absence of the sun. Insects now take refuge in the hearts of plants; birds, nestling in foliage, repose with their heads under their wings; a flock of sheep retires to rest under the shelter of a hedge, and the watchful dog, who guards them, sinks into slumber, after hav-: ing turned his body several times round. All the functions of intelligence are suspended, in the $a b$ sence of that orb which produces its images; nay, several of the smaller insects find their existence terminated by the setting sun; for the ephemeral fly does not see a second dawn. Soon, however, comes

* Irarmonies of Nature.

B b 
forth the moon to give new life to the world. like the sun, she has her plants, her insects, her birds, her quadrupeds; it is by her doubtful light that the mirabilis, and other nocturnal plants, open their flowers; that various species of fish pursue their progress to another clime; that the tortoise lays her eggs on the solitary strand; and that the nightingale, the bird of spring, delights to make the echoes of the forest resound with its song.

"Many insects live only during one of the lunar quarters; others live a fortnight, others a month; some go through an entire season, and die at the summer solstice; but the greater number perishes at the autumnal equinox, at the time when the sun proceeds to enlighten another hemisphere. It is then that the marmot retires and falls asleep in the hollow rock, to awaken only at the return of the spring equinox; for to her the year seems a day and a night of six months each. A crowd of animals suspend their labours, in our hemisphere, at the same season; the bees take rest in their hives; several species of birds, like the quail and swallow, follow the course of the sun, and pass into the hemisphere which he warms; while a multitude perishes in that which he abandons. Carnivorcus animals are dispersed in all directions to devour theil remains; the furred fox, and the white bear, penetrate even into the bosom of the frozen zone, into regions of snow and ice, which hardly any living animal can inhabit. The currents of the ocean still carry to the shore a quantity of marine substances coming from the temperate and tor- 
rid zones. It is thus that the instinct which carries the foxes and white bears to the sea coast of our frozen zone during winter, leads me to suppose that the currents of the ocean bring them a supply of food, which would not be the case, unless these currents descended from an opposite pole.

"There exists the greatest differenees in respect to the extent of the orbits of the different planets; one requires only a month for its revolution round the sun; others, respectively, three months, eight months, two years, twelve years, thirty years, and, finally, nearly eighty-four years. To all these, a calculator may find, or fancy that he finds, corresponding periods in the duration of vegetable and animal life. He may compute that several kinds of insects, such as butterflies, live between one month and eight; others, such as the May bug, two years, or one year of Mar's Several birds and quadrupeds, among others, goats are understood to live twelve years, or a year of Jupiter; other quadrupeds thirty years, or a year of Saturn; while the life of man may be oc. casionally brought forward as completing the longest period of all, the revolution of the Georgium Sidus. A farther inquiry might lead such a speculator to ascertain examples of still longer life in the animal and regetable world, and to find, perhaps, parallels to the return of comets

"Leaving these visionary speculations, I am to observe, that the animals which die of old age go off the stage as they came upon it, without being aware of the change The last steps in the descent of life 
are on as gentle a slope as those of its commence. ment. They have not been led, by vain ambition, to climb precipices, or to incur a violent death; but, faithful to the laws received from Nature, they restore her that instinct which has now become useless in an exhausted machine: they expire without regret, remorse, or murmur. When a tranquil death takes place in the night, the moon may be said to untie those links which she strung together at the time of birth. Her light still sheds a pale ray over their breathless bodies, and covers them with her funereal crape; while the earth, their common mother, which receives them in her bosom, raises, as an ornament to their tomb, the broad foliage of the burdock, or a garland of ivy. Time, like a reaper, cuts down ge. neration after generation of animals; and he likewise plants and gather's, but in comparatively smaller numbers, the individuals of cur species.

"Let man, however, not vent complaints on the short duration of life; his celestial harmonies will subsist after his terrestial are at an end. The $\mathrm{Au}$ thor of Nature has attached to his bodily existence several years of bitterness and trial; but he has given his soul an eternity of joy and delight. $\mathrm{He}$ is by no means a being condemned to creep on this globe, or to tear its bosom with the ploughshare for the sake of supporting a frail existence His life is transient, but it has an object, and that object is sublime. Behold him expiring in his bed; his body is in pain, but he already contemplates a God prepared to receive him. Can this being, so weak and helpless, 
be so strongly impressed with a thought that would not have been sanctioned by the Creator of all thoughts! No; it is not in vain that he has opened his hopes to a future destiny. He quits a world of darkness for a world of light; he quits misfortune, and frail mortals like himself, to enter on an abode where death is not known. His eyes will no longer be distressed by the sight of distress; every ob. ject will be replete with content and satisfaction. How great must be the transports of man, when, cscaped from the agony of life, he sees the gates of heaven open to him. He is no longer a creature of the dust; he is an angel, a superior being, advanced to an upper region. After remaining, during a season, a slave and in irons, now behold him free, and the possessor of a new domain! But lately sad and suffering, he dragged his step towards death, and he rises from it full of glory. He inhabited a world covered with funereal cypress, bedewed with tears, where all are subject to change and to death; where we indulge love only to experience suffering, and where we meet our friends only to part with them. He is now transported to an abode where all is eternal; his soul is kindled with everlasting love, and he easts, from the height of the firmament, a sympathizing look towards his fellow-creatures in this lower world."

EINIS. 
Hin.

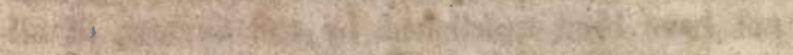

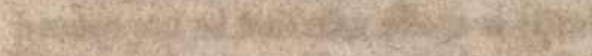

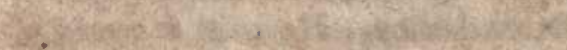

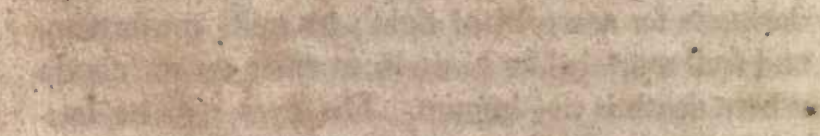

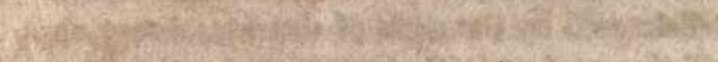

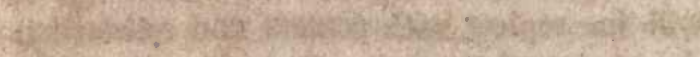

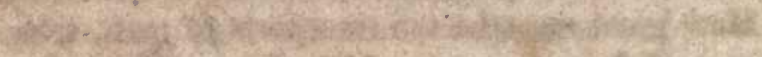

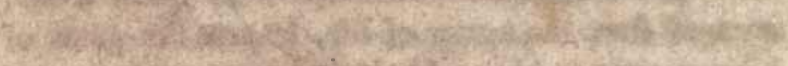

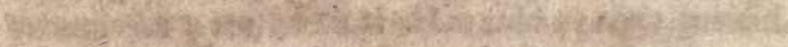

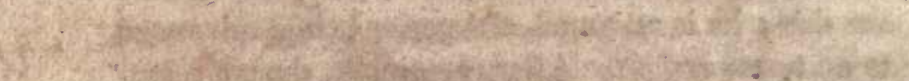

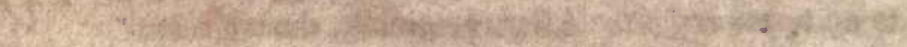

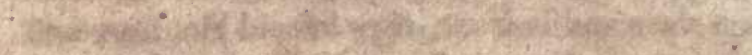

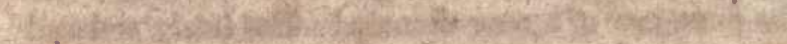

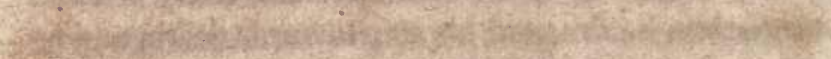

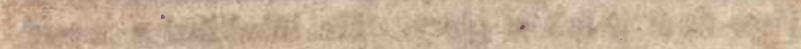

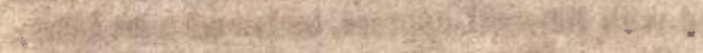
lathe

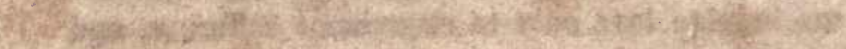

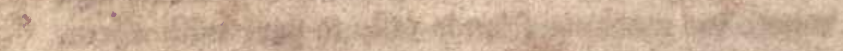

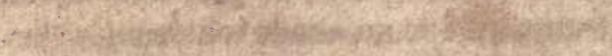

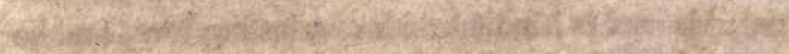

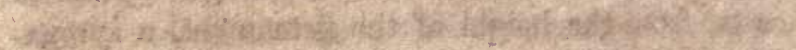

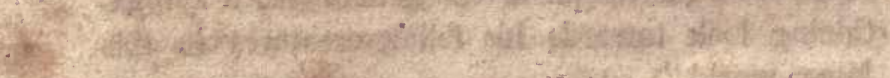
3.

sese

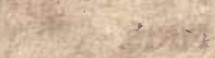





\section{YB 35745}

\section{in: $x$}

yes:

wes

.

ES
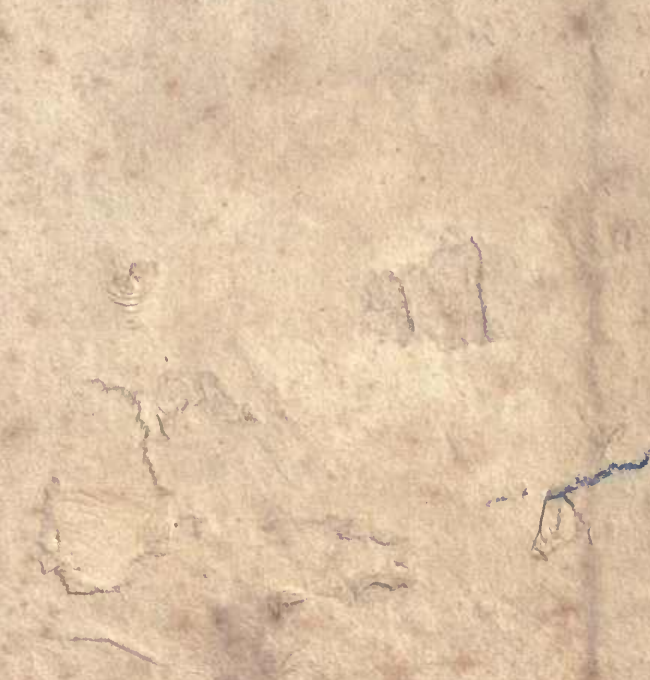

A.

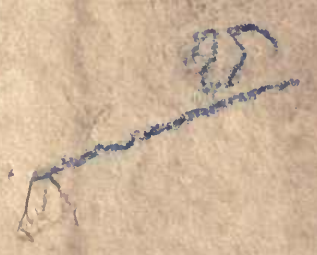

部 
